\title{
Investigation and Demonstration of a Rich Combustor Cold-Start Device for Alcohol-Fueled Engines
}

\author{
J.W. Hodgson \\ D.K. Irick \\ University of Tennessee
}

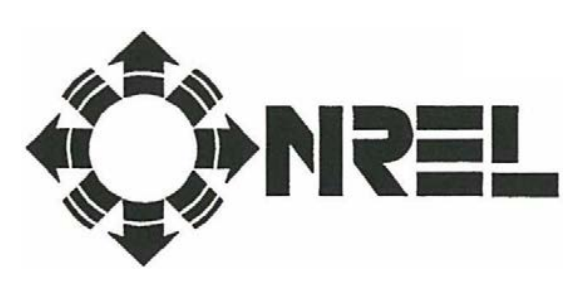

Alternative Fuels Hotline: 1-800-423-1DOE

Alternative Fuels Data Center World Wide Web Site: http://www.afdc.doe.gov

National Renewable Energy Laboratory

1617 Cole Boulevard

Golden, Colorado 80401-3393

A national laboratory of the

U.S. Department of Energy

Managed by the Midwest Research Institute

For the U.S. Department of Energy

Under Contract No. DE-AC36-83CH10093 


\section{NOTICE}

This report was prepared as an account of work sponsored by an agency of the United Siates government. Neither the United States govemment nor any agency thereof, nor any of their employees, makes any warranty, express or implied, or assumes any legal liability or responsibility for the accurecy, completeness, or usefulness of any infurmation, apparatus, product, or process disclosed, or represents that its use would not infringe privately owned rights. Reference herein to any specific commercial product, process, or service by trade name, trademark, manufacturer, or otherwise does not necessarily constitute or imply its endorsement, recommendation, or favoring by the United States govemment or any agency thereof. The views and opinions of authers expressed herein do not necessarily state or reflect those of the United States government or any agency thereof.

Available to DOE and DOE contractors from:

Office of Scientific and Technical Information (OSTI)

P.O. Box 62

Oak Ridge, TN 37831

Prices available by calling (423) 576-8401

Available to the public from:

National Technical Information Service (NTIS)

U.S. Department of Commerce

5285 Port Royal Road

Springtield, VA 22161

(703) 487-4650 


\title{
Investigation and Demonstration of a Rich Combustor Cold-Start Device for Alcohol-Fueled Engines
}

\author{
J.W. Hodgson \\ D.K. Irick \\ University of Tennessee
}

NREL Technical Monitor: Peg Whalen

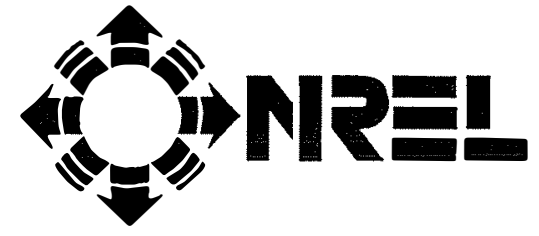

Alternative Fuels Hotline: 1-800-423-1DOE

Alternative Fuels Data Center World Wide Web Site: http://www.afdc.doe.gov

\author{
National Renewable Energy Laboratory \\ 1617 Cole Boulevard \\ Golden, Colorado 80401-3393 \\ A national laboratory of the \\ U.S. Department of Energy \\ Managed by the Midwest Research Institute \\ For the U.S. Department of Energy \\ Under Contract No. DE-AC36-83CHI0O93
}

Prepared under Subcontract Number XCF-5-14050-03

April 1998 


\section{Preface}

\section{Background}

The use of alcohols (methanol or ethanol) as transportation fuels has been identified as one strategy that has the potential to ameliorate some problems associated with the use of petroleum-based fuels. These problems include a growing dependence on imported oil and the persistent contributions that mobile sources make to urban air pollution.

Both ethanol and methanol can be produced from renewable resources, and their combustion characteristics result in a different mix of organic emissions compared to petroleum fuels. The propensity of the exhaust to form ozone is generally less than the exhaust from gasoline-fueled vehicles.

Unfortunately, the low vapor pressures of the alcohols at low temperatures present problems for starting engines under these conditions. The current solution to this problem is to mix primers with the alcohol fuel that provide sufficient volatility that starting is enabled generally to temperatures around $0^{\circ} \mathrm{C}$. Because the primers detract from the favorable emissions characteristics of the alcohols, it would be desirable to have a way to cold start engines operating on "neat" or "near-neat" alcohol fuels.

\section{The Present Study}

The present study was undertaken to investigate an approach to cold starting spark-ignition engines. In this approach a portion of the fuel is burned outside the engine under fuel-rich conditions. This rich combustion creates a product stream that contains significant amounts of hydrogen and carbon monoxide (along with other gases such as carbon dioxide, nitrogen, water vapor, and organics). The hydrogen and carbon monoxide are combustible and noncondensable and provide the fuel for starting the engine. Once the engine starts the engine transitions to the normal fuel system.

\section{Acknowledgments}

Several people contributed to the success of this study. We would like to express our appreciation to the National Renewable Energy Laboratory for supporting the study and to our subcontract technical monitors, Chris Colucci and Peg Whalen, who provided encouragement and advice during the study. 


\section{Summary}

We have completed a study in which we investigated the use of a rich combustor to aid in cold starting spark-ignition engines fueled with either neat ethanol or neat methanol. The rich combustor burns the alcohol fuel outside the engine under fuel-rich conditions to produce a combustible product stream that is fed to the engine for cold starting. The rich combustor approach significantly extends the cold starting capability of alcohol-fueled engines.

A design tool was developed that simulates the operation of the combustor and couples it to an engine/vehicle model. This tool allows the user to determine the fuel requirements of the rich combustor as the vehicle executes a given driving mission.

The design tool was used to design and fabricate a rich combustor for use on a $2.8 \mathrm{~L}$ automotive engine. The system was tested using a unique cold room that allows the engine to be coupled to an electric dynamometer. The engine was fitted with an aftermarket engine control system that permitted the fuel flow to the rich combustor to be programmed as a function of engine speed and intake manifold pressure.

Testing indicated that reliable cold starts were achieved on both neat methanol and neat ethanol at temperatures as low as $-20^{\circ} \mathrm{C}$. Although starts were experienced at temperatures as low as $-30^{\circ} \mathrm{C}$, these were erratic. We believe that an important factor at the very low temperatures is the balance between the high mechanical friction of the engine and the low energy density of the combustible mixture fed to the engine from the rich combustor. 


\section{Table of Contents}

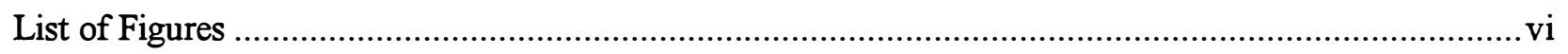

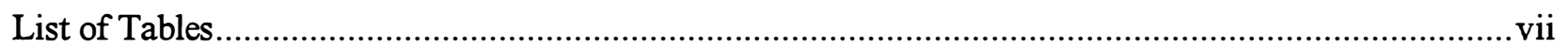

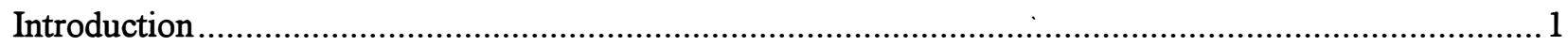

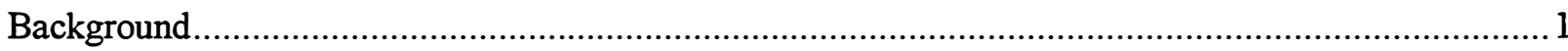

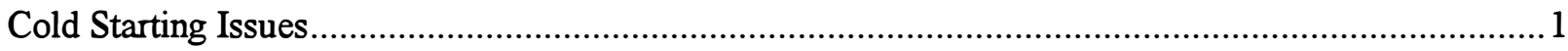

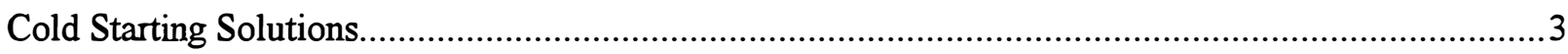

Modeling (Task 1) ................................................................................................................

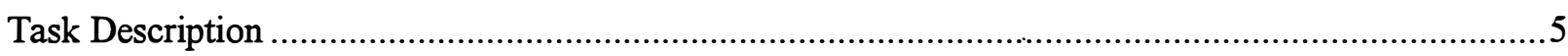

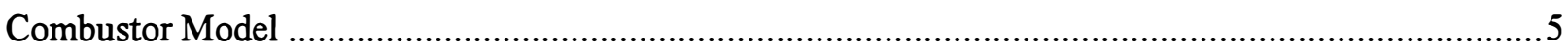

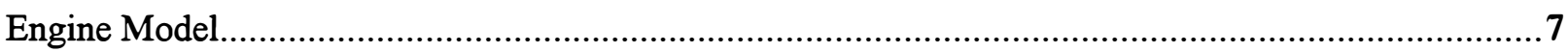

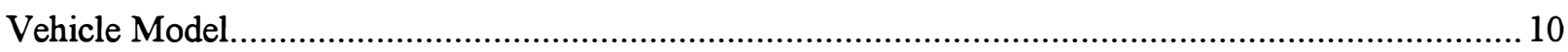

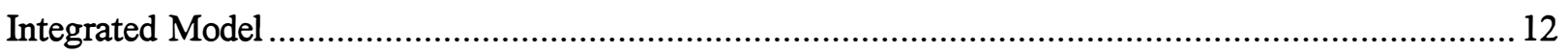

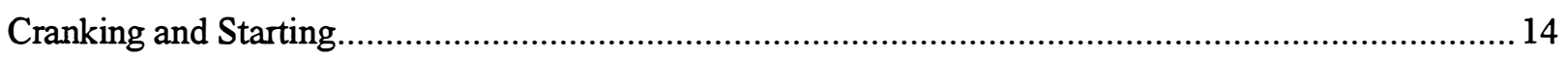

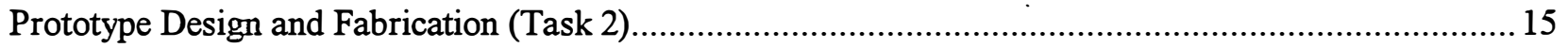

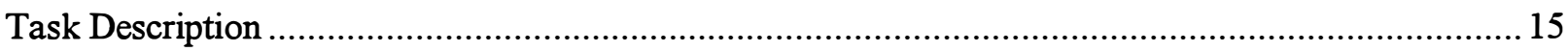

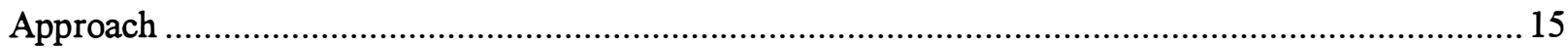

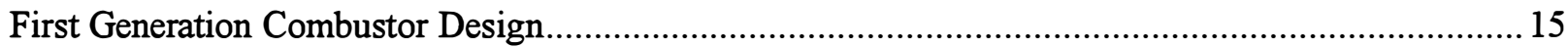

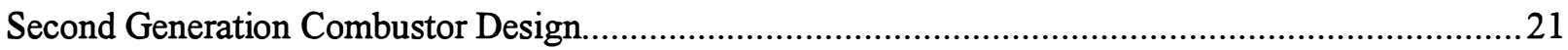

Prototype Testing and Vehicle Interface and Testing (Tasks 3 and 4) ...................................................26

Task Description (Prototype Testing and Evaluation-Task 3) .........................................................26

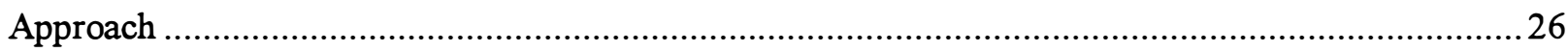

Task Description (Vehicle Interface and Testing —Task 4) ……................................................26

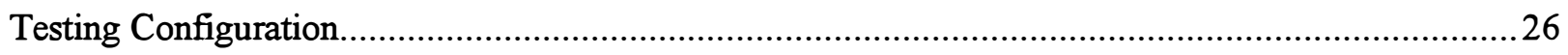

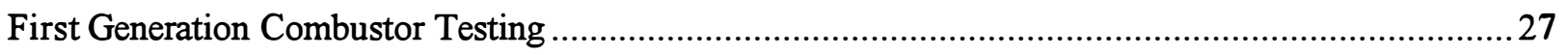

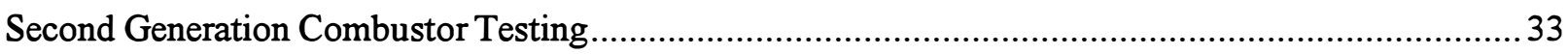

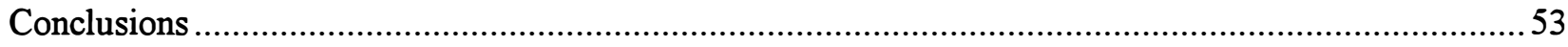

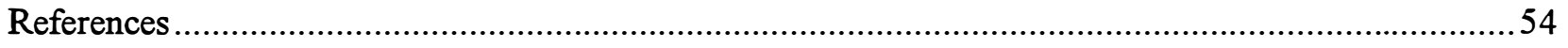




\section{Table of Contents (continued)}

Appendix A Design Drawings_First Generation Rich Combustor ..............................................A-1

Appendix B Design Drawings_Second Generation Rich Combustor ............................................. B-1

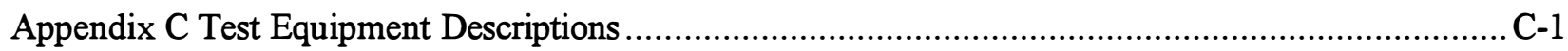




\section{List of Figures}

Figure 1. Methanol vapor pressure versus temperature ..........................................................

Figure 2. Saturated vapor/air equivalence ratio versus temperature ............................................2

Figure 3. Calculated product composition for methanol-fueled combustor ........................................6

Figure 4. Calculated product composition for ethanol-fueled combustor ........................................... 7

Figure 5. Calculated engine output for both modes of fueling ..................................................... 10

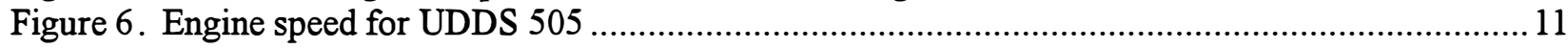

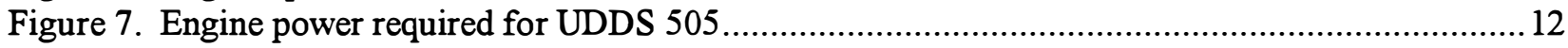

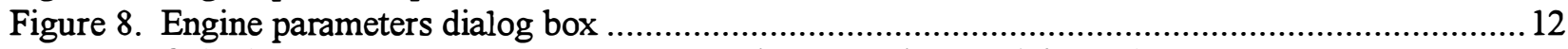

Figure 9. Calculated performance map for test engine operating on rich combustor ........................... 13

Figure 10. Chassis parameters dialog box............................................................................. 13

Figure 11. Calculated fuel consumption for test engine operating on rich combustor ......................... 14

Figure 12. Rich combustor dynamometer installation .............................................................. 16

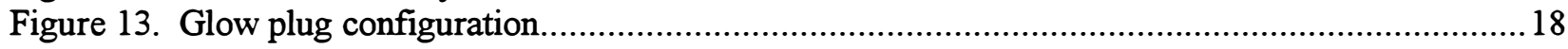

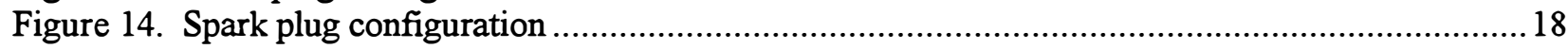

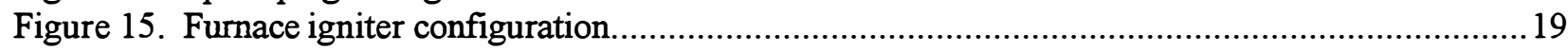

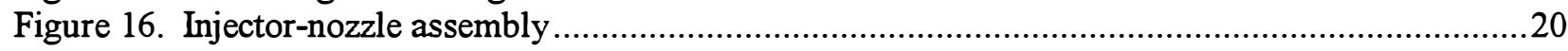

Figure 17. First generation design final configuration ........................................................20

Figure 18. First generation final configuration installed on test engine ........................................2 21

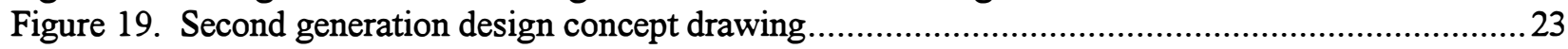

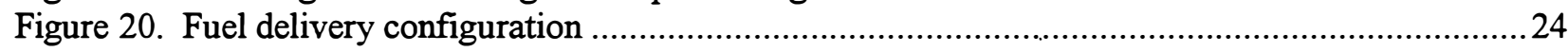

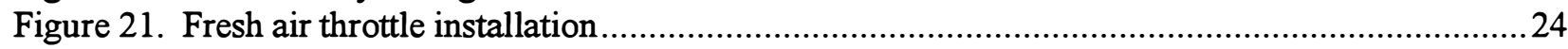

Figure 22. Second generation combustor installed on test engine ..............................................25

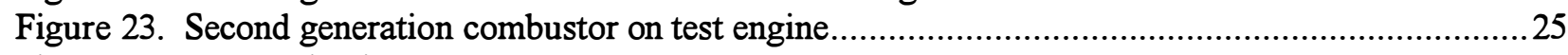

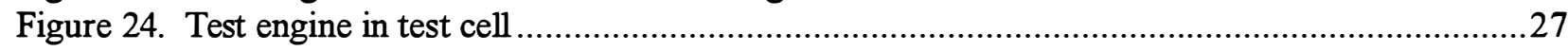

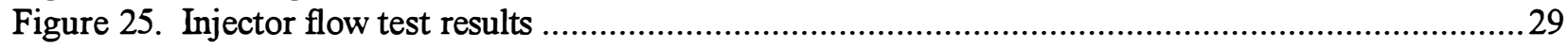

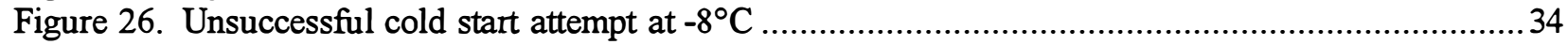

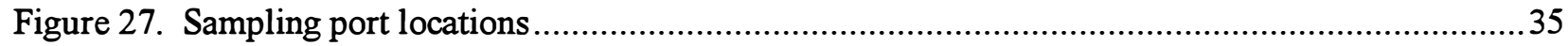

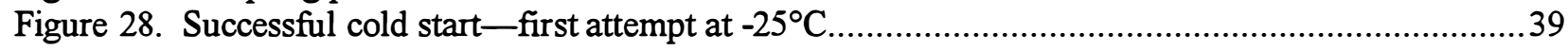

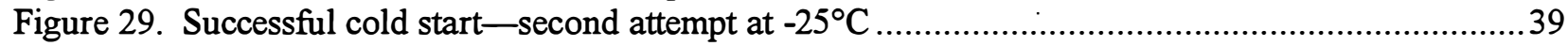

Figure 30. Start attempt at $-9^{\circ} \mathrm{C}$ after fresh air throttle installation ................................................41

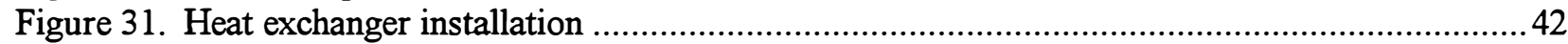

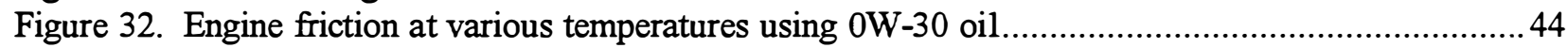

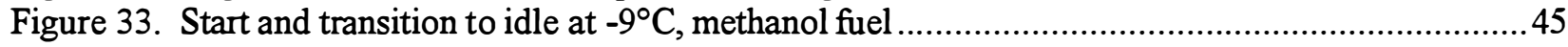

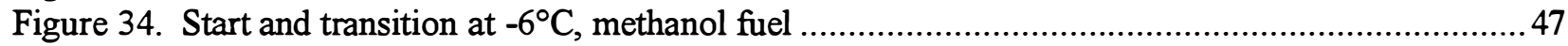

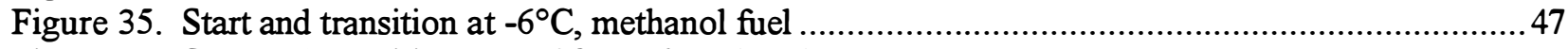

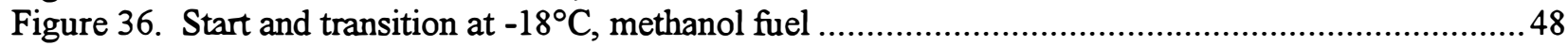

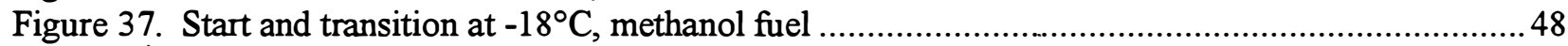

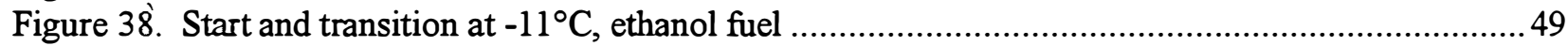

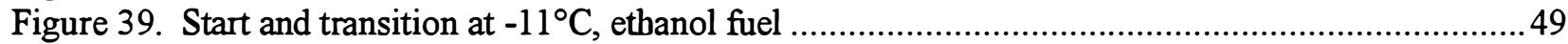

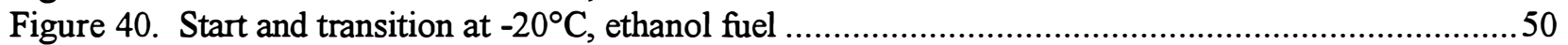

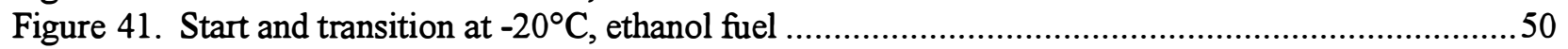

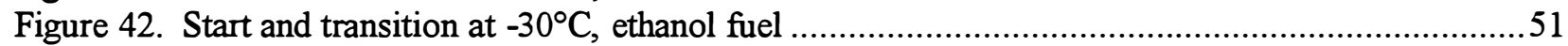

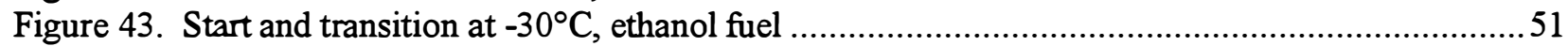

Figure 44. Start and step-wise transition at $-11^{\circ} \mathrm{C}$, ethanol fuel ...................................................52

Figure 45. Start and step-wise transition at $-11^{\circ} \mathrm{C}$, ethanol fuel ....................................................52 


\section{List of Tables}

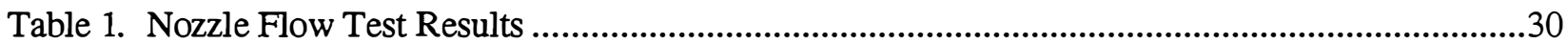

Table 2. First Generation Combustor Product Composition ..................................................................31

Table 3. Combustor Product Composition-Downstream Port...............................................................36

Table 4. Combustor Product Composition_-Upstream Port ....................................................................36

Table 5. Combustor Product Composition by Nozzle...........................................................................37

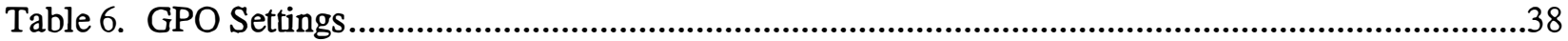

Table 7. Calibration Testing with Fresh Air Throttle .........................................................................40 


\section{Introduction}

\section{Background}

Methanol $\left(\mathrm{CH}_{3} \mathrm{OH}\right)$ has several properties that distinguish it as an attractive alternative to petroleum fuels. Its high octane rating and high latent heat of vaporization enhance its appeal as an alternative to gasoline in spark-ignition engines. Emissions from an alcohol-fueled engine contain up to 58\% less hydrocarbons (HC) and oxides of nitrogen ( $\left.\mathrm{NO}_{\mathrm{x}}\right)$, compared to a gasoline-fueled equivalent (Höchsmann 1989). Compared to their gasoline equivalent, the emissions from methanol-fueled engines are less photochemically reactive (Pefley 1984). The low volatility and high latent heat vaporization of methanol reduce the evaporative emissions from a methanol-fueled vehicle (Hodgson 1994). Together, these properties make it an attractive alternative fuel from an environmental perspective.

\section{Cold Starting Issues}

Unfortunately, the low volatility and high latent heat of vaporization also lead to low vapor pressures at low temperatures, which severely reduce the cold start performance of an alcohol-fueled engine. This problem is compounded by the fact that the low air/fuel ratio required for methanol means less air is available per unit mass of fuel in the fresh charge to supply the energy for vaporization. Unlike gasoline, which can be blended to achieve desired phase equilibrium behavior (winter blends are more volatile than summer blends), methanol is a pure substance with a known fixed phase equilibrium behavior. The vapor pressure at various temperatures (Perry's 1993) is shown in Figure 1. The equivalence ratio assuming saturated vapor at the temperature considered, shown for methanol (Pefley 1986) in Figure 2, indicates the minimum (richest) achievable air/fuel ratio during cold starting.

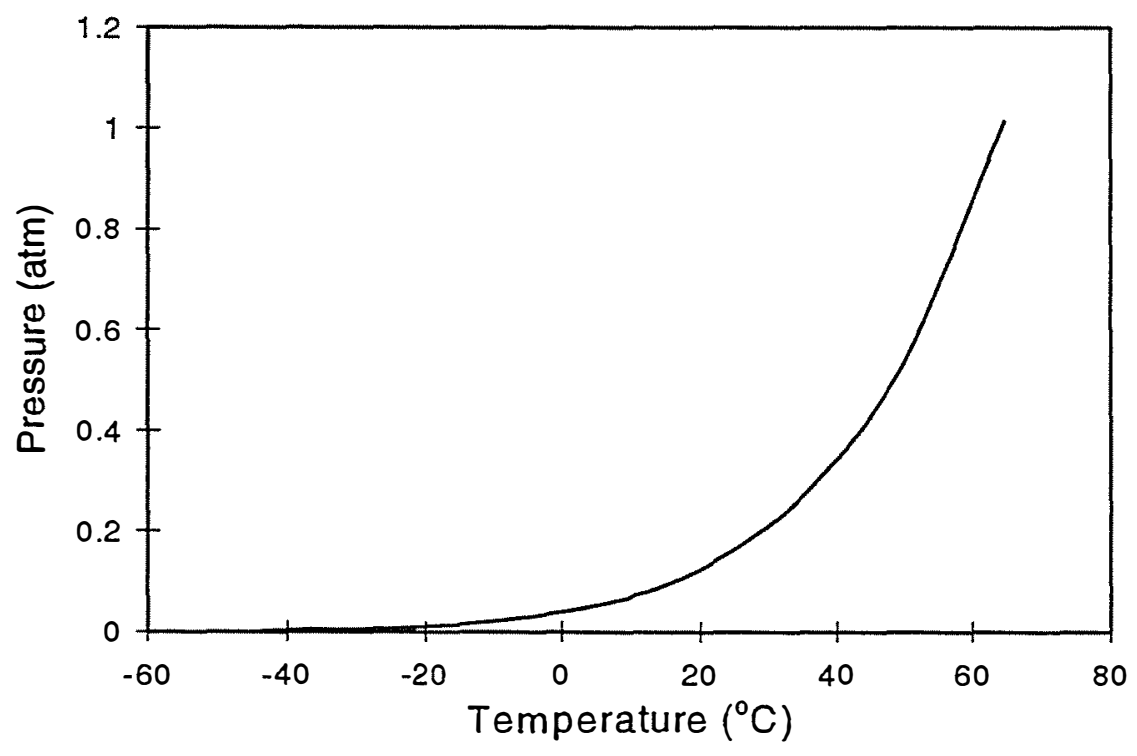

Figure 1. Methanol vapor pressure versus temperature 


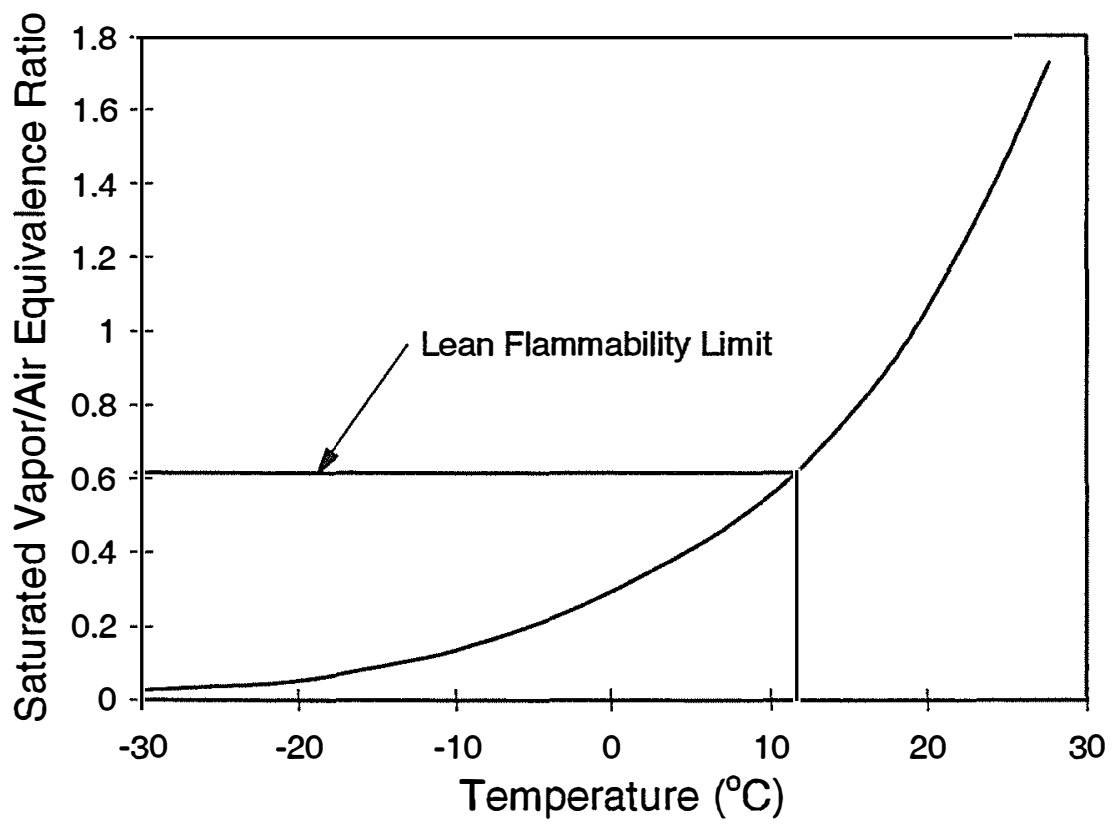

Figure 2. Saturated vapor/air equivalence ratio versus temperature

The traditional manner in which an adequate air/vapor ratio is achieved is to overfuel the engine to ensure that enough fuel evaporates. This is accomplished on carburetor-equipped engines by employing a choke, and on fuel-injected engines by a warmup enrichment cycle. As is evident from Figure 2, overfueling to provide an adequate air/vapor ratio is not possible for methanol below approximately $12^{\circ} \mathrm{C}$.

This overfueling during cold start and driveaway account for a substantial portion of the emissions generated during the U.S. Environmental Protection Agency (EPA) Federal Urban Dynamometer Driving Schedule (UDDS) by a typical current model car. Because of overfueling, the exhaust is rich in unburned fuel and carbon monoxide. During this initial starting period, the catalyst is cold and ineffective. The net result is that the engine produces more undesirable emissions as a result of the overfueling when the catalyst is unable to convert the emissions. Reducing the overfueling during cold starting would reduce the cold start emissions (Hodgson 1994).

Aside from the fuel and emissions issues concerning cold starting, other issues must also be considered. The power required to crank the engine is increased because of the increased viscosity of the engine oil at low temperatures. This places a high current demand on the battery and therefore, on the battery's ability to sustain cranking is reduced to the point where it becomes an issue during cold cranking and starting. 


\section{Cold Starting Solutions}

Because the implementation of methanol as an automotive fuel may be limited by cold start problems, much research has been done taking many approaches. Some of the approaches taken are described below (Hodgson 1994).

\section{Supplementary Fuel}

This approach involves using a volatile fuel, typically gasoline, to start the engine and warm it up, after which the engine is switched to the alcohol fuel. This approach requires auxiliary fuel storage and delivery systems. On-board generated hydrogen, which requires heaters and catalysts, has also been used (Hydrogen Consultants 1995).

\section{Blended Fuel}

This approach uses a volatile fuel as a blending agent to provide the required air/vapor ratio for starting. M85 (85\% methanol, 15\% unleaded gasoline) is an example of this approach. The advantage of this approach is that a single fuel system can be used, but the advantages of methanol are compromised by adding the blending fuel.

\section{Engine Modifications}

Many approaches to engine modifications have been taken to extend the cold start range of alcohol-fueled engines. High-energy ignition systems, "prompt EGR" (exhaust gas recirculation) (Gardiner 1993), and optimization of injection parameters (Höchsmann 1989) are among the research efforts in the field. The most effective of these (prompt EGR) requires internal modifications to the engine (installation of a special camshaft).

\section{Air Heating}

Two approaches have been taken to heat the intake air. A combustor was used to provide its exhaust to the hot side of a "air to air" heat exchanger located immediately upstream of the intake ports and injectors, with the engine intake air as the cool side (Höchsmann 1989). This combustor was fueled with liquid methanol from the fuel tank; a glow plug served as the ignition system. The air flow through the combustor was provided by an external fan.

The second approach taken (Hodgson et al. 1993) was to burn liquid methanol directly in the intake air stream. The air/fuel ratio was maintained very lean so sufficient oxygen remained in the intake stream to support combustion in the engine.

In both cases, cold start testing determined that the intake fresh charge would cool because of contact with the cold engine surfaces to the point that a combustible mixture was not present at the spark event.

\section{Fuel Heating}

Efforts to use fuel preheating have not significantly extended the cold start range of methanol (Höchsmann 1989). This results from the same cooling of the fresh charge that limits the contribution from air heating. 


\section{Fuel Reforming}

In this approach, the fuel is reformed by various processes to produce other combustible species. Two approaches have been to reform methanol into dimethyl ether (Karpuk 1988), dissociating methanol into hydrogen and carbon monoxide (Karpuk 1989), and steam reforming (Lalk 1984).

All these approaches require heat for the fuel and the catalysts to produce the reformed fuel. The required heat is not available during cold start and warmup, so the fuel must be reformed when operating temperatures are higher and stored on the vehicle for later use. This requires the additional systems described for the supplementary fuel approach.

\section{Rich Combustion}

This is the approach taken in this study. Liquid methanol is burned in a rich diffusion flame in the combustor to produce the noncondensable gases hydrogen and carbon monoxide. These combustible gases are then mixed with additional air and fed to the engine. Proof of concept testing has been conducted by multiple researchers (Hodgson 1993; Iwai 1984; and Pettersson 1991), which shows that rich combustion or partial oxidation is a viable means to extend the cold start range of alcohol fueled engines. This study addresses the development and application of this technology to a methanol-fueled vehicle. 


\section{Modeling (Task 1)}

\section{Task Description}

In this task the offeror shall develop and use a theoretical model to determine the important combustor design variables. The model shall help determine the relationships between the combustor's inputs (fuel and air flow) and outputs (composition, temperature, and flow rate of exhaust products). The exhaust product flow rates needed to achieve adequate alcohol cold start over a range of temperatures shall also be determined.

\section{Combustor Model}

To understand the design and operating variables of the combustor, a design tool has been developed to simulate constant pressure adiabatic combustion, including dissociation of the products. The model uses the thermodynamic and reaction data, and follows the methodology presented in Campbell (1979) to determine the composition and temperature of the products. Chemical kinetics are not considered.

The model performs an enthalpy balance of the reactants and products using the thermodynamic data from Campbell. Dissociation of the product gases is included in the enthalpy balance; therefore, the final temperature (constant pressure adiabatic flame temperature) and equilibrium composition of the combustor products are determined using an iterative scheme. The following species are considered in the dissociated products: $\mathrm{CO}, \mathrm{CO}_{2}, \mathrm{H}_{2}, \mathrm{H}, \mathrm{H}_{2} \mathrm{O}, \mathrm{O}_{2}, \mathrm{O}, \mathrm{OH}, \mathrm{N}_{2}$, and $\mathrm{NO}$. Chemical equilibrium among these species is governed by conservation of the elements $\mathrm{C}, \mathrm{O}, \mathrm{H}$, and $\mathrm{N}$, plus the following six equilibrium reaction equations:

$$
\begin{aligned}
& \mathrm{CO}+\frac{1}{2} \mathrm{O}_{2} \stackrel{k_{1}}{\longleftrightarrow} \mathrm{CO}_{2} \\
& 2 \mathrm{O} \stackrel{k_{2}}{\longleftrightarrow} \mathrm{O}_{2} \\
& \mathrm{O}_{2}+\mathrm{N}_{2} \stackrel{k_{3}}{\longleftrightarrow} 2 \mathrm{NO} \\
& 2 \mathrm{H} \stackrel{k_{4}}{\longleftrightarrow} \mathrm{H}_{2} \\
& \mathrm{O}+\mathrm{H} \stackrel{k_{5}}{\longleftrightarrow} \mathrm{OH} \\
& \mathrm{H}_{2}+\frac{1}{2} \mathrm{O}_{2} \stackrel{k_{6}}{\longrightarrow} \mathrm{H}_{2} \mathrm{O}
\end{aligned}
$$

The reaction equilibrium constants $k_{i}$ are functions of temperature; therefore, a product temperature is assumed, and the 10 equations governing chemical equilibrium are solved using the algorithm presented in Hodgson (1990). With an assumed product temperature and a calculated equilibrium composition, the enthalpy of the products is compared to the enthalpy of the fuel and air mixture. If the difference in the 
two enthalpy values is greater than the desired convergence criteria, a new product temperature is assumed. The product temperature and equilibrium composition are determined iteratively in this manner.

The combustor model allows examination of methanol, ethanol, n-octane, and other fuels not considered in this project. The air/fuel ratio and the temperatures of the fuel and air may be separately specified.

Calculations have been made using the model to simulate combustion of rich mixtures of both methanol and ethanol with air at $-30^{\circ} \mathrm{C}$ to determine the concentration of hydrogen and carbon monoxide in the product gas under the equilibrium assumption; the results are shown in Figures 3 and 4 . The calculated results for methanol are in good agreement with the calculated results presented in Iwai (1984), which compare well with the experimental results that were presented.

Although it appears that extremely rich combustion (equivalence ratios $>2$ ) would give more hydrogen and carbon monoxide in the product gas, experimental results of Iwai showed that this did not occur. We believe that this is due to nonhomogeneous combustion. Iwai concluded that an equivalence ratio of 2 was appropriate.

As detailed in the following section on the engine model, the combustor product stream contains significant inert or noncombustible species that result in the charge being fed to the engine having a lower energy density than the charge without the rich combustor operating.

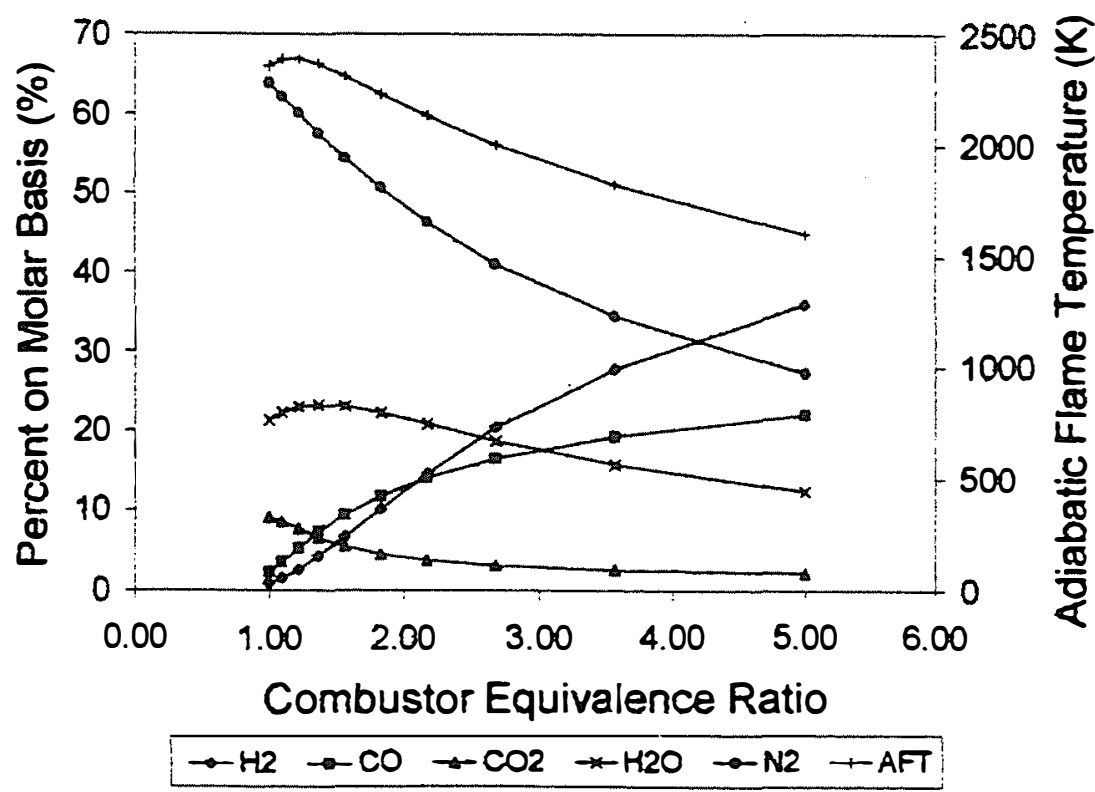

Figure 3. Calculated product composition for methanol-fueled combustor 


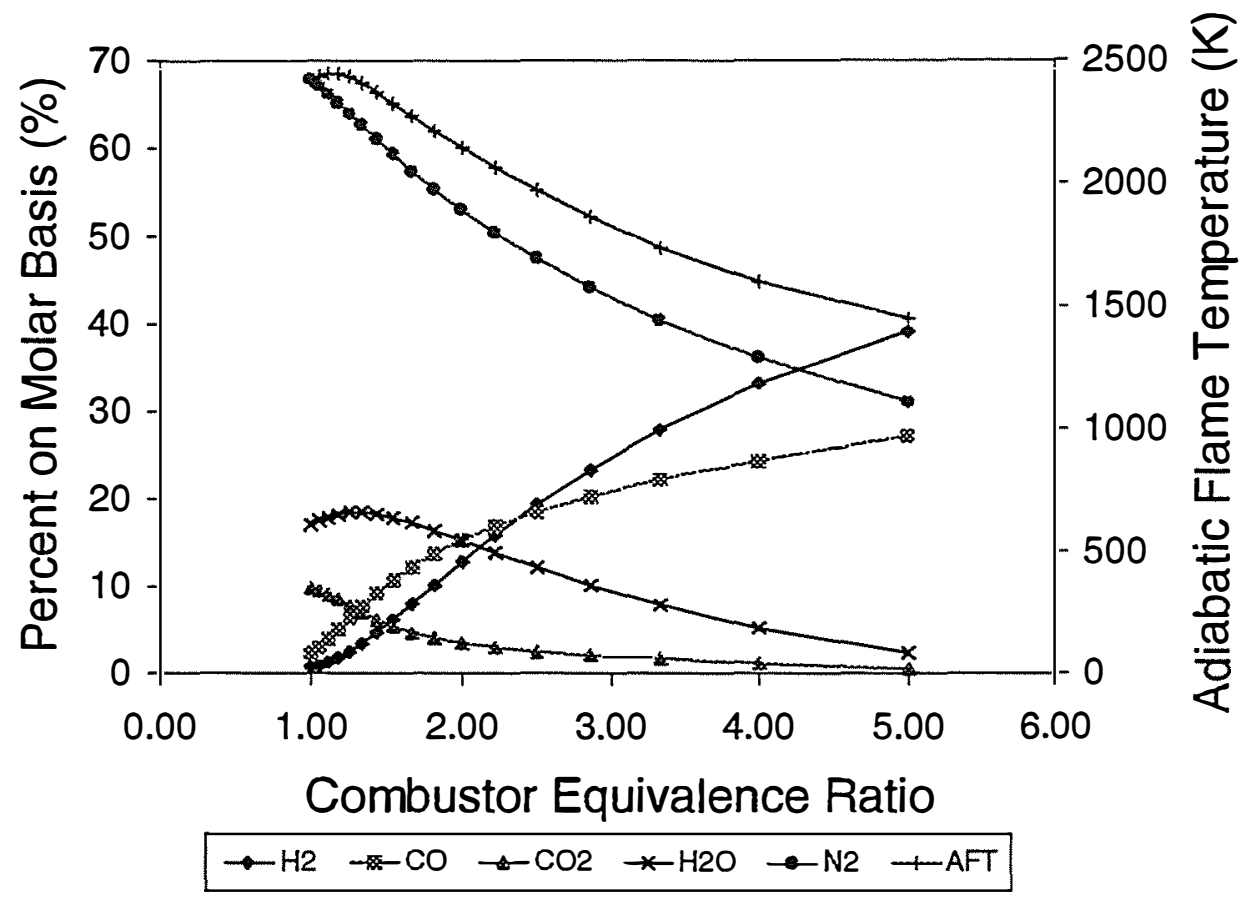

Figure 4. Calculated product composition for ethanol-fueled combustor

\section{Engine Model}

The design tool includes an engine model that simulates the use of the combustor products, as well as the primary fuel, for fueling the engine. This model follows the same methodology as the rich combustor model for determining the thermodynamic properties and product composition. The four-stroke Otto cycle is modeled including the effects of progressive combustion (spark advance and combustion duration), volumetric efficiency, and part-throttle operation to calculate the range of output of the engine using engine geometry, engine volumetric efficiency versus engine speed/manifold pressure tables, and ambient conditions as inputs.

The engine model requires a selection of fuel, equivalence ratio for the engine, and fueling strategyprimary fuel or rich combustor operation. Ambient temperature and pressure must be specified, as well as the pertinent engine dimensions-bore, stroke, compression ratio, connecting rod length, and number of cylinders. A lookup table approach was chosen for incorporating the effects of volumetric efficiency rather than calculating the flow rate through the engine based on engine characteristics and operating conditions. The latter approach requires knowledge or estimation of many engine dimensions and operating parameters as well as numerical modeling of their effects on volumetric efficiency. The lookup table approach requires only that the candidate engine's volumetric efficiency be calculated from flow rates measured as a function of engine speed and manifold pressure. The volumetric efficiency data file required by the model contains volumetric efficiency for operating points from 100 to $4,000 \mathrm{rpm}$ and 65 to 100 kiloPascals $(\mathrm{kPa})$, with operating point spacing of $100 \mathrm{rpm}$ and $5 \mathrm{kPa}$. 
The four-stroke Otto cycle is used as the basis for the thermodynamic engine model. Valve events are modeled as occurring instantaneously at top dead center (TDC) or bottom dead center (BDC), except for the intake closing event. This event is used to include the volumetric efficiency effect of reduced fresh charge. The theoretical fresh charge volume (volume at BDC minus volume at TDC) is multiplied by the volumetric efficiency to determine the volume of the actual fresh charge at intake manifold temperature and pressure. The engine geometry is then used to determine the crank angle (degrees after BDC) at which the intake valve should close corresponding to that volume. In this manner, the volumetric efficiency effects of port flow area, valve timing, EGR, and other parameters too numerous to list are all incorporated in the volumetric efficiency lookup table and are all modeled by the late closing intake valve feature.

The intake manifold conditions are assumed to be the same as ambient. In the case of primary fuel use, both the fuel and the air are at the specified ambient temperature and pressure. If operation of the rich combustor is chosen, the products are assumed to mix with air and be cooled to ambient temperature in the intake manifold as described below.

The constant volume combustion of the Otto cycle is replaced by progressive combustion in the engine model with spark advance and combustion duration as required inputs. A linear model of the burning rate is used; the portion of the fuel burned per degree of crankshaft rotation is assumed constant. The products of combustion are modeled using the shifting equilibrium method; chemical equilibrium among the combustion products is maintained throughout the cycle. Equilibrium composition is calculated at each state point based on the temperature, pressure, and element abundancies.

With engine speed and manifold pressure as inputs, and the lookup table used to determine volumetric efficiency, the engine model calculates the state point temperatures around the cycle. The temperature at the end of the intake stroke is used as the test for convergence; the model usually converges within three or four iterations. With the temperature and equilibrium composition at each state point determined, the thermodynamic data can be evaluated to calculate the indicated work for the cycle. The cycle calculations are based on one mole of fuel, which corresponds to a very large displacement engine. The actual displacement, as determined from the engine dimensions, is then used to proportionally reduce the calculated indicated work and amount of fuel to the appropriate values for the actual engine considered. The engine speed is then used to calculate the indicated power and fuel consumption rate. Engine friction power, including accessory load, is calculated using the following equation suggested by Ross (1993).

$$
\text { Friction Power }=\eta_{t h} * .00567 * \text { Engine Speed } * \text { Engine Displacement }
$$

where $\eta_{\text {th }}$ is the thermal efficiency of the engine.

For the current study, this equation does not include temperature effects. The friction power of a cold engine will be higher than this equation predicts. The engine friction was measured at various temperatures for the test engine. Although these data are engine specific, the trend should hold for other engine configurations and is included in the model. The engine brake power is then evaluated by subtracting the friction power from the indicated power. At each operating point (engine speed and manifold pressure), the following are calculated:

- Brake power output

- Fuel consumption

- Efficiency

- Cycle temperatures 
- Cycle pressures

- Exhaust composition (equilibrium)

A preliminary analysis of the indicated engine output using the rich combustor versus using the primary fueling system gives a basis for evaluating the model results. An analysis of the two modes of operation based on the heating value of the fuels, treating all gases as ideal, should yield a good approximation of the relative values of the indicated engine output. The analysis is presented for methanol for comparison to the model prediction; calculations for ethanol are similar.

Assuming the engine torque is proportional to the heating value per mole of intake charge (proportional to the heating value per unit volume of intake charge), the following analysis can be used to estimate the effect on engine torque using the rich combustor to fuel the engine.

From Obert (1973), the constant volume lower heating values of interest are:

$$
\begin{aligned}
& \mathrm{LHV}_{\mathrm{CH}_{3} \mathrm{OH}}=292089 * 2.326=679399 \mathrm{~kJ} / \mathrm{kmol} \\
& \mathrm{LHV}_{\mathrm{CO}}=103500 * 2.326=240741 \mathrm{~kJ} / \mathrm{kmol}(\text { est }) \\
& \mathrm{LHV}_{\mathrm{H}_{2}}=103435 * 2.326=240589 \mathrm{~kJ} / \mathrm{kmol}
\end{aligned}
$$

Operation of the rich combustor with an equivalence ratio of 2.0 gives the following product mixture:

$$
\mathrm{CH}_{3} \mathrm{OH} \rightarrow .76 \mathrm{CO}+.7325 \mathrm{H}_{2}+4.33 \text { noncombustibles }
$$

Therefore, based only on considerations of the heating value per mole of fuel, the indicated output of the engine using the rich combustor products for fuel is reduced by the following factor.

$$
C_{L H V}=\frac{\left(0.76 * \mathrm{LHV}_{\mathrm{CO}}+0.7325 * \mathrm{LHV}_{\mathrm{H}_{2}}\right) / 1.4925}{\mathrm{LHV}_{\mathrm{CH}_{3} \mathrm{OH}}}=0.354
$$

This reduction in indicated output accounts only for the lower heating value of the rich combustor products versus the heating value of the methanol. The indicated output is further reduced because the total number of moles in the fresh charge for induction into the engine is greater using the rich combustor. For conventional operation at stoichiometric, the total number of moles in the fresh charge is :

$$
\mathrm{CH}_{3} \mathrm{OH}+1.5\left(\mathrm{O}_{2}+3.76 \mathrm{~N}_{2}\right)=8.14 \text { moles }
$$

For operation using the rich combustor with the engine operating at stoichiometric, the total number of moles in the fresh charge is:

$$
0.76 \mathrm{CO}+0.7325 \mathrm{H}_{2}+4.33 \text { non - combustibles }+0.75\left(\mathrm{O}_{2}+3.76 \mathrm{~N}_{2}\right)=9.39 \text { moles }
$$

Assuming the indicated engine output is proportional to the energy density and the fresh charge using the rich combustor is cooled to the same temperature as the fresh charge for the conventional fueling, the indicated engine output is further reduced by the factor:

$$
C_{m}=8.14 / 9.39=0.867
$$


Therefore, assuming the incoming fresh charge is at the same temperature for the two modes of operation, the indicated output of the engine using the rich combustor is only $30.7 \%$ of the indicated output of the engine using the conventional fueling system. Further, if the fresh charge using the rich combustor is not cooled to the same temperature, the indicated output of the engine is reduced by a temperature factor based on the ideal gas law:

$$
C_{T}=\frac{\mathrm{T}_{\text {combustor }}}{\mathrm{T}_{\text {conventional }}}
$$

For the case considered, the uncooled fresh charge using the rich combustor would be approximately $1,100 \mathrm{~K}$, which would give an effective indicated output of only approximately $7 \%$ of a conventionally operated engine. Fortunately, the rich combustor products cool; thus, we consider the rich combustor rather than a simple air heater (Hodgson 1993). The results obtained from the design tool agree with this preliminary analysis.

Several operating points were examined using parameters obtained from the test vehicle to compare the brake power engine output for the two modes of operation. Typical results are presented in Figure 5.

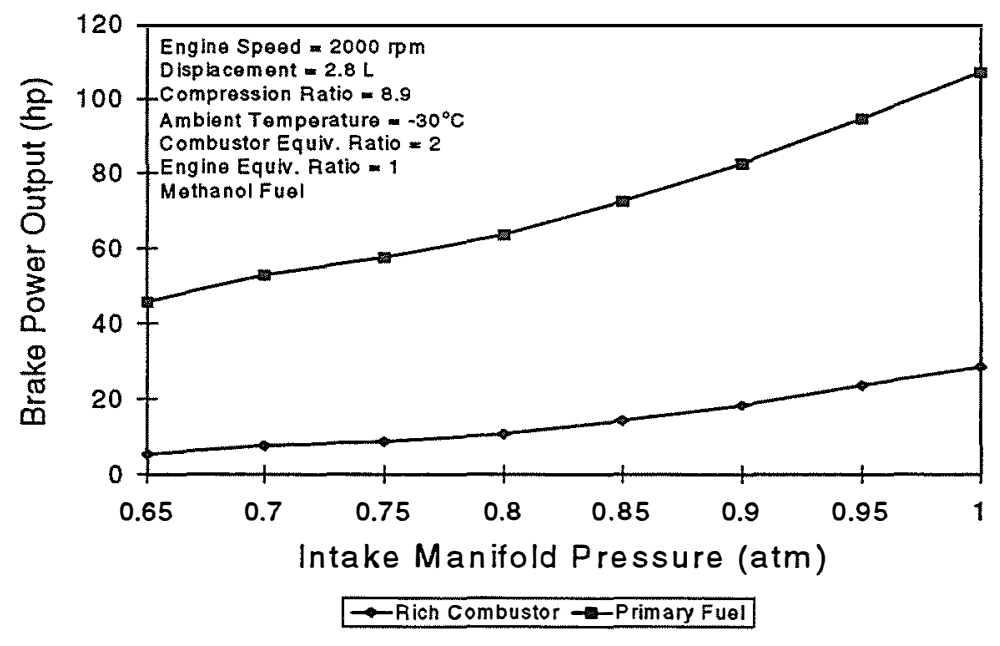

Figure 5. Calculated engine output for both modes of fueling

\section{Vehicle Model}

The design tool also includes a vehicle model for determining the road load power requirements for the driving cycle considered. The vehicle model operates in discrete time steps corresponding to the data for the prescribed driving cycle. For the UDDS, the time steps are 1 second. The vehicle model assumes that the engine is idling at time $=0$ and does not address cranking and starting. The model also assumes that the engine is idling during braking. Shifting of the transmission is per the default specifications of the driving cycle.

The vehicle parameters required by the model are vehicle mass, tire size, transmission gear ratios, and axle ratio. The model calculates the engine speed and the engine power required as functions of vehicle speed and acceleration. The engine speed is determined from the vehicle speed, tire size, transmission 
gear ratio, and axle ratio. The power required at the drive axle for constant speed is calculated using the following equation suggested by Obert (1973).

$\mathrm{hp}=\frac{\mathrm{V}}{375}\left(0.0148 \mathrm{~W}+0.00128 \mathrm{AV}^{2}\right)$

where

$\mathrm{V}=$ vehicle speed $(\mathrm{mph})$

$\mathrm{W}=$ vehicle weight $(\mathrm{lb})$

$A=$ frontal area $\left(\mathrm{ft}^{2}\right)$

The power required at the drive axle for acceleration is calculated using

Power $=\mathrm{MV} \frac{d \mathrm{~V}}{d \mathrm{t}}$

where

$\mathrm{V}=$ vehicle speed

$\mathrm{M}=$ vehicle mass corrected for rotating inertia

$\frac{d \mathrm{~V}}{d \mathrm{t}}=\frac{\mathrm{V}_{\mathrm{t}+1}-\mathrm{V}_{\mathrm{t}}}{\Delta \mathrm{t}}$

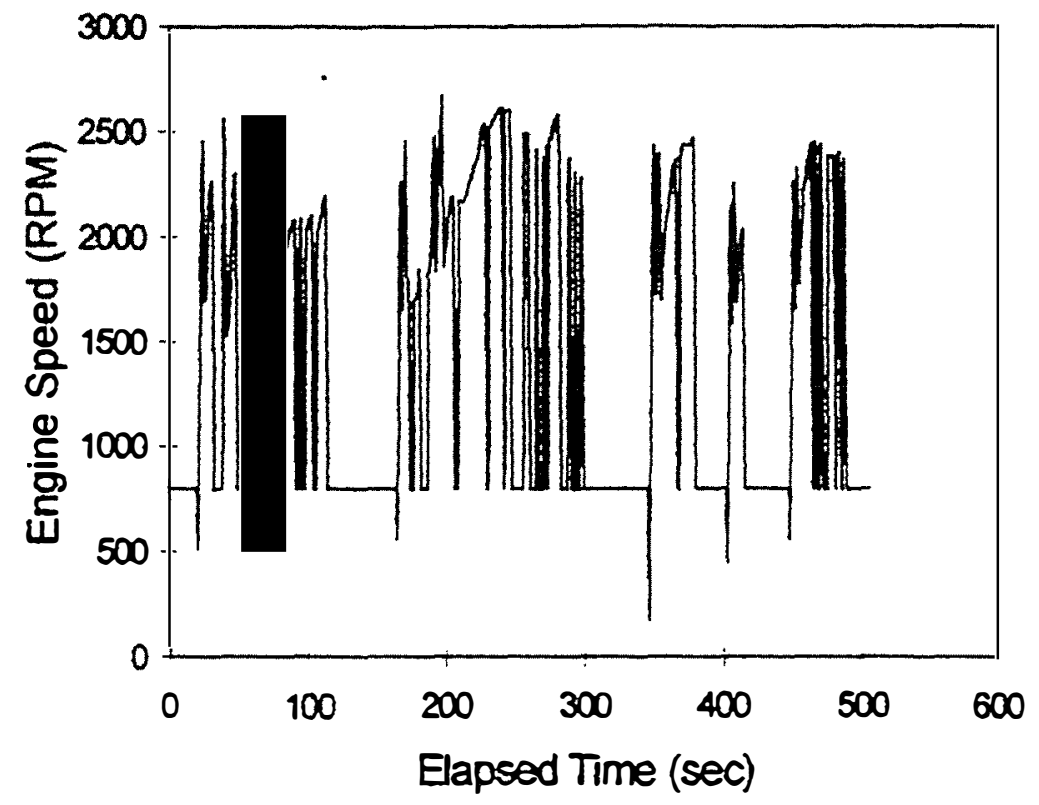

Figure 6. Engine speed for UDDS 505

The total power required at the drive axle is then the sum of the two calculated values. For calculating the required engine brake power, the vehicle model assumes a 70\% efficient driveline. Figure 6 shows the engine speed and Figure 7 shows the engine brake power required for the first 505 seconds of the FUDS calculated for the test vehicle, a 1988 Chevrolet Corsica. 


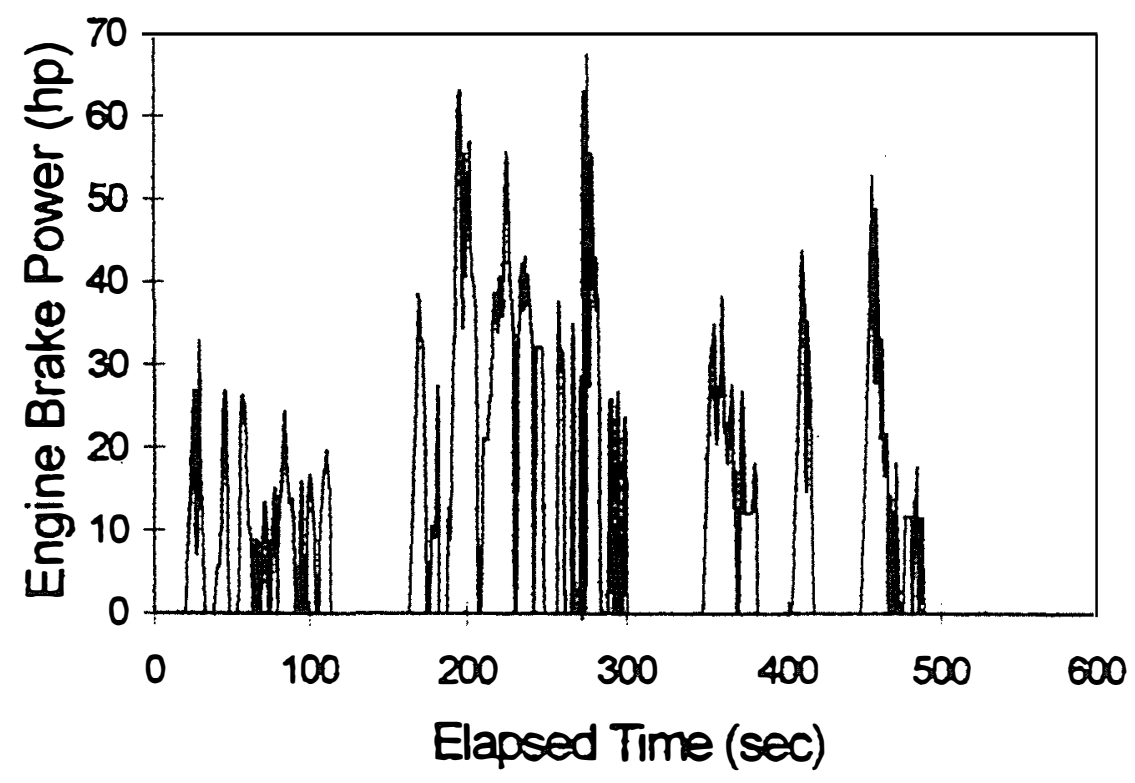

Figure 7. Engine power required for UDDS 505

\section{Integrated Model}

The three models described above are integrated into a single software package, "Thermodynamic Engine Model with Rich Combustor," written in Microsoft Visual Basic ${ }^{\circledR}$ for Windows ${ }^{\mathrm{TM}}$. The logistics of the model are as follows.

Through the Engine Parameters dialog box, shown in Figure 8, the user specifies the ambient conditions, fuel, fueling strategy, rich combustor equivalence ratio (if applicable), engine equivalence ratio, engine dimensions, and ignition parameters.

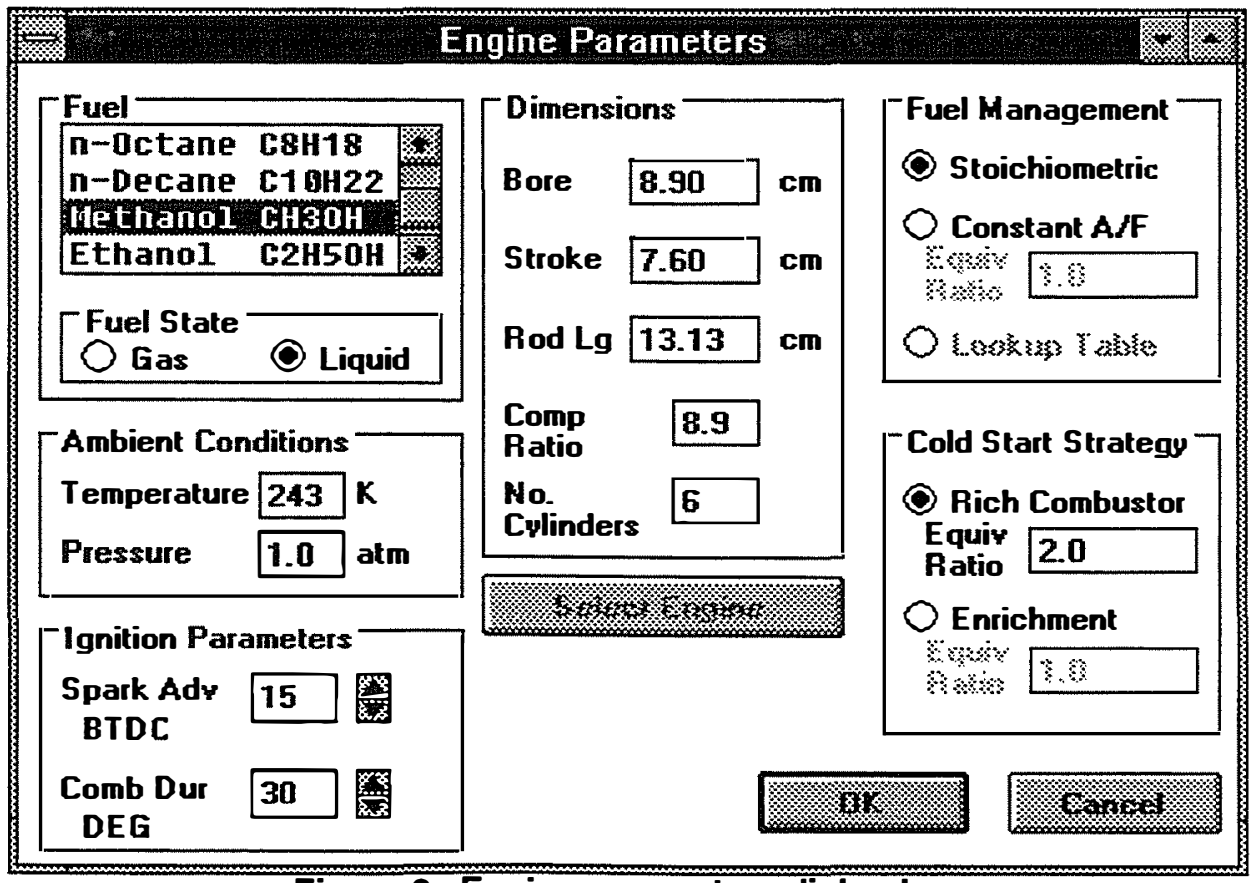

Figure 8. Engine parameters dialog box 
If rich combustor operation is specified, the combustor model calculates the composition of the combustor output used to fuel the engine. Incorporating the user-specified volumetric efficiency data file, the engine model calculates the performance map for the engine as specified in the Engine Parameters section. The results of this calculation are stored in a lookup table; engine brake horsepower and fuel consumption rate are stored versus engine speed and intake manifold pressure at $100 \mathrm{rpm}$ and $5 \mathrm{kPa}$ increments. Figure 9 shows a three-dimensional plot of the calculated performance map for the test engine with the rich combustor providing the fuel.

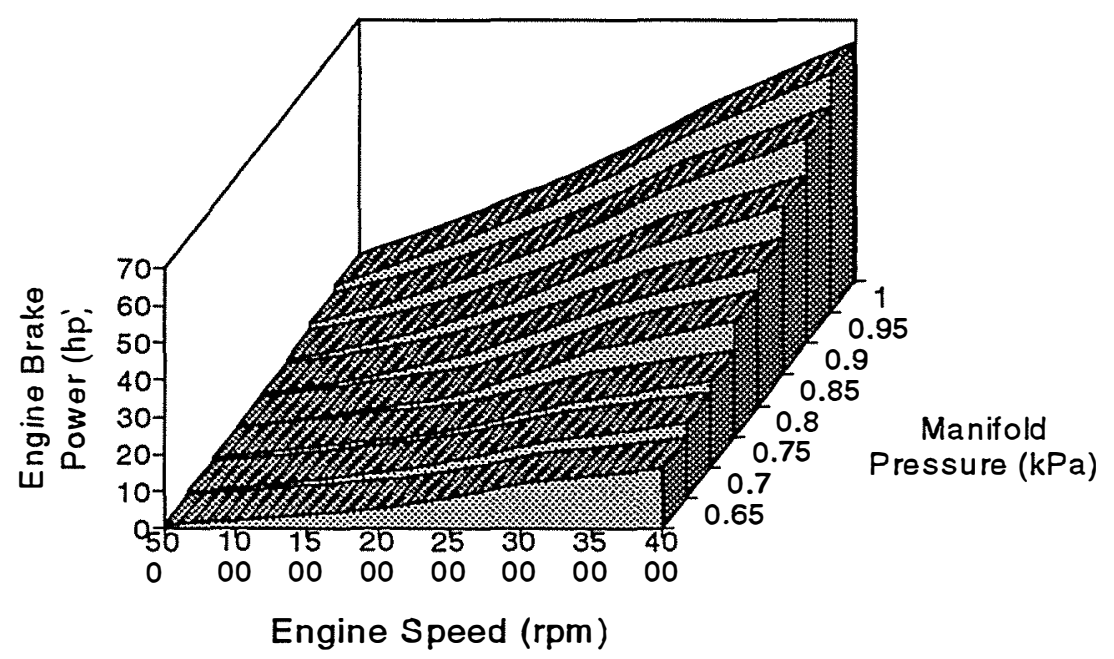

Figure 9. Calculated performance map for test engine operating on rich combustor

Through the Chassis Parameters dialog box, shown in Figure 10, the user specifies the vehicle weight, tire size, axle ratio, and transmission ratios. Using the chassis parameters and the specified driving cycle, the vehicle model calculates the engine speed and required engine brake power for each time step of the driving cycle.

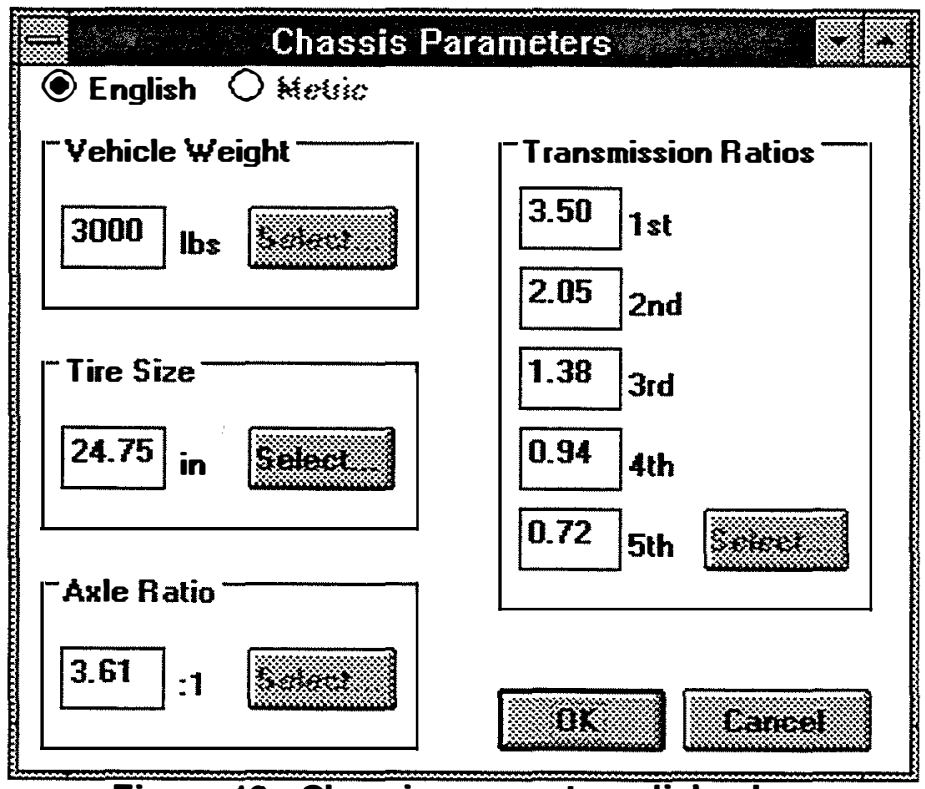

Figure 10. Chassis parameters dialog box 
For each time step in the driving cycle, the operating point of the engine is determined in the following manner. The engine speed is considered first. Because the performance map lookup table has data every $100 \mathrm{rpm}$, the two engine speed entries that bracket the operating point are determined. Then for each of the two engine speed entries, the brake power values are determined that bracket the required brake power calculated by the vehicle model. The operating point is then found by linearly interpolating in both directions (engine speed and intake manifold pressure) between the four operating points described above. Once the operating point is determined, the fuel consumption and other values available in the performance map lookup table are calculated using the same linear interpolation. Figure 11 shows the fuel consumption rate for the first 505 seconds of the FUDS for the engine operating on the rich combustor.

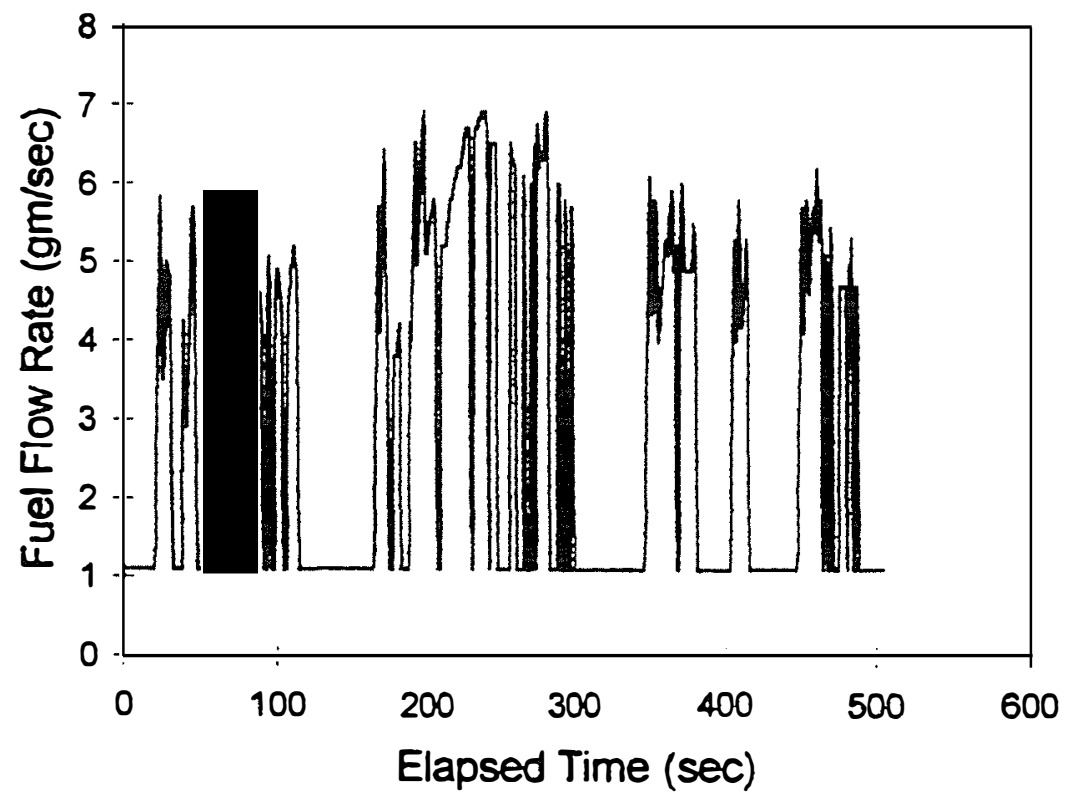

Figure 11. Calculated fuel consumption for test engine operating on rich combustor

\section{Cranking and Starting}

Based on actual cold room engine starting tests at $-30^{\circ} \mathrm{C}$ using gasoline, we estimate that a combustor fuel flow rate of $0.25 \mathrm{~g} / \mathrm{s}$ (methanol) will be required during engine cranking at $100 \mathrm{rpm}$. This figure rises to $1.1 \mathrm{~g} / \mathrm{s}$ at an idle speed of $800 \mathrm{rpm}$. These estimates were obtained from the design tool by calculating the engine output using the measured operating parameters from cold room testing using gasoline, then determining the operating parameters to provide that same engine output using the rich combustor fueled with methanol. 


\section{Prototype Design and Fabrication (Task 2)}

\section{Task Description}

In this task, the offeror, using the understanding obtained from the modeling effort in Task 1 , shall design a prototype combustor. The design shall include among other concerns: nozzle selection, air and fuel flow regulation, ignition system selection, material type, and fabrication method.

\section{Approach}

From a previous investigation of the rich combustor concept for cold starting (Hodgson 1994), the following areas of concern were noted:

1. The device should be downsized to be more suitable for under-hood installation.

2. Appropriate controls should be incorporated to make the system operation automatic.

3. More control over the air/fuel ratio is required.

These areas, together with the concerns listed in the Task Description above, were taken as the design criteria for the prototype rich combustor. The criteria will be addressed individually by describing their incorporation into the prototype design. Some features of the design address multiple concerns.

\section{First Generation Combustor Design}

A brief description of the prototype rich combustor and its operation will be beneficial. The prototype is fundamentally an "air-splitter." It is installed between the throttle body and the intake manifold on the engine, and divides the air flowing through the throttle body into two (physically three) streams. One stream flows through the combustion chamber where fuel is added and ignited. The fuel droplets burn in a rich diffusion flame to produce the desired products that will be used to fuel the engine. This stream can be throttled to reduce the flow through it as the engine warms up and the requirement for the noncondensable gases is reduced. The remaining air flow is directed around the combustion chamber unaffected except for heat transfer from the combustion chamber and rejoins the combustor products before entering the intake manifold. A complete set of prints of the design drawings is included as Appendix A in this report.

\section{Downsizing}

This project involves the demonstration and investigation of the rich combustor cold start device, so the ultimate goal was to install the device on a vehicle and demonstrate the ability to start and drive under the cold ambient conditions required. The under-hood space available in a modern vehicle is very limited; therefore, the device must be small enough to allow installation with minimum modification to the vehicle. 
The prototype design was obviously not downsized to meet the requirement of vehicle installation. This prototype was not intended to be installed under-hood; instead, it was used in the dynamometer installation shown in Figure 12. Evaluation of this prototype on the dynamometer installation allowed the determination of the minimum size for the rich combustor to be installed on the vehicle.

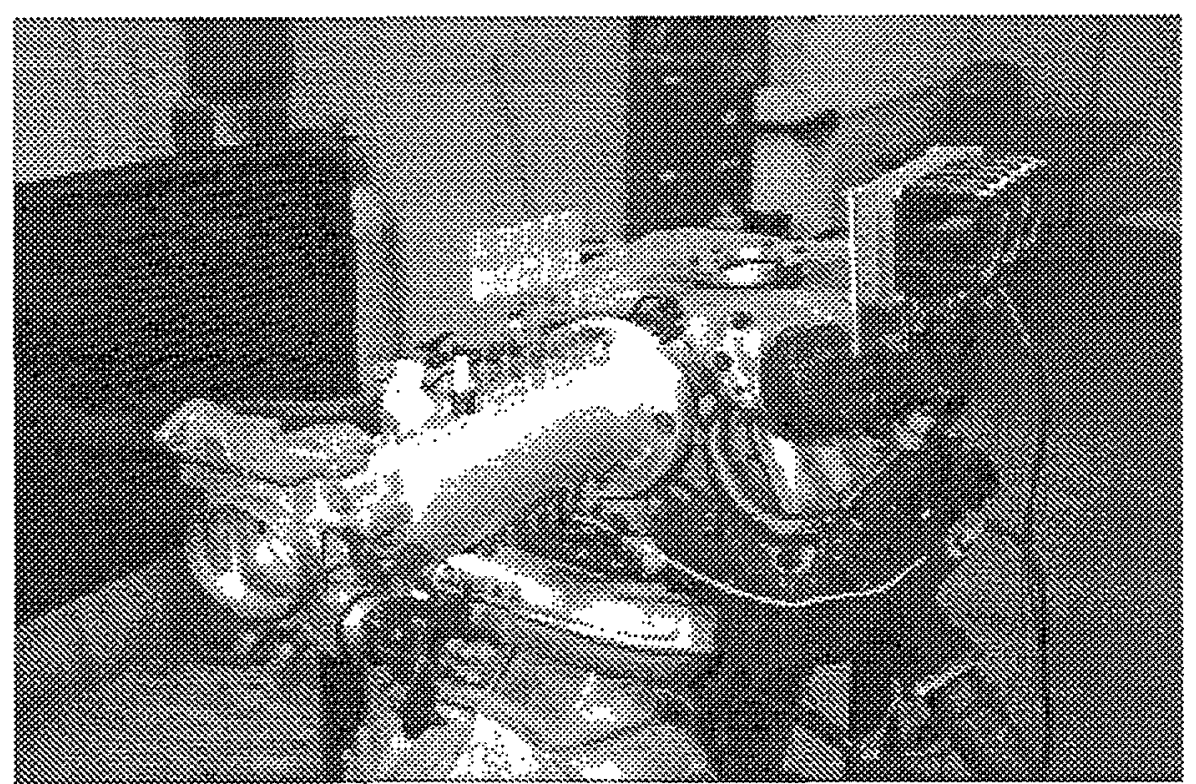

Figure 12. Rich combustor dynamometer installation

\section{Control}

The approach taken in the design of the prototype combustor was to minimize the amount of control required; the operation was to be as automatic as reasonable. The only control requirements anticipated were positioning of the throttle plate versus engine temperature, and fuel flow to the combustor and the main fuel injection system.

The throttle plate was positioned using temperature input to a positioning device such as a stepping motor. The goal is to position this throttle plate using some simple device.

Control of the fuel flow was managed by the engine control computer. The aftermarket computer to be used on the engine in the dynamometer installation allows programming of the enrichment schedule for fuel management. The design tool developed in Task 1 predicts the fuel flow requirements for operating the rich combustor. Actual testing will determine the operation schedule of the rich combustor as a function of engine warmup, or the position of the throttle plate as described above. The fuel flow to the combustor's injector(s) must then be controlled to maintain the desired air/fuel ratio in the rich combustor, with the appropriate fuel directed to the main injector system to maintain the desired overall engine air/fuel ratio.

\section{Air and Fuel Flow Regulation}

Regulation of the air flow is the primary reason for choosing the "air-splitter" approach. The desired operating equivalence ratio for the rich combustor will be nominally 2 . This dictates that initially, when 
the engine is operating on the products of the rich combustor alone, half the air flowing through the engine's throttle body will be used by the rich combustor, with the remaining half used to burn the combustor's products in the engine. The combustor is designed such that the flow area of the combustion chamber is equal to the sum of the areas of the two air passages. Further, this flow area is equal to the flow area through the original throttle body, allowing undisturbed operation of the engine with the combustor's throttle plate completely closed.

Fuel flow is controlled by the engine control computer. The design tool developed in Task 1 has predicted the fuel flow requirements for operating the rich combustor. Testing determines the combustor's operating schedule and therefore the air flow through it; the fuel flow to the combustor must then be controlled to maintain the desired air/fuel ratio in the rich combustor. The fuel flow to the main injection system must also be controlled in concert with operation of the rich combustor. The design tool can be used to predict this fuel flow requirement also, once the rich combustor's operating schedule is known. We plan to accomplish this by determining an overall fuel flow requirement (enrichment table) together with a map of fuel flow requirement for each system. This "fuel-splitter" approach will be accomplished electronically, with the goal to be "generic" with respect to the engine control computer.

\section{Nozzle and Ignition System Selection}

The fuel injectors and ignition system are basic to the operation of the rich combustor. Rather than designing the prototype for a particular injector and/or ignition system, it was designed to allow investigation and testing of available systems.

\section{Material Type and Fabrication Method}

The current prototype is not the final configuration for installation on the vehicle, so it was designed to minimize cost associated with material and construction. As shown on the included drawings, the prototype is primarily aluminum welded construction. The design considerations for the combustor to be installed in the vehicle will be primarily space limitations; therefore, the physical design of the device may be quite different. However, the operation of the device is not expected to change.

\section{General}

Ports are spaced along the axis of the prototype to allow installation of thermocouples and/or sampling probes to monitor the progression of the reaction. This will help to determine the minimum size required for the rich combustor. Access to the combustion chamber is provided to allow incorporation of flamequenching devices. A port has been machined in the intake manifold plenum and fitted with a sight glass to allow visual inspection of the operation of the rich combustor.

\section{Design Evolution}

The first generation rich combustor design was modified as a result of the testing described below. The two areas that were modified were the ignition system and the fuel system. 
The original design for the ignition system included conventional spark plugs. However, during fabrication we decided to evaluate the use of small glow plugs as an ignition source. This type ignition has the advantage of requiring only a voltage source for the thin wires of the glow plugs; no other components such as coils are required. This configuration is shown in Figure 13. Testing of this configuration, as described below, showed that the glow plugs could not maintain sufficient temperature for ignition in the air stream as the engine was cranked. Raising the voltage supplied to the glow plugs to overcome this would result in immediate burnout when the air flow was disrupted.
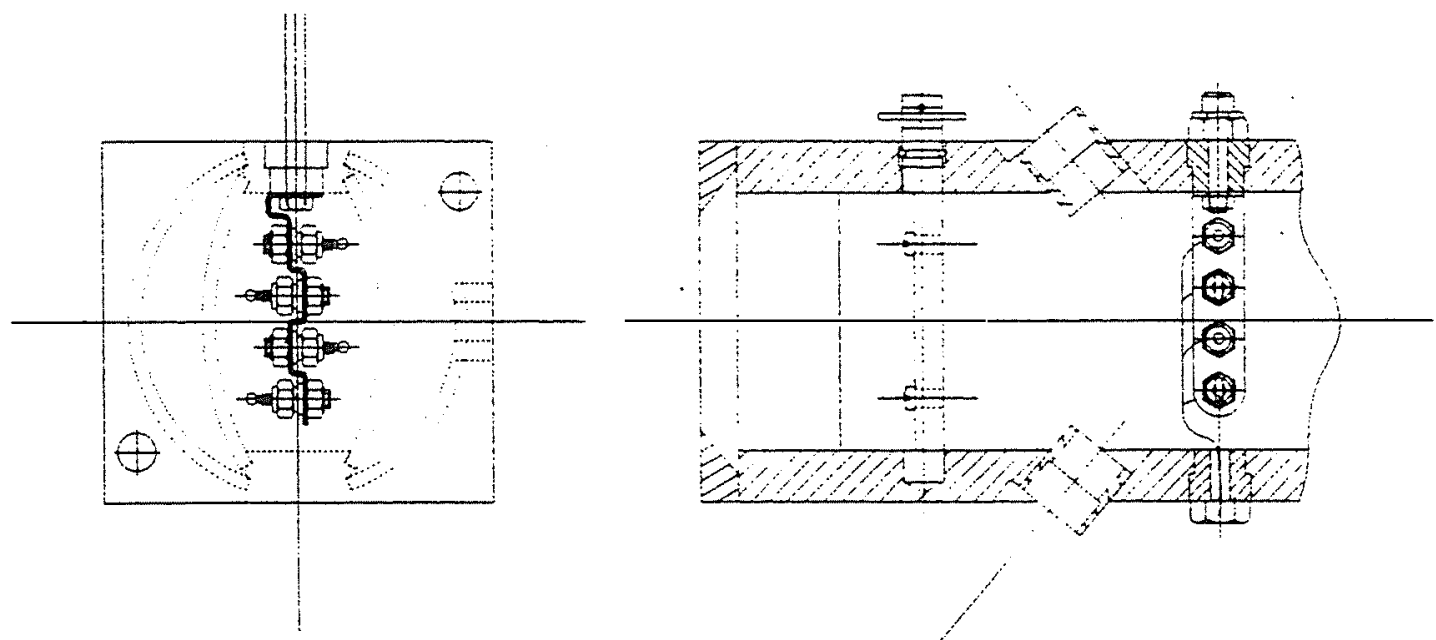

Figure 13. Glow plug configuration

The glow plug ignition system was replaced by conventional spark plugs. The spark plugs were mounted in the combustor as shown in Figure 14.
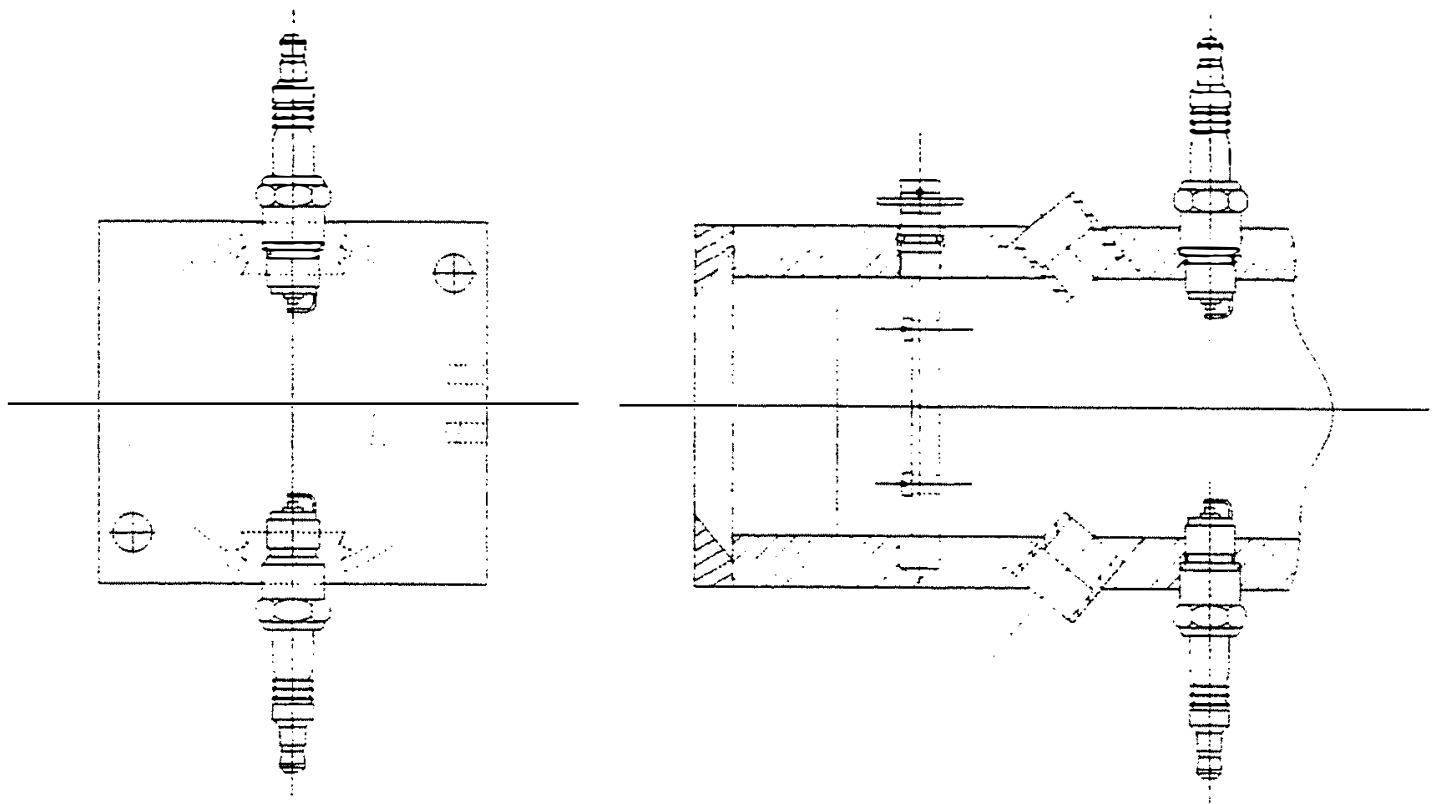

Figure 14. Spark plug configuration 
A coil assembly from a Saturn automobile was used to fire the spark plugs; a single coil fired both spark plugs in a manner similar to the ignition system used on the engine. A device that operates independently of the engine was fabricated to provide the required excitation signal to the coil assembly. This made the combustor ignition system completely self-contained.

This configuration suffered from two problems. The spark plug gap was near the wall and was not exposed to very much of the fuel spray from the injectors. The other problem was a result of the vertical mounting and the conductivity of methanol. The annulus between the insulator and body of the lower plug filled up with methanol and essentially grounded the electrode, causing that spark plug to not fire.

This conventional spark plug configuration was replaced by igniters used in oil furnaces. This igniter has an electrode that extends well beyond the insulator and does not have a ground electrode, because these igniters are intended to arc to a ground that is part of the furnace. For this application, however, two igniters were used with the modified Saturn ignition system and were installed such that the arc was from one igniter to the other (see Figure 15). The gap between the electrodes of the two igniters was approximately $1 / 4 \mathrm{inch}$, although the ignition system would allow a gap larger than 1 inch.

This configuration proved satisfactory and no problems were encountered during testing at temperatures as low as $-30^{\circ} \mathrm{C}$. This ignition system was carried over to the second generation combustor design.

The original design for the fuel system included conventional automotive injectors for delivering the fuel. Methanol compatible injectors with a rated flow rate of $3.9 \mathrm{~g} / \mathrm{s}$ were obtained from Rochester Products. Calculations from the model indicated that two of these injectors would be adequate to deliver the fuel at a rate for drive-away. Initial testing of the injectors was conducted with the conventional spark plug configuration with poor results; the fuel was not reliably ignited. Subsequent off-line testing of the injectors revealed that the injectors had an almost jet-like spray pattern. Previous work (Hodgson 1993; Iwai 1984), indicated that a fine spray would be required to ignite the methanol.
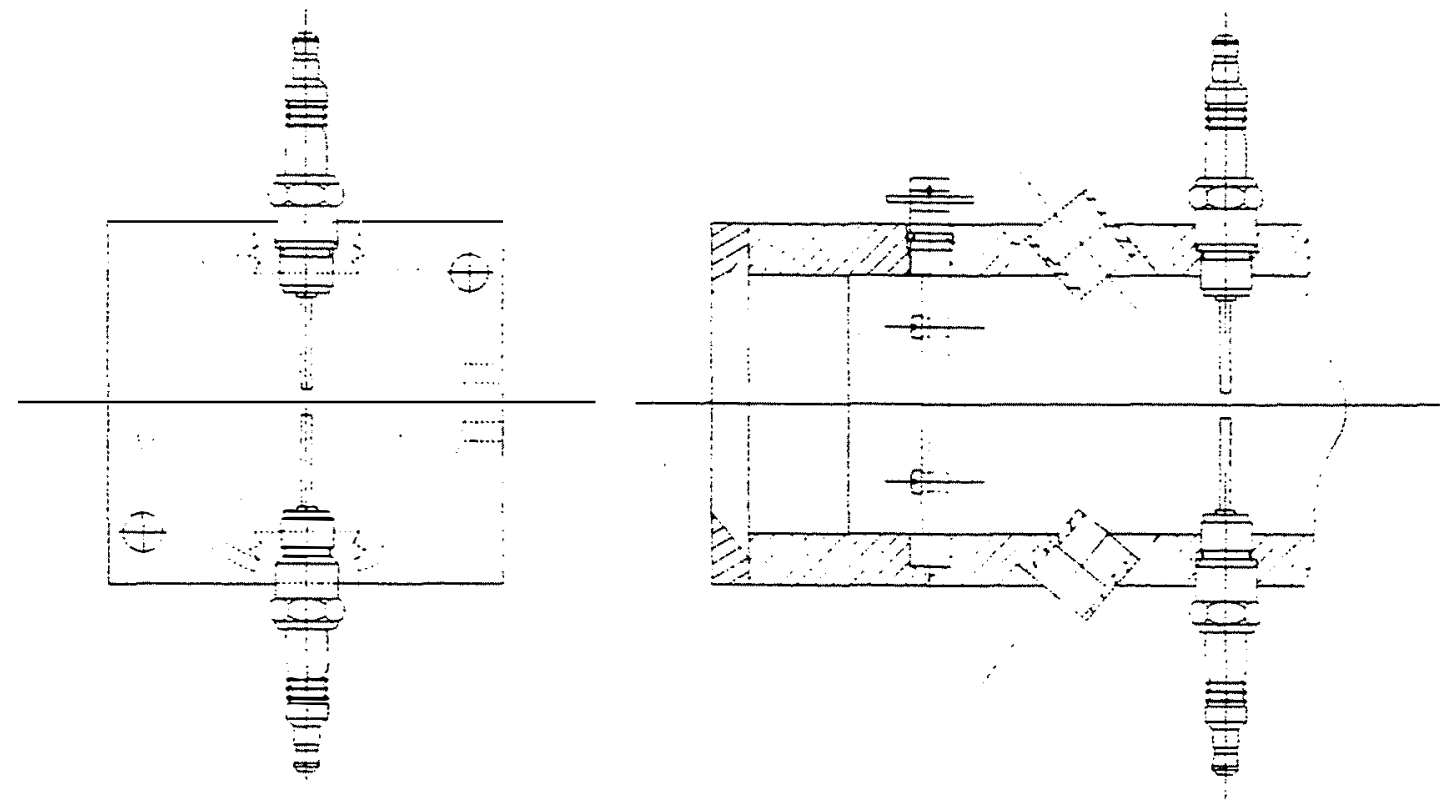

Figure 15. Fumace igniter configuration 
The injectors could, however, provide the control of the fuel flow as required. Nozzles such as those used in oil furnaces were chosen to provide the required spray pattern. As shown in Figure 16, the resultant design was an assembly of the injectors for flow control in line with the nozzles for providing the required spray pattern. This configuration proved satisfactory and was carried over to the second generation combustor design.

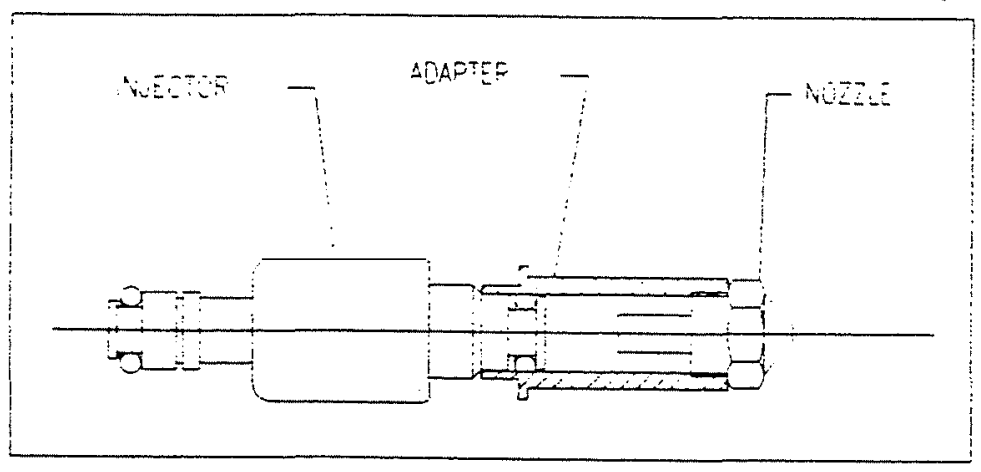

Figure 16. Injector-nozzle assembly

Several nozzles were flow tested to determine the flow rate and spray pattern. We decided to use one nozzle with a measured flow rate of $0.97 \mathrm{~g} / \mathrm{s}$ without an injector, which meant that it delivered that flow rate at all times. That flow rate corresponded to the idle fuel flow rate requirements predicted by the model. The injector-nozzle assembly was used in the other injector position with a nozzle with a measured flow rate of $1.57 \mathrm{~g} / \mathrm{s}$ for initial cold start testing.

Other modifications to the original design were incorporated as a result of, and during, the testing of the first generation combustor. A baffle arrangement was added to disrupt the flow through the combustor and provide more surface area for quenching the flame. In addition, a quenching nozzle was added to both quench the flame and cool the products. The final configuration of the first generation combustor design is shown in Figure 17. Figure 18 shows the final configuration installed on the test engine.

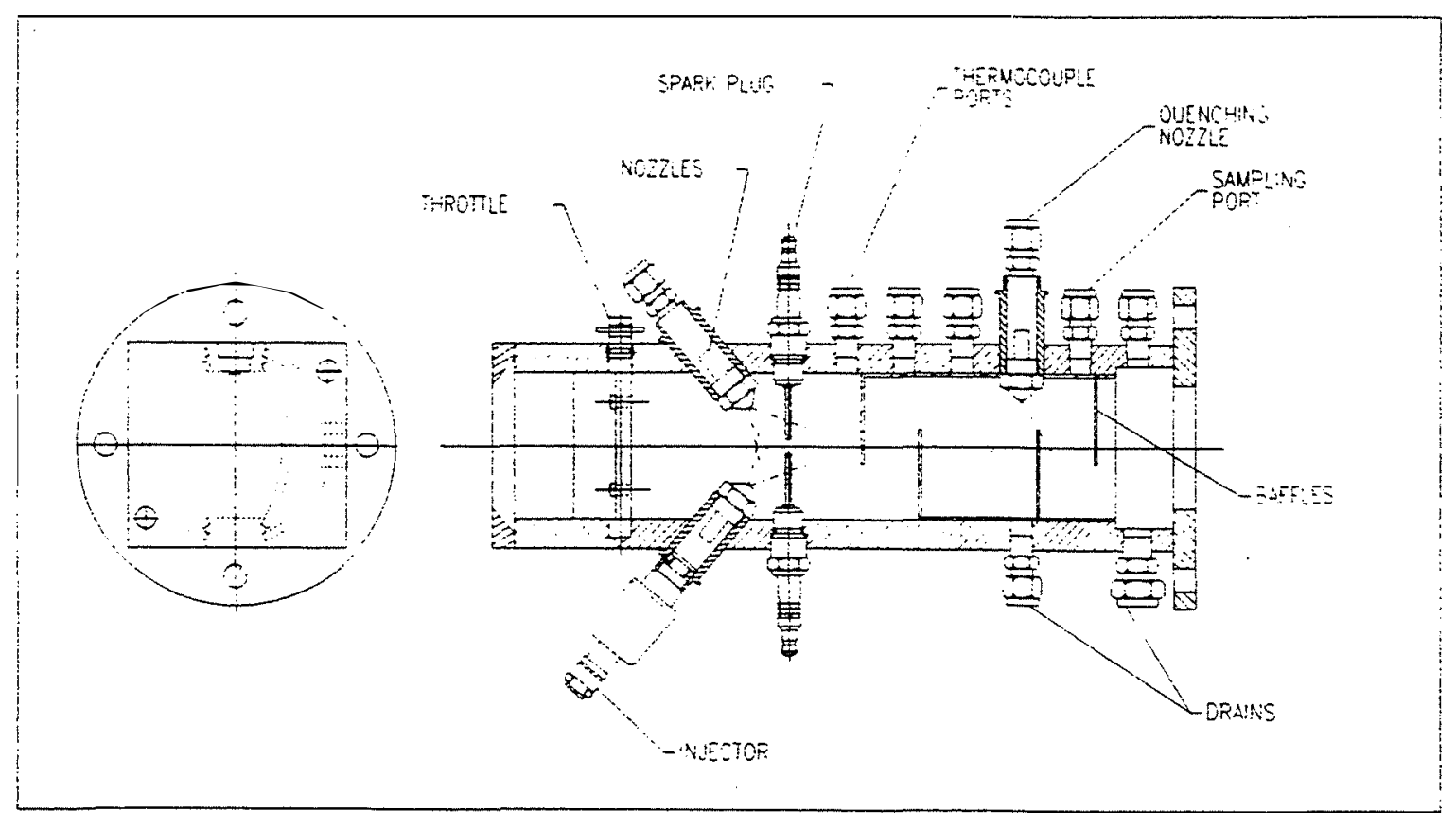

Figure 17. First generation design final configuration 


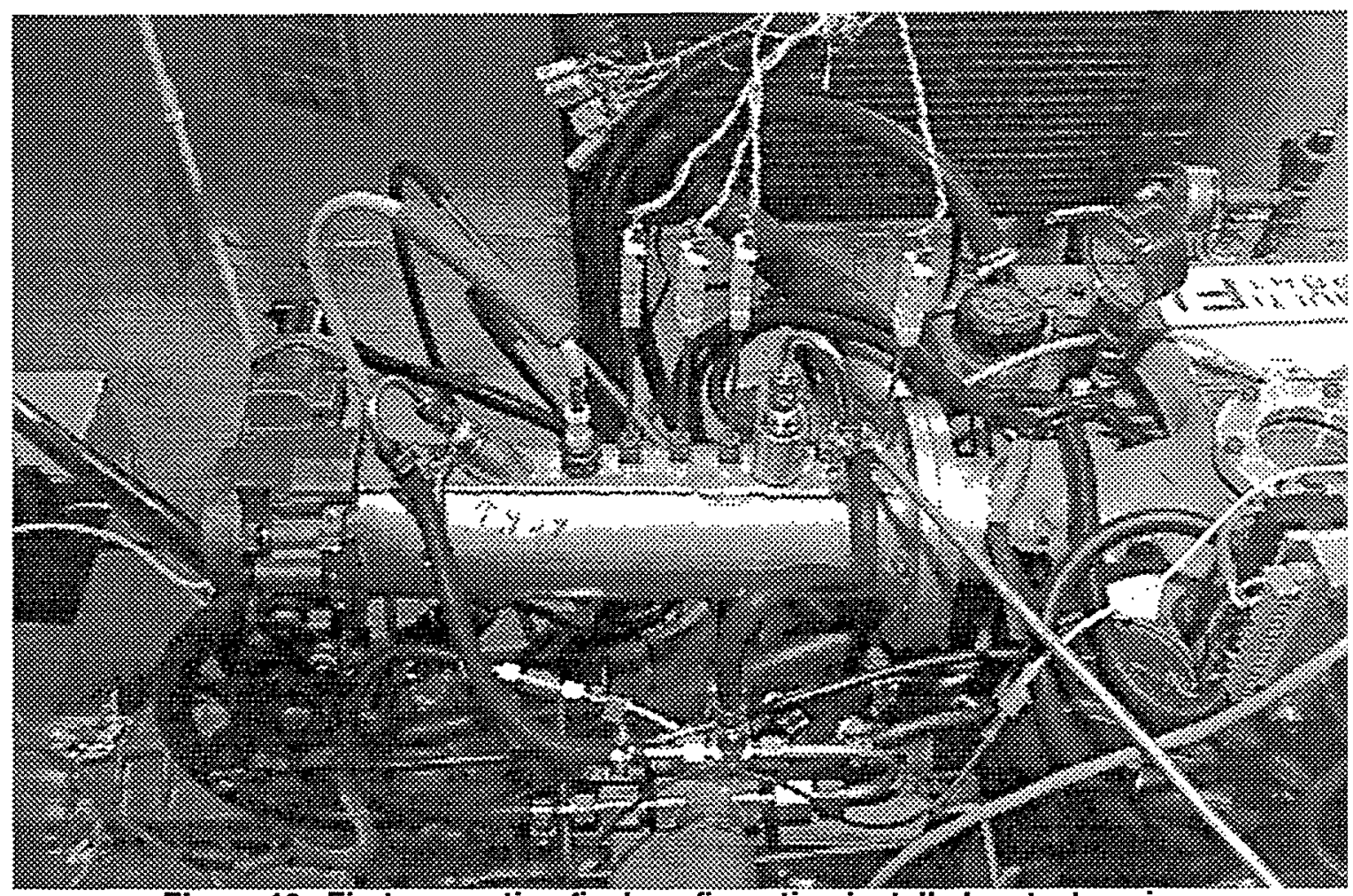

Figure 18. First generation final configuration installed on test engine

\section{Second Generation Combustor Design}

Two major problems with the first generation combustor design surfaced during testing. The combustion zone exceeded the length of the combustor and the flame continued past the point where the fresh air rejoined the combustor products. In fact, the flame continued on into the intake manifold, which resulted in all the combustible gases being consumed before they reached the engine cylinder. The second problem was associated with the splitting of the air. Due to the reaction occurring in the combustor area, splitting the air flow through the combustor and fresh air areas could not be accomplished by simply using equal flow areas.

The second generation design addressed both problems while maintaining the original overall concept for operating the rich combustor as described above. The ignition system developed for the first generation design was included in the second generation design. The injector/nozzle hybrid system for fuel delivery was also used in the second generation combustor design. In addition, the second generation design addressed under-hood installation in a vehicle. A complete set of prints of the design drawings is included as Appendix B of this report.

\section{Design Features}

The combustion zone length problem associated with the first generation design could not be overcome by the baffle arrangement as described above; therefore, the only solution was to increase the length of the combustion chamber in the second generation design. Keeping in mind the vehicle integration issue of limited under-hood space, a flat spiral type configuration that would be installed on top of the plenum emerged as the most promising configuration. However, manufacturing a design of this type would be 
very expensive; fabrication would require either extensive machining or very difficult forming of tubing. A compromise design was chosen that maintained the general configuration described above, but was considerably simpler to manufacture. Rather than a flat spiral, a square cornered maze-type configuration was used to simplify the fabrication considerably. The original concept drawing for this design is shown in Figure 19. This configuration could be fabricated as a weldment from rectangular steel mechanical tubing readily available. This configuration increases the length of the combustor flow path by a factor of approximately 10 .

The second generation combustor is installed on top of the plenum with the combustor outlet mated to the added port in the plenum previously used for a sight glass. The overall height of the second generation combustor is 3 inches above the top of the plenum, which allows for under-hood installation.

The problem associated with air splitting was originally addressed by using larger tubing for the combustion chamber than for the fresh air. The flow area of the combustor was approximately 6 in. ${ }^{2}$; the fresh air side was approximately 4 in $^{2}$. This proved to be an improvement to the first generation design but did not completely solve the problem. Testing showed that too much air was flowing through the fresh air side, resulting in a very lean mixture supplied to the engine. Modifications to the design for proper air splitting are described below.

\section{General}

With the configuration chosen for the second generation design, the combustor could not be fit between the main throttle body and the intake manifold as with the first generation design. To maintain the overall concept for control, the throttle body must be mounted at the inlet of the combustor. This required that the opening in the plenum be capped where the throttle body originally was installed.

The fuel delivery system was designed to deliver the fuel flow rate required for drive-away as predicted by the model; this would require two injectors (in addition to the one serving for idle). The configuration shown in Figure 20 was chosen. The idle injector is upstream of the ignition system where the flame is established. The two additional injectors are installed immediately downstream of the ignition system and deliver fuel, under the control of the engine controller, to the established flame. Provisions for a quenching nozzle are also provided.

\section{Design Evolution}

As described above, the air flow through the fresh air side was too high. An additional throttle was installed in the fresh air side, as shown in Figure 21, to further restrict the flow. Testing showed that the mixture provided to the engine was closer to stoichiometric.

The original design featured drains at both ends of the second leg of the combustion chamber. This configuration was adequate for removing any liquid that collected and flowed on the floor of the combustor. However, liquid droplets were observed through the sight glass being carried in the gas stream. To prevent these droplets from being carried to the engine, a fine mesh stainless steel wire cloth was installed immediately upstream of the second drain to knock the droplets down to the floor where 


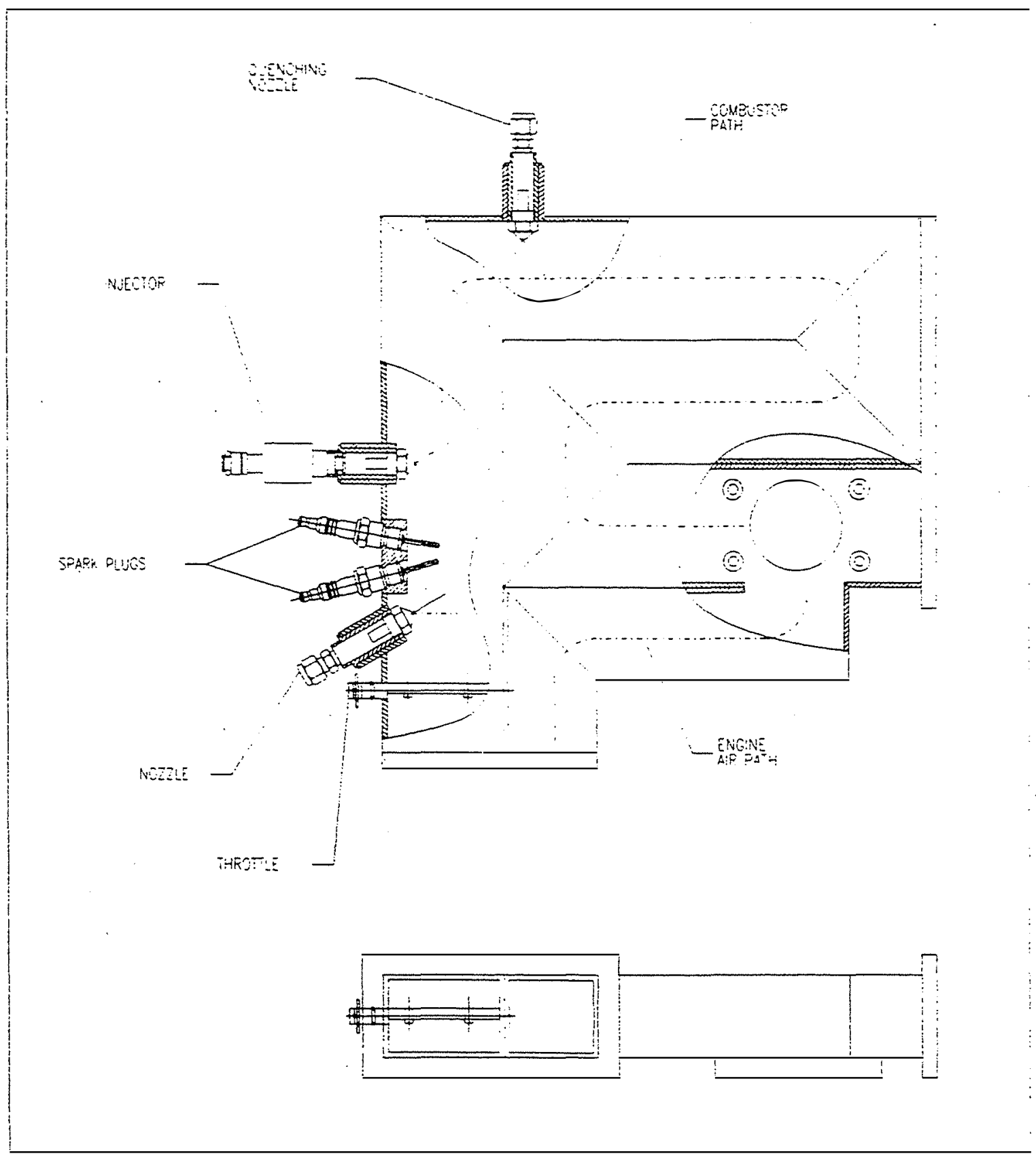

Figure 19. Second generation design concept drawing 


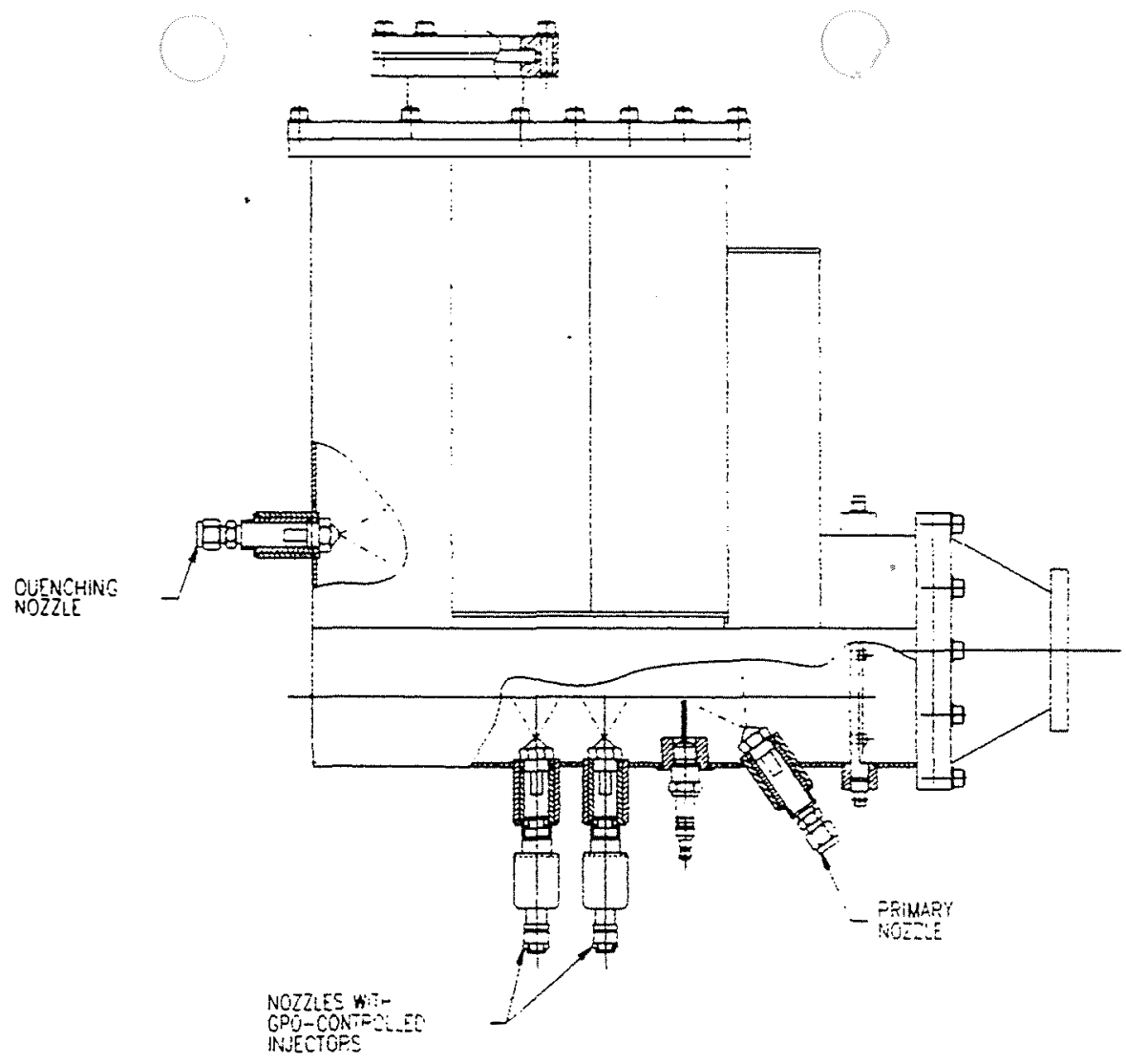

Figure 20. Fuel delivery configuration

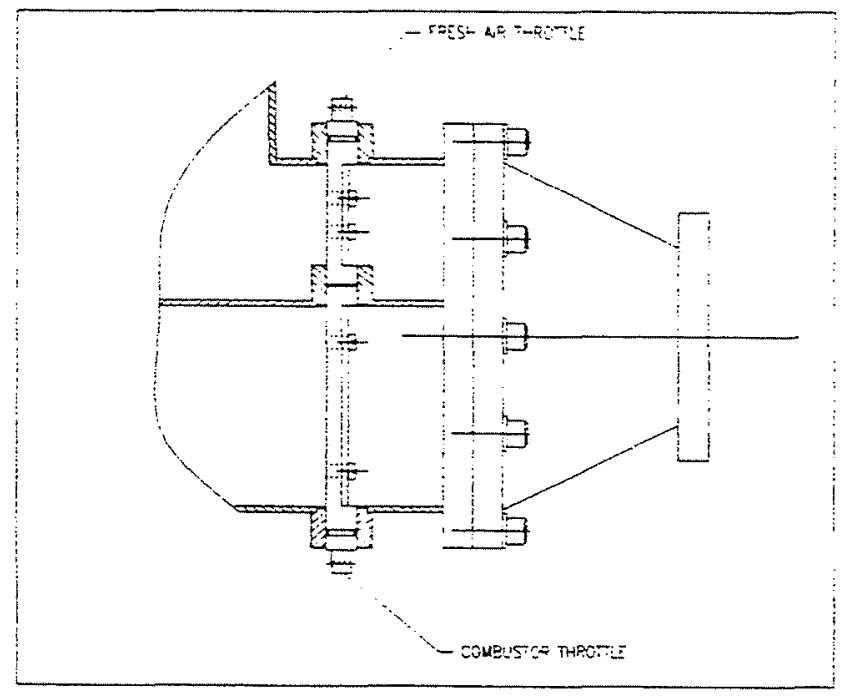

Figure 21. Fresh air throttle installation

they would flow out the drain. This screen was mounted to a frame that served also as a sort of dam to any liquid flowing along the floor. Testing showed that this screen heated up and glowed red, which tended to cause whatever fuel was being carried by the gas stream to burn when it reached the screen.

The current configuration of the second generation combustor is shown installed on the test engine in Figures 22 and 23. 


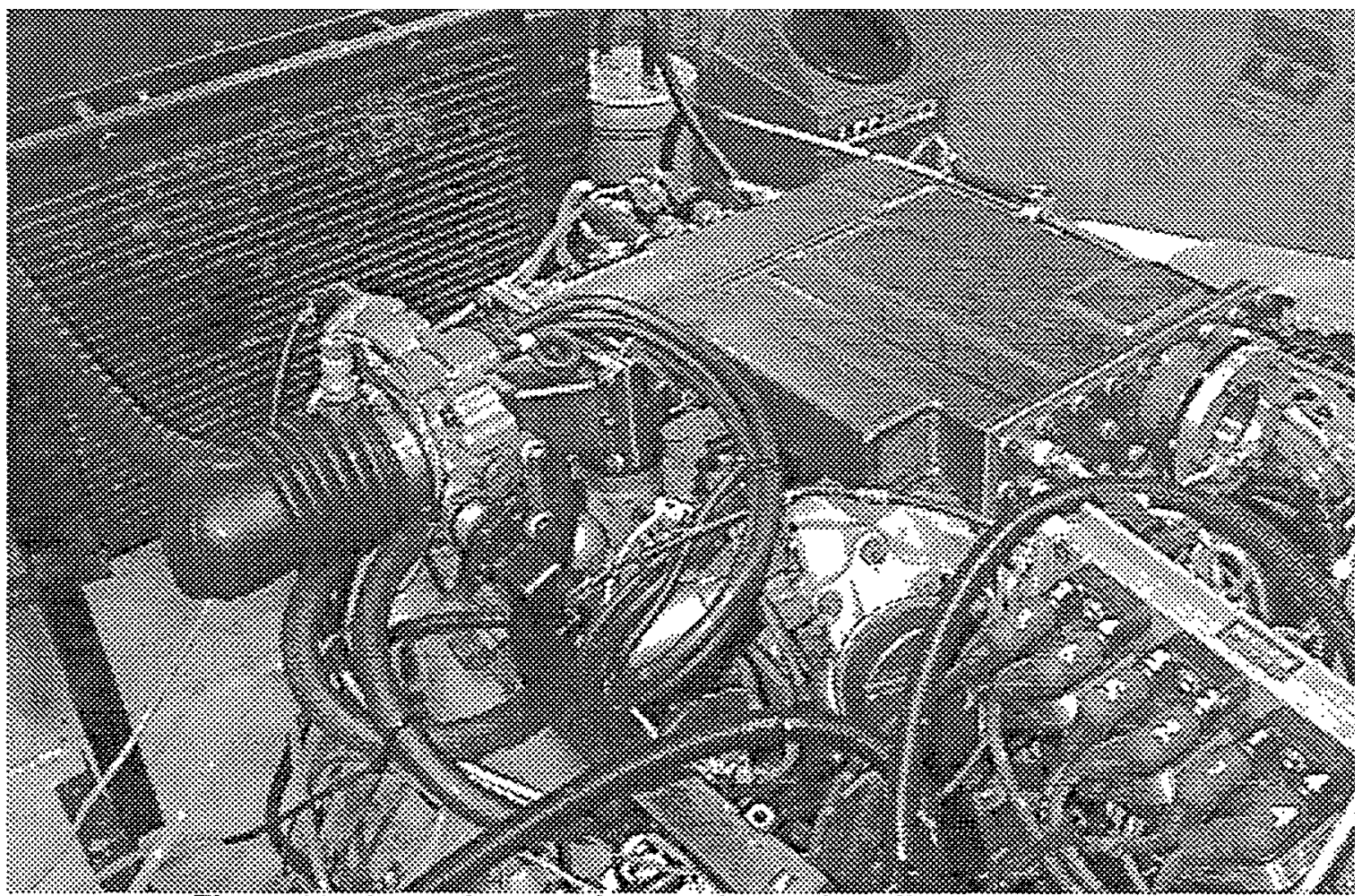

Figure 22. Second generation combustor installed on test engine

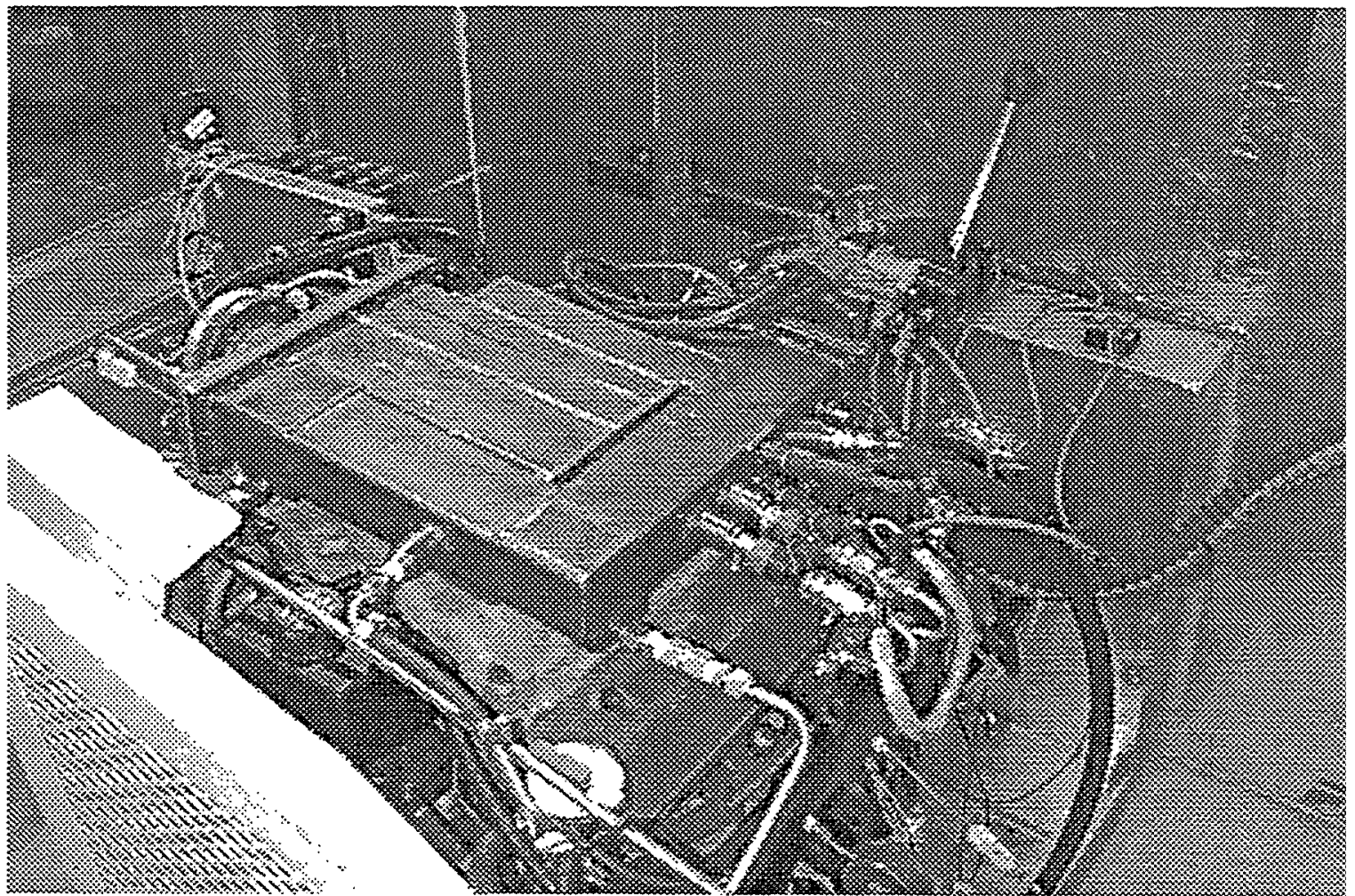

Figure 23. Second generation combustor on test engine 


\title{
Prototype Testing and Vehicle Interface and Testing (Tasks 3 and 4)
}

\author{
Task Description (Prototype Testing and Evaluation-Task 3)
}

In this task, the offeror shall test the prototype rich combustor produced in Task 2 to determine its performance. The tests shall be done over a range of ambient temperatures and shall include performance mapping of the following parameters: fuel and air flow, output gas composition and temperature, and combustor temperature (at different locations on the apparatus). The evaluation shall initially be based on bench tests of the apparatus but shall include issues associated with vehicle applications such as air flow and pressure drops.

\section{Approach}

Because of the availability of cold temperature testing capabilities, including an engine dynamometer, and an engine identical to the engine in the test vehicle, the task of vehicle integration could logically be combined, to a great extent, with the testing and development of the prototype. We could use the dynamometer driving the engine as a pump to test the combustor while the issues of fit, interfaces, and control were concurrently addressed. With this capability, many of the problems associated with vehicle integration were addressed early in the development of the combustor. This parallel approach was taken rather than the original task breakdown, which included bench testing. The task description for the vehicle interface and testing task is included below, followed by the complete description of the testing configuration.

\section{Task Description (Vehicle Interface and Testing-Task 4)}

Based on the test results from the previous tasks, the offeror shall install the prototype rich combustor device(s) on vehicles for cold-start testing. The combustor and installation shall take into consideration all the criteria for proper vehicle operation such as requirements for actuating, shutdown, and phase-out of the device at different operating conditions. The objective of the rich combustor apparatus for methanol is to achieve satisfactory cold startability at low temperatures.

\section{Testing Configuration}

The testing facility consists of a refrigerated enclosure built on one end of the dynamometer mounting bed plate. The walls and floor are frame construction with approximately 12 inches of Styrofoam insulation. The refrigeration unit is capable of cooling the chamber, including a hot engine, to $-30^{\circ} \mathrm{C}$ in approximately 9 hours. Access to the dynamometer is through a driveshaft tunnel in the rear wall.

As mentioned above, the engine in the test cell is identical to the engine in the test vehicle, a $2.8 \mathrm{~L} \mathrm{~V}-6$ Chevrolet. The engine is port-injected and comes originally with a distributor-less ignition system. The original engine controller has been replaced with an aftermarket Electromotive TEC-II engine controller for controlling the ignition, fuel injection, and fuel management for the rich combustor. Monitoring access to the data inputs to the engine controller is provided by a PC-based system, which also serves as the programming and file transfer software.

The engine in the test vehicle is mounted transverse for front wheel drive, but a transmission is used in the test cell to couple the engine to the dynamometer. Figure 24 shows the test engine, with the first generation combustor installed, installed in the test cell. 


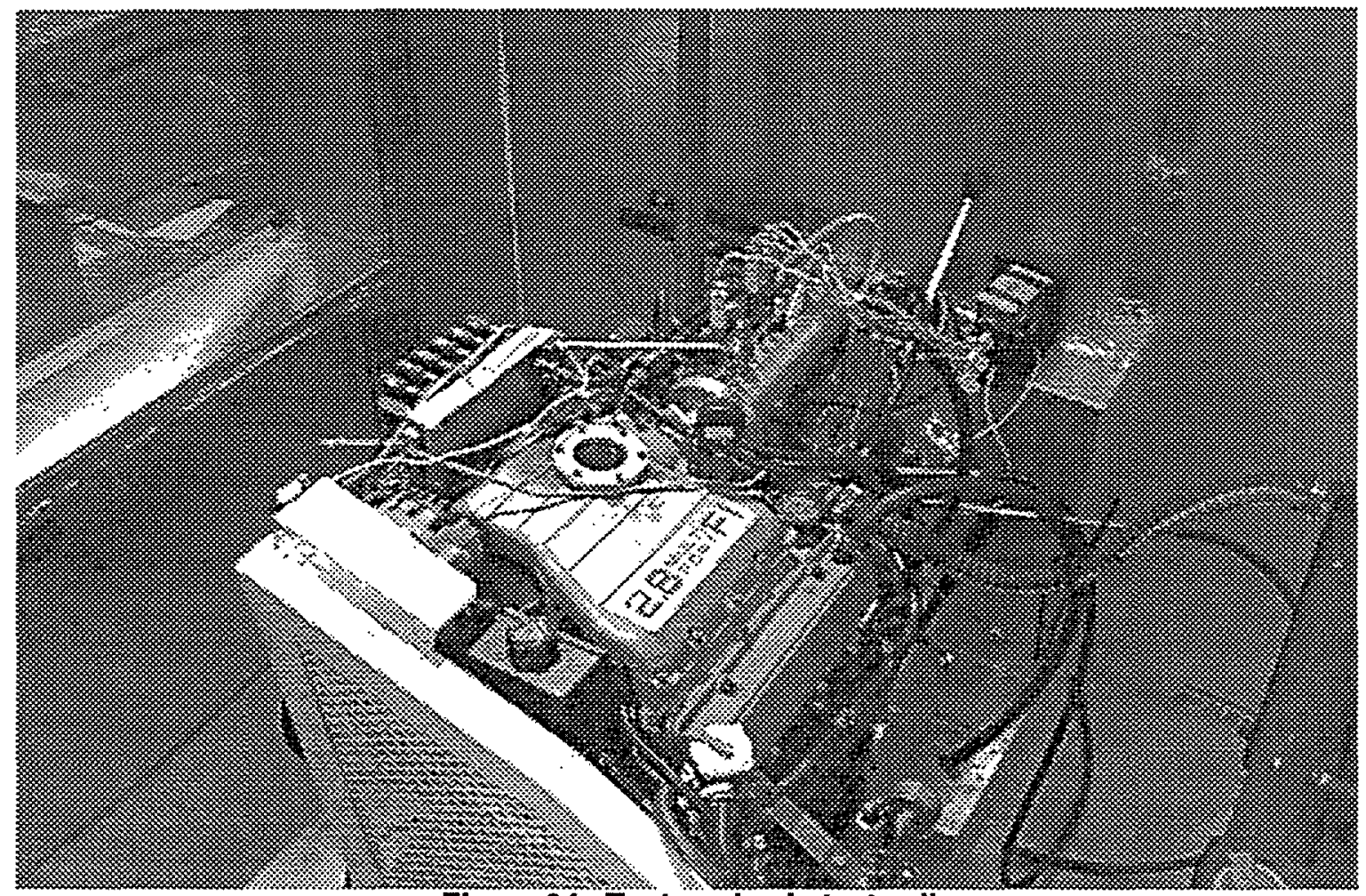

Figure 24. Test engine in test cell

The engine sensors outputs as well as thermocouples installed in the combustor and the engine are monitored and recorded using the data acquisition system. Complete descriptions of the test equipment are included in Appendix C.

\section{First Generation Combustor Testing}

Testing of the first generation combustor began with evaluation of the candidate ignition systems. A reliable ignition system is an absolute requirement for success of the combustor.

\section{Ignition System Testing}

\section{Glow Plug Ignition System}

The original design incorporated threaded holes at the top and bottom of the combustor as shown in the drawings included in Appendix A. As described above, the first ignition system tested was a "tree" of small glow plugs as shown in Figure 13. This configuration required two adapters for assembling the tree in the combustor using the holes provided for spark plugs. One adapter was used to mount and ground the device in the upper hole and the required electrical wire was fed through the other adapter in the lower hole. This modification to the design is also detailed in the drawings.

The glow plugs were wired in parallel to prevent a single glow plug failure from causing the entire tree to fail. As shown by testing, however, when a failure occurred all the plugs failed. At room temperature, the resistance of the parallel-wired plugs was measured as approximately $0.5 \mathrm{ohms}$. To heat the glow plugs, the power supply was used to maintain approximately 11 amps. Since the resistance of the glow plugs is a function of temperature, the power supply adjusted the voltage to maintain the current at the 
appropriate setting.

Once the operating parameters were determined, the glow plug ignition was installed in the rich combustor. At room temperature, the engine was motored using the dynamometer up to $600 \mathrm{rpm}$ with the glow plugs energized to simulate an engine start. As the engine speed was increased up to the desired set point, the air flow past the glow plugs cooled them to the extent that the methanol would not ignite. The liquid hitting the plugs of course cooled them even further. Increasing the current would have overcome the cooling of the air flow, but initial testing to determine the operating parameters showed how quickly the glow plugs failed when their maximum power dissipation was exceeded. Any disruption of the air flow, such as might occur during a cold cranking and starting event, would certainly cause the glow plugs to fail. The combustor was then reconfigured to the original design of conventional spark plugs fired by a coil.

\section{Conventional Spark Plug Ignition System}

The spark plugs used in the combustor were specified for the engine as shown in Figure 14. The engine controller does not have provisions for firing any additional spark plugs; therefore, a separate ignition system was required to fire the spark plugs in the combustor. A dual-coil module from a Saturn was available that would fire both spark plugs from one of the coils; however, an input signal was required to drive the system. A solid state device was fabricated by our in-house instrument shop to independently drive the Saturn ignition system; details are included with the other equipment specifications in Appendix C.

This ignition system was then installed in the combustor and tested as before at room temperature with the dynamometer motoring the engine. Problems with the configuration developed because of the orientation of the lower spark plug. This plug pointed vertically up, which created an annular pool for methanol to collect between the ceramic insulator at the tip and the steel body of the spark plug. Because methanol is electrically conductive, this would ground the lower plug and prevent it from firing. When this grounding was not present and using the fuel delivery system as described below, the methanol spray could be ignited with the engine rotating at $600 \mathrm{rpm}$. The flame produced extended well past the end of the combustor and into the plenum portion of the intake manifold as viewed through the sight glass. The operation of the rich combustor requires that the combustion reaction reach completion before the combustion products reach the engine fresh air stream; otherwise, the reaction will continue until all combustibles are consumed. With the reaction continuing into the intake manifold, no combustibles reach the engine cylinders.

Because of the configuration of the combustor and spark plugs, the ignition zone was near the upper and lower walls of the combustor. A Lexan throttle plate was fabricated for the main throttle body to allow observation of the ignition system and combustion. From viewing the operation through this throttle plate, this problem was thought to be causing poor initial flame formation, which caused the total combustion time to increase, resulting in the combustion reaction continuing beyond the confines of the combustor. The next and final iteration on the ignition system addresses both the grounding and ignition zone location issues associated with the conventional spark plug design.

\section{Extended Tip Spark Plug Ignition System}

The extended tip spark plugs, shown in Figure 15, are the type used in oil-fired furmaces. They have a tip that extends approximately $1 \frac{1 / 2}{2}$ inches beyond the end of the threaded portion of the body. The ceramic insulator extends well beyond the end of the body, eliminating the problem of grounding through a methanol pool. Two plugs were used in the rich combustor with one plug arcing to the other across an approximately $1 / 4$-inch gap. The gap, and thus the ignition zone, was located in the center of the flow area 
of the combustion side of the combustor; this location was possible because of the length of the extended tip. Typically, these plugs are used singly and driven by a transformer operating on the residential power grid (110 VAC). Initially, such a transformer was used, but it was replaced with the modified Satum ignition system with no change in performance.

Observation through the Lexan throttle plate revealed that the new location of the ignition zone appeared to improve the early formation of the flame. The flame appeared to fill the entire volume of the combustor more quickly than the conventional spark plug configuration. This ignition system appeared to adequately meet the operational requirements for the combustor, and later testing would prove it to be very reliable over the entire temperature range considered. However, with the engine rotating at $600 \mathrm{rpm}$ with the combustor operating, the flame was still visible in the intake manifold as described below in the operational testing section.

\section{Fuel System Testing}

As stated above, the original design used automotive fuel injectors obtained from Rochester Products that were methanol compatible. The spray from these injectors was jet-like, unsuitable for this application. The nozzles were available from previous cold start research (Hodgson 1993), which provide an ignitable spray of liquid methanol. These nozzles would be used to provide the desired methanol spray pattern; the injectors could, however, be used to control the flow through the nozzles.

The general purpose output (GPO) of the Electromotive controller would be used to adjust the methanol flow rate. The GPO is a 12-volt square wave output with pulse width modulation operating at $31 \mathrm{~Hz}$. The percent-on time can be programmed in the controller software as a function of engine speed and intake manifold pressure. The GPO can drive any device (solenoid, etc.) with an impedance of greater than 45 ohms. The injectors used are the saturation type and have an impedance considerably less than this requirement, $2.8 \mathrm{ohms}$. A relay would be required to drive the injectors using the signal from the GPO as input. A solid state relay was chosen; details are included in Appendix C.

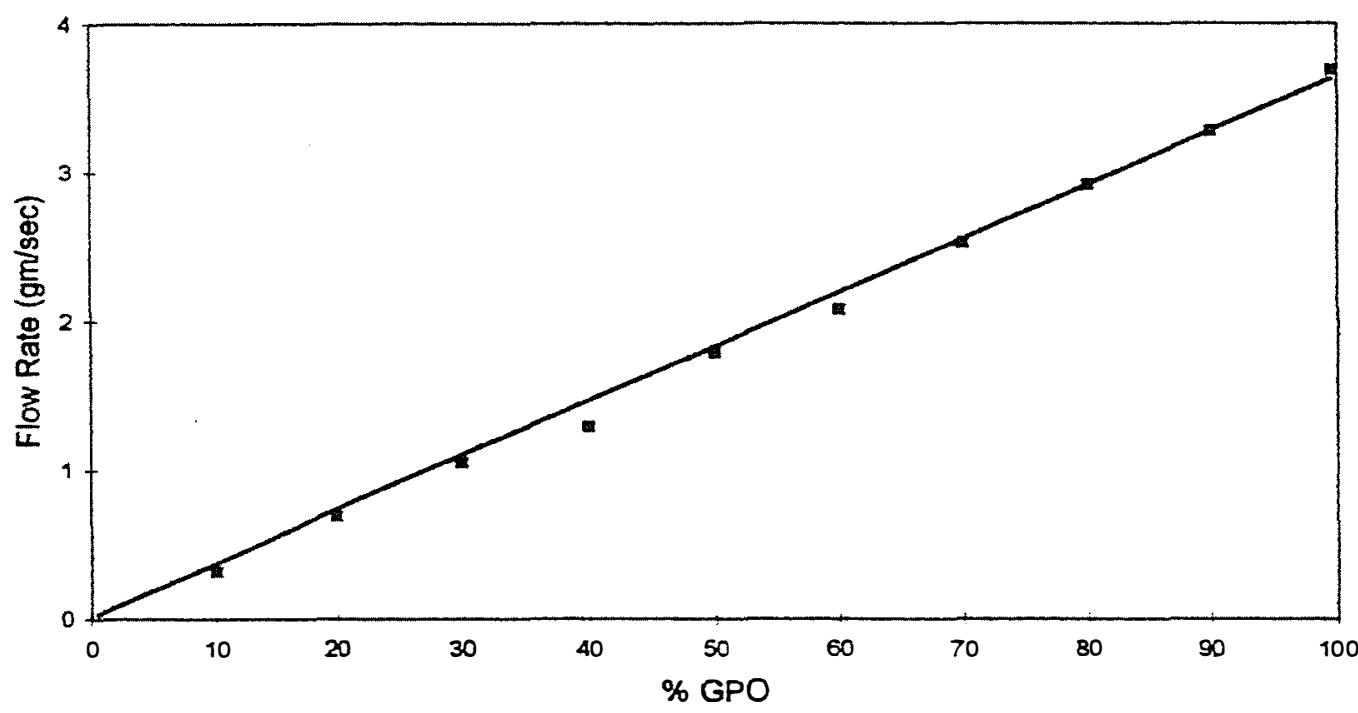

Figure 25. Injector flow test results 
Before implementing the injector-nozzle configuration shown in Figure 16, the injectors were tested to determine the effect of the pulse width modulation on the flow rate. A bench test rig was assembled using a fuel pump identical to the pump used on the test engine feeding an injector being controlled by the GPO. The flow was directed into a graduated cylinder to measure the volumetric flow rate as the percent GPO was varied. The results are shown in Figure 25. As Figure 25 shows, the flow rate through the injector is approximately linear with percent GPO. This characteristic simplifies the task of calibrating the fuel flow rate.

In addition to the two nozzles used on the previous project, several other nozzles were obtained to have a range of flow rates. These nozzles are standard hollow cone spray nozzles commonly used in industrial applications for rinsing, cooling, etc. They are typically equipped with a sintered bronze filter element integral with the filter body. The nozzles are rated in gallons per hour at $100 \mathrm{psi}$ and stamped with that number. Several of the nozzles were tested on the bench test rig described above, without the GPOcontrolled injector, with the results shown in Table 1.

Table 1. Nozzle Flow Test Results

\begin{tabular}{|l|l|}
\hline Nozzle ID & Mass Flow Rate $(\mathrm{g} / \mathrm{s})$ \\
\hline .75 & 0.42 \\
\hline .85 & 0.44 \\
\hline 1.00 & 0.50 \\
\hline 1.25 & 0.97 \\
\hline 1.35 & 1.59 \\
\hline 1.50 & 0.74 \\
\hline 1.75 & 0.98 \\
\hline 2.00 & 1.13 \\
\hline 2.00 & $\begin{array}{l}0.39 \text { *nozzle from previous } \\
\text { work }\end{array}$ \\
\hline
\end{tabular}

Table 1 shows some variation in the measured flow rate versus "advertised" flow rate. Therefore the nozzles used in the combustor must be flow tested before use.

The nozzle identified 1.25 with a measured flow rate of $0.97 \mathrm{~g} / \mathrm{s}$ was chosen to be used in the upper position in the combustor. This flow rate is close to the flow rate for idling as predicted by the model. The strategy for fuel delivery is then to use that nozzle, without an injector, supplying methanol to the combustor at the rate required for idling. The nozzle identified 2.00 with a measured flow rate of $1.13 \mathrm{~g} / \mathrm{s}$ was used in the lower position with an injector controlling the flow rate using GPO control. Other nozzles would be tested in the lower position. As a result of operational testing described below, a third nozzle was added downstream for quenching as shown in Figure 17.

\section{Operational Testing}

The first operational testing of the rich combustor was conducted with the conventional spark plug ignition and one fuel injector controlled by the GPO with the percent GPO set from $30 \%$ to $60 \%$. The engine was motored by the dynamometer at $600 \mathrm{rpm}$. At all settings, the result was a strong flame in the plenum section of the intake manifold. As stated above, the spray from the injector alone was jet-like, which caused the flame to extend well into the intake manifold. Methanol, not products of combustion as described below, was burning in the intake manifold. 
The nozzles described in the previous section were then incorporated with the GPO-controlled injectors. Initially, the two nozzles used in the previous study were installed without performing the flow test described above. The nozzle identified 0.75 was installed in the upper position without an injector; the nozzle identified 2.00 was installed in the lower position with GPO control set at $30 \%$. With the dynamometer motoring the engine, the fuel and ignition systems for the combustor were switched on. At $600 \mathrm{rpm}$ the engine produced $32 \mathrm{ft}-\mathrm{lb}$ of torque; at $900 \mathrm{rpm}$, it produced $17 \mathrm{ft}-\mathrm{lb}$. The engine also was started at room temperature using this configuration. Encouraged by these results, the nozzle flow tests were performed on the bench test rig to provide operational data for nozzle selection and control application.

Based on the fuel requirements predicted by the model and the results of the nozzle flow testing, the rich combustor fuel system was configured as follows for further testing. The nozzle identified 1.25 with a measured flow rate of $0.97 \mathrm{~g} / \mathrm{s}$ was installed in the upper position in the combustor. The nozzle identified 2.00 with a measured flow rate of $1.13 \mathrm{~g} / \mathrm{s}$ was used in the lower position with an injector controlling the flow rate using GPO control.

Two modifications to the combustor were made to address the problem of the reaction continuing into the intake manifold. The extended tip spark plugs were used, fired by the transformer, to more centrally locate the ignition zone. It was thought that this would improve the early flame formation and decrease the overall time for the reaction to reach completion. The other modification involved adding a set of baffles downstream of the ignition zone, as shown in Figure 17, to disrupt the flow through the combustor and increase the mixing of the reacting gases.

A sampling port was also installed downstream of the ignition zone in a position originally provided for a thermocouple. The test plan was to motor the engine and collect a sample from the combustor (before the combustor product stream rejoined the fresh air stream) to determine the product mixture. The equilibrium composition curves calculated using the model would then be used to determine the operating equivalence ratio. Samples would also be taken from a sampling port in the exhaust pipe to determine the composition of the stream after the combustor products rejoined the engine fresh air stream. This sample would represent the mixture being fed to the engine.

With the engine motored at approximately $800 \mathrm{rpm}$, the fuel and ignition systems were switched on. The combustor was allowed to operate until the readings on the gas analyzer reached steady state; this was required because of the length of the sampling line from the sampling port to the analyzer. Samples were taken first from the combustor at various values of percent GPO, then from the exhaust port at the same values. Results are shown in Table 2.

Table 2. First Generation Combustor Product Composition

\begin{tabular}{|l|l|l|}
\hline $\begin{array}{l}\text { Lower Nozzle } \\
\text { GPO }\end{array}$ & $\begin{array}{l}\text { Combustor } \\
\text { Sample }\end{array}$ & $\begin{array}{l}\text { Exhaust } \\
\text { Sample }\end{array}$ \\
\hline \multirow{3}{*}{$10 \% \mathrm{GPO}$} & $11.1 \% \mathrm{CO}$ & $0.4 \% \mathrm{CO}$ \\
& $5.8 \% \mathrm{CO}_{2}$ & $6.7 \% \mathrm{CO}_{2}$ \\
& $6.4 \% \mathrm{O}_{2}$ & $7.9 \% \mathrm{O}_{2}$ \\
\hline & $11.3 \% \mathrm{CO}$ & $0.6 \% \mathrm{CO}$ \\
$15 \% \mathrm{GPO}$ & $5.9 \% \mathrm{CO}_{2}$ & $1.5 \% \mathrm{CO}_{2}$ \\
& $3.4 \% \mathrm{O}_{2}$ & $6.4 \% \mathrm{O}_{2}$ \\
\hline \multirow{3}{*}{$20 \% \mathrm{GPO}$} & $7.7 \% \mathrm{CO}$ & $0.4 \% \mathrm{CO}$ \\
& $6.3 \% \mathrm{CO}_{2}$ & $5.5 \% \mathrm{CO}_{2}$ \\
& $2.8 \% \mathrm{O}_{2}$ & $9.5 \% \mathrm{O}_{2}$ \\
\hline
\end{tabular}


These results show that the combustor was producing a combustible product mixture. Based on the model calculations shown in Figure 3, the combustor was operating at an equivalence ratio of approximately 1.7. However, the composition of the sample taken from the exhaust pipe port indicates that the combustibles were being consumed after leaving the combustor even though the flame was not visible in the intake manifold. Observation through the Lexan throttle plate also revealed that the flame was traveling upstream from the ignition zone and curling around the wall dividing the combustion chamber from the engine fresh air chamber.

Based on testing up to this point, we concluded that the combustion zone provided in the first generation combustor was not long enough to allow the reaction to reach completion before rejoining the fresh air, thus allowing the reaction to continue into the intake manifold. The flame traveling upstream and curling around the wall was attributed to the increased flow restriction caused by the baffles.

To verify that this conclusion was correct, a simple adapter consisting of tubing with flanges on both ends was fabricated, which added approximately 12 inches to the overall length of the combustor. The two fresh air passages in the combustor were plugged such that the combustor was configured as a single chamber from the combustor throttle plate to the outlet of the adaptor. The sight glass port in the plenum section of the intake manifold was used to mount the adaptor/combustor assembly, and the engine main throttle body was moved back to its original position. This meant that there were two throttles in parallel, which is not desirable from a control standpoint, but for the purposes of this test control was not required. A third nozzle for quenching was also added at this time. The fuel system for this test was as follows. The nozzle identified 1.25 with a measured flow rate of $0.97 \mathrm{~g} / \mathrm{s}$ was installed in the upper position in the combustor. The nozzle identified 2.00 with a measured flow rate of $1.13 \mathrm{~g} / \mathrm{s}$ was used in the lower position with an injector controlling the flow rate using 30\% GPO control. The nozzle identified 0.75 with a measured flow rate of $0.42 \mathrm{~g} / \mathrm{s}$ was used for the quenching nozzle. The extended tip spark plugs, fired by the transformer, were used for ignition.

With the dynamometer motoring the engine at approximately $800 \mathrm{rpm}$, a sample was taken from the combustor. The results were $11.3 \% \mathrm{CO}, 8.1 \% \mathrm{CO}_{2}$, and $1.6 \% \mathrm{O}_{2}$. This showed that the combustor was indeed producing a combustible mixture, and that the reaction was reaching completion in the combustor. We concluded that the combustor product stream was exiting the combustor at a temperature high enough that the combustibles reacted with the engine fresh air once the two streams were rejoined. The additional complication of parallel throttle control made this configuration unacceptable. However, the results were encouraging, and we felt that adding the quenching nozzle to cool the combustor products would improve the combustor performance. The problem of restricted flow resulting in upstream flame travel, however, still remained.

The combustor was then relocated to its original position between the engine main throttle body and the intake manifold; the adaptor was removed. The fuel and ignition systems remained as described above. The plug was removed from the idle air bypass side of the fresh passage to determine whether the curling phenomenon was associated with the operation of the idle air control motor. The engine was motored as before with the following results for a sample taken from the combustor: $13.5 \% \mathrm{CO}, 6.1 \% \mathrm{CO}_{2}, 3.4 \% \mathrm{O}_{2}$. Flame was observed curling around the wall and going down the side of the fresh air passage that was unplugged, as well as in the intake manifold. The other plug was removed with no appreciable change in the observed result. Finally, the baffles were removed, which resulted in no observed curling of the flame down the fresh air side, but a strong flame was present in the intake manifold caused by the "straightthrough" flow. 
From the testing of the first generation design combustor, we came to the following conclusions:

- The rich combustor concept for cold starting is viable.

- The combustion zone length was too short for the reaction to reach completion before rejoining the fresh air stream.

- The flow restriction associated with the baffles caused the flame to travel upstream and curl around the wall separating the combustor passage from the fresh air passage.

- The quenching nozzle is required to cool the combustor products to prevent the combustibles from being consumed in the intake manifold.

- The series throttle arrangement of the original design must be maintained for simplicity of control.

- The first generation combustor was too large for under-hood application.

These conclusions drove the design for the second generation rich combustor. The second generation design significantly increased the combustion zone length, thus eliminating the need for baffles and the resulting flow restriction. The physical layout of the combustor was completely changed to accommodate installation underhood. The series throttle arrangement, as well as the fuel and ignition systems developed thus far, were carried over to the second generation design.

\section{Second Generation Combustor Testing}

The initial configuration of the fuel system for the second generation combustor was the same as the final configuration for the first generation combustor. The nozzle identified 1.25 with a measured flow rate of $0.97 \mathrm{~g} / \mathrm{s}$ was installed in the upper position in the combustor. The nozzle identified 2.00 with a measured flow rate of $1.13 \mathrm{~g} / \mathrm{s}$ was used in the lower position with an injector controlling the flow rate using 30\% GPO control. The nozzle identified 0.75 with a measured flow rate of $0.42 \mathrm{~g} / \mathrm{s}$ was used for the quenching nozzle. An additional nozzle/injector assemble was installed in the third port, but the injector was not connected to the controller. The extended tip spark plugs were again used; however, the transformer was replaced by the Saturn ignition system driven by the in-house developed device.

The first start attempt after installation, at room temperature, was successful; the engine started using the starter. A series of cold start attempts was performed, first at $-30^{\circ} \mathrm{C}$ and then at $-8^{\circ} \mathrm{C}$. Although the engine fired sporadically during several of the attempts, there were no successful starts. Data from one of the start attempts are shown in Figure 26.

After a few unsuccessful attempts, the spark plugs in the engine would become very wet with water, unburned methanol, and partial-combustion products contained in the product stream from the combustor, and then would not fire. Figure 26 shows this plainly; the data show no evidence of firing after the second attempt at $0 \%$ GPO. The cold start testing was suspended in favor of more systematic testing to determine the operating parameters of the combustor required to maintain the correct stoichiometry in the combustor and the engine. 


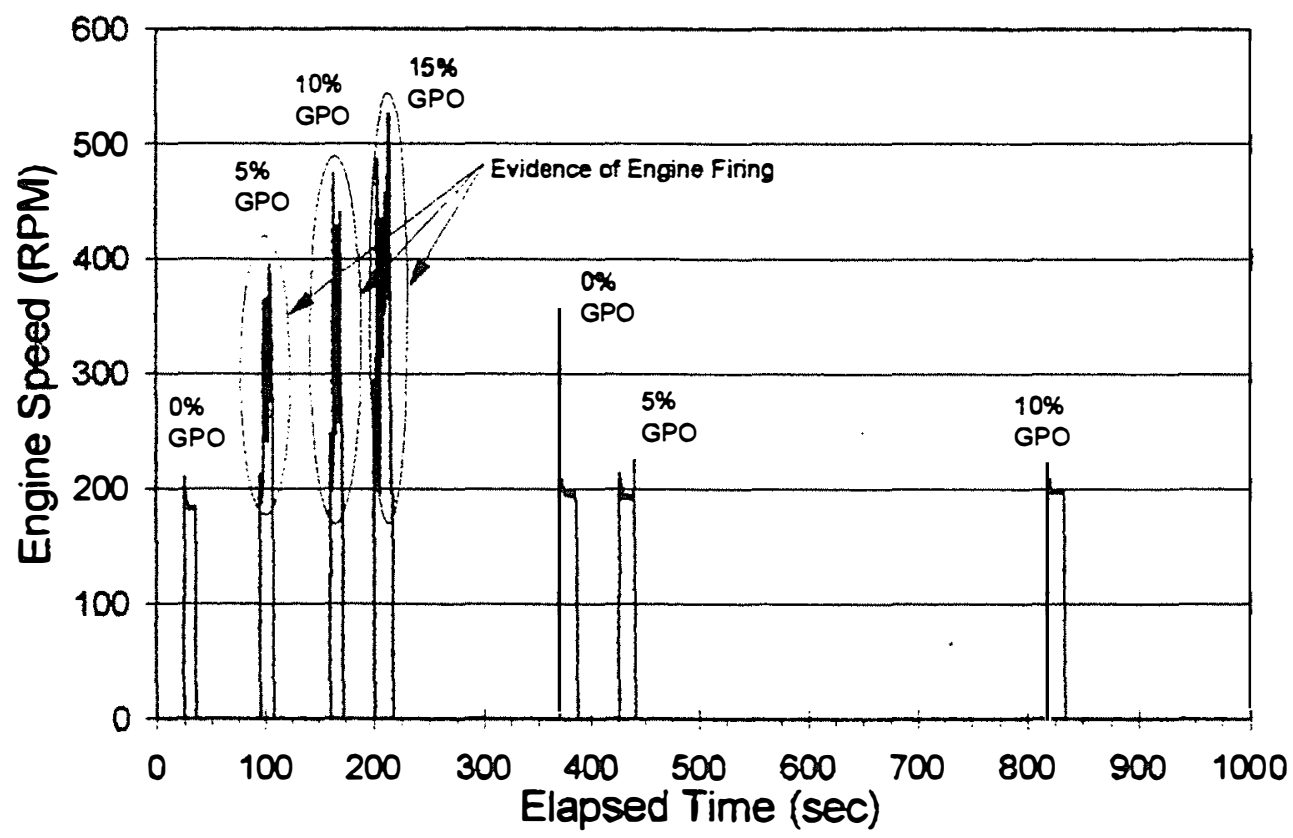

Figure 26. Unsuccessful cold start attempt at $-8^{\circ} \mathrm{C}$

\section{Stoichiometry Testing}

The operating equivalence ratio of the combustor is determined by motoring the engine with the dynamometer with the engine's ignition system disabled such that the engine is serving as an air pump for the combustor. The gas analyzer is used to determine the $\mathrm{CO}$ and $\mathrm{CO}_{2}$ content of the combustor product stream by sampling from the port near the sight glass as shown in Figure 27. The downstream sampling port was used to determine whether the product composition changed as it flowed through the third "leg" of the combustor which would indicate that the reaction was continuing.

The output of the gas analyzer is on a dry basis because the water vapor condenses from the sample stream. The measured value of $\mathrm{CO}$ concentration was compared to the equilibrium composition calculations, shown in Figure 3, to estimate the operating equivalence ration for the combustor.

The operating equivalence ratio of the engine was determined using the gas analyzer sampling from a port in the exhaust pipe approximately 24 inches downstream of the EGO sensor. The EGR valve was disabled, the PCV valve disconnected, and the tubing to the intake manifold plugged for these tests. Because the gas analyzer was located outside the cold cell, the sample lines were necessarily long. Dilution of the sample was a concern, but the later data from the EGO sensor with the engine running indicated that the results for this testing were accurate. For the range of combustor equivalence ratios considered, the concentrations of hydrogen and $\mathrm{CO}$ are approximately equal. For the stoichiometric combustion of an equimolar mixture of hydrogen and $\mathrm{CO}$, the molar amounts of the $\mathrm{CO}, \mathrm{H}_{2}$, and $\mathrm{O}_{2}$ should be equal. 


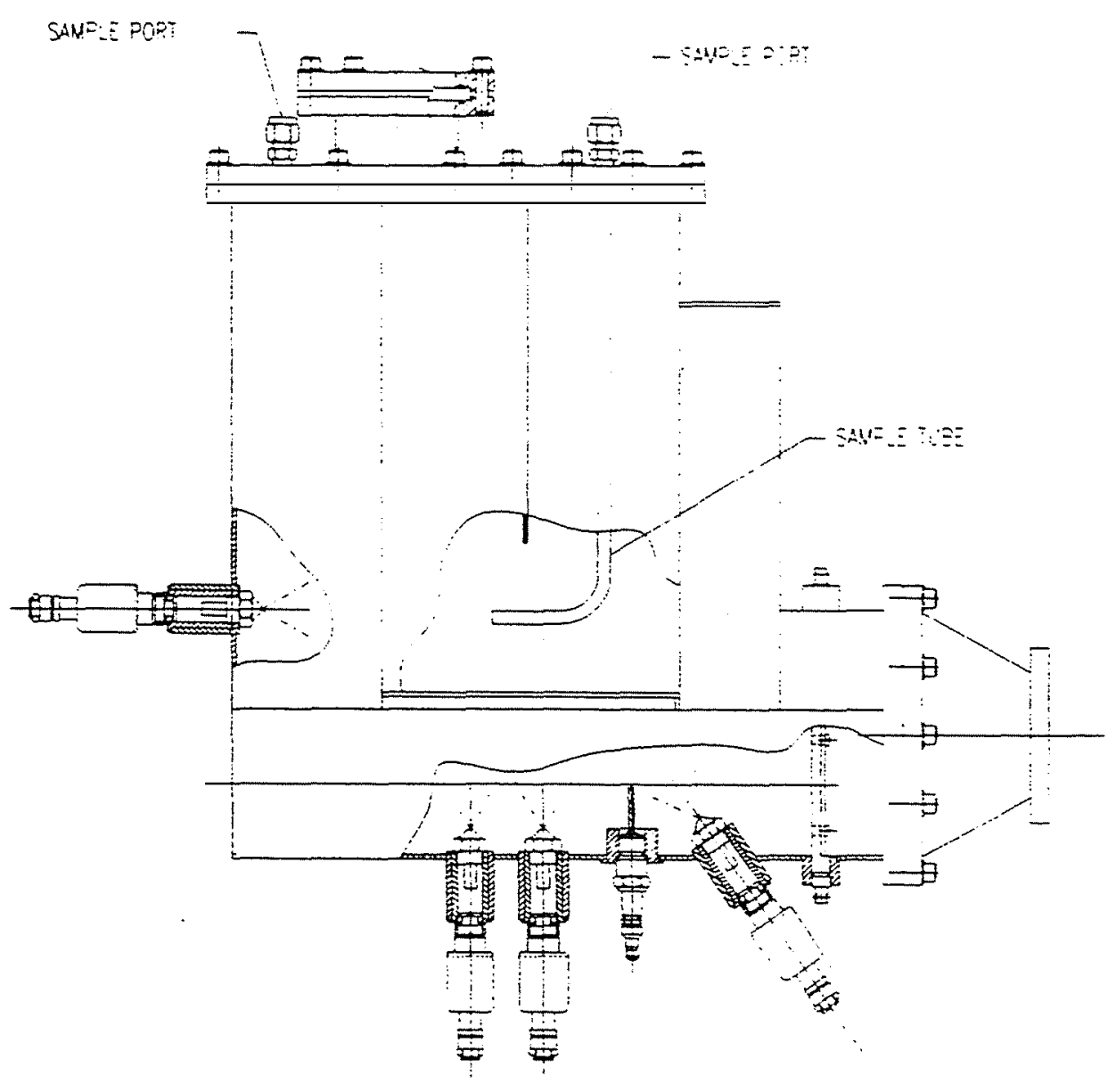

Figure 27. Sampling port locations

$\mathrm{CO}+\mathrm{H}_{2}+\mathrm{O}_{2} \rightarrow \mathrm{CO}_{2}+\mathrm{H}_{2} \mathrm{O}$

The concentrations of the $\mathrm{CO}$ and $\mathrm{O}_{2}$ were compared to estimate the operating equivalence ratio for the engine. This estimate is then used to determine the balance of the air flow through the two sides of the combustor. A lean condition, indicated by more $\mathrm{O}_{2}$ than $\mathrm{CO}$, indicates that too much air is flowing through the engine fresh air side of the combustor; a rich mixture indicates too much flow through the combustor side.

Testing began with the fuel system unchanged from the initial cold start testing the nozzle identified 1.25 with a measured flow rate of $0.97 \mathrm{~g} / \mathrm{s}$ was installed in the position upstream of the spark plugs (position \#1). The nozzle identified 2.00 with a measured flow rate of $1.13 \mathrm{~g} / \mathrm{s}$ was used in the first position downstream of the spark plugs (position \#2) with an injector controlling the flow rate. The nozzle identified 1.50 with a measured flow rate of $0.74 \mathrm{~g} / \mathrm{s}$ was installed in the second position downstream of the spark plugs (position \#3) with an injector controlling the flow rate. The port for the quenching nozzle was plugged. 
The test cell was cooled to approximately $-9^{\circ} \mathrm{C}$; the temperature was monitored to ensure that the engine had reached a steady state temperature. The engine was then motored at various speeds while the percent GPO was varied. The gas analyzer, sampling from the downstream sampling port initially, was used to determine the concentrations of $\mathrm{CO}, \mathrm{CO}_{2}$, and $\mathrm{O}_{2}$. Table 3 shows the results of testing with only the first downstream nozzle operating.

Table 3. Combustor Product Composition-Downstream Port

\begin{tabular}{|l|l|l|l|l|}
\hline $\begin{array}{l}\text { Engine } \\
\text { Speed } \\
\text { (rpm) }\end{array}$ & $\%$ GPO & $\% \mathrm{CO}$ & $\% \mathrm{CO}_{2}$ & $\% \mathrm{O}_{2}$ \\
\hline 200 & 0 & 9.9 & 7.2 & 2.3 \\
\hline 200 & 5 & 10.2 & 7.0 & 2.1 \\
\hline 200 & 10 & 9.9 & 6.9 & 1.9 \\
\hline 200 & 15 & 9.6 & 6.9 & 2.1 \\
\hline 300 & 0 & 9.9 & 6.8 & 1.8 \\
\hline 300 & 5 & 10.5 & 6.7 & 3.2 \\
\hline 300 & 10 & 10.5 & 6.7 & 3.4 \\
\hline 300 & 15 & 10.1 & 6.8 & 2.8 \\
\hline 400 & 0 & 9.7 & 7.0 & 2.9 \\
\hline 400 & 5 & 10.3 & 6.8 & 2.7 \\
\hline 400 & 10 & 10.4 & 6.8 & 1.6 \\
\hline 400 & 15 & 10.5 & 6.7 & 3.3 \\
\hline 400 & 20 & 10.3 & 6.8 & 1.8 \\
\hline 500 & 0 & 9.1 & 7.4 & 2.3 \\
\hline 500 & 5 & 10.2 & 6.9 & 2.7 \\
\hline 500 & 10 & 10.4 & 6.8 & 1.9 \\
\hline 500 & 15 & 10.8 & 6.7 & 1.7 \\
\hline
\end{tabular}

The sampling location was moved to the upstream port to compare the results from the two locations. The results for the upstream location are shown in Table 4.

Table 4. Combustor Product Composition-Upstream Port

\begin{tabular}{|l|l|l|l|l|}
\hline $\begin{array}{l}\text { Engine } \\
\text { Speed } \\
(\mathrm{rpm})\end{array}$ & \% GPO & $\% \mathrm{CO}$ & $\% \mathrm{CO}_{2}$ & $\% \mathrm{O}_{2}$ \\
\hline 500 & 0 & 8.4 & 8.8 & 0.9 \\
\hline 500 & 5 & 10.9 & 7.6 & 0.5 \\
\hline 500 & 10 & 10.7 & 7.5 & 1.0 \\
\hline 500 & 30 & 11.0 & 7.2 & 1.4 \\
\hline
\end{tabular}

The results indicate that turbulence in the area of the port into the intake manifold, where the fresh air joins the combustor product stream, may be causing oxygen from the fresh air stream to be introduced into the sample. The upstream location was used for all subsequent combustor product sampling. 
As shown in Table 3, the $\mathrm{CO}$ content of the combustor product stream is fairly insensitive to the percent GPO, above 5\% GPO. The nozzle in the first downstream position was changed to investigate whether this phenomenon was related to that particular nozzle and/or the effect of small percent GPO values on the spray pattern or flow rates from the nozzle. The nozzle identified 1.00 with a measured flow rate of $0.50 \mathrm{~g} / \mathrm{s}$ was assembled with an injector and installed in the first downstream position (position \#2), with the other two nozzles unchanged. The procedure described above was repeated with the results shown in Table 5.

Table 5. Combustor Product Composition by Nozzle

\begin{tabular}{|c|c|c|c|c|c|}
\hline $\begin{array}{l}\text { Engine } \\
\text { Speed } \\
\text { (rpm) }\end{array}$ & $\begin{array}{l}\text { Active } \\
\text { Nozzle } \\
\text { Number }\end{array}$ & $\%$ GPO & $\% \mathrm{CO}$ & $\% \mathrm{CO}_{2}$ & $\% \mathrm{O}_{2}$ \\
\hline 200 & 3 & 0 & 10.4 & 7.7 & 1.7 \\
\hline 200 & 3 & 5 & 10.5 & 7.5 & 1.4 \\
\hline 200 & 3 & 10 & 10.3 & 7.3 & 1.5 \\
\hline 200 & 3 & 15 & 10.0 & 7.0 & 2.6 \\
\hline 200 & 3 & 20 & 9.9 & 6.9 & 2.3 \\
\hline 200 & 3 & 5 & 10.5 & 6.8 & 2.7 \\
\hline 200 & 2 & 0 & 10.8 & 7.0 & 1.9 \\
\hline 200 & 2 & 5 & 10.6 & 7.1 & - \\
\hline 200 & 2 & 10 & 10.2 & 7.3 & 1.3 \\
\hline 200 & 2 & 15 & 10.4 & - & - \\
\hline 200 & 2 & 20 & 9.3 & 6.7 & 4.6 \\
\hline 500 & 2 & 0 & 5.3 & 9.9 & 8.0 \\
\hline 500 & 2 & 5 & 6.5 & 9.2 & 8.8 \\
\hline 500 & 2 & 10 & 7.0 & - & - \\
\hline 500 & 2 & 15 & 10.9 & 7.2 & 2.8 \\
\hline 500 & 2 & 20 & 10.9 & 6.9 & 6.1 \\
\hline 500 & 3 & 0 & 5.1 & 10.4 & - \\
\hline 500 & 3 & 5 & 6.7 & 9.8 & 1.8 \\
\hline 500 & 3 & 10 & 6.5 & 10.1 & 2.6 \\
\hline 500 & 3 & 15 & 10.2 & 7.9 & 1.6 \\
\hline 500 & 3 & 20 & 10.2 & 7.7 & 1.5 \\
\hline 500 & 3 & 30 & 10.1 & 7.7 & 1.8 \\
\hline 500 & $2 \& 3$ & 0 & 3.8 & 11.1 & 7.9 \\
\hline 500 & $2 \& 3$ & 5 & 4.6 & 10.5 & 10.0 \\
\hline 500 & $2 \& 3$ & 10 & 9.5 & 8.2 & 1.1 \\
\hline 500 & $2 \& 3$ & 15 & 10.6 & 7.3 & 1.2 \\
\hline 500 & $2 \& 3$ & 20 & 10.7 & 7.2 & 1.4 \\
\hline 200 & $2 \& 3$ & 0 & 10.3 & 7.2 & 2.4 \\
\hline 200 & $2 \& 3$ & 5 & 10.4 & 7.2 & 1.1 \\
\hline 200 & $2 \& 3$ & 10 & 9.6 & 7.1 & 3.0 \\
\hline
\end{tabular}

Based on the results of this test, a GPO table was constructed to be downloaded to the Electromotive controller. After adjusting the set point values for the engine speed, the percent GPO was specified for each rpm set point. The GPO table also allows setting the percent GPO for manifold pressure set points 
at each engine speed set point; however, a single value of percent GPO was used for all values of manifold pressure at each engine speed set point. This should be sufficient for starting and idling, but the table will be modified later to include manifold pressure dependence for off-idle operation. Table 6 lists the GPO settings.

\section{Table 6. GPO Settings}

\begin{tabular}{|l|l|}
\hline $\begin{array}{l}\text { Engine } \\
\text { Speed } \\
\text { (rpm) }\end{array}$ & $\%$ GPO \\
\hline 200 & 5 \\
\hline 500 & 15 \\
\hline 1000 & 30 \\
\hline 1500 & 45 \\
\hline
\end{tabular}

With both injectors downstream of the spark plugs (positions 2 and 3) being controlled per this GPO table, the engine was cranked using the starter. Samples were analyzed from the combustor and the exhaust pipe. The combustor product stream composition was $11.4 \% \mathrm{CO}, 7.7 \% \mathrm{CO}_{2}$, and $0.8 \% \mathrm{O}_{2}$. The composition of the sample taken from the exhaust pipe was $4.5 \% \mathrm{CO}, 3.8 \% \mathrm{CO}_{2}$, and $12.4 \% \mathrm{O}_{2}$. This indicates a very lean mixture being fed to the engine resulting from too much air flowing through the fresh air side of the combustor. A thin rectangular shim was installed between the flanges of the main combustor body and the adaptor for the engine throttle body. This shim could be positioned to restrict the flow through the fresh air side by various amounts depending on the position of the shim. The shim was initially positioned such that there remained approximately $1 \mathrm{in}^{2}$ of flow area for the fresh air side compared to 4 in. $^{2}$ for the unrestricted case.

The tests described above were repeated at various shim location settings with the engine motored by the dynamometer. The engine operating equivalence ratio, as indicated by the composition of the sample taken from the exhaust pipe with the engine not firing, could be affected by adjusting the position of the shim. Cold start attempts resulted in sporadic firing of the engine, but no true start and idling. After a few unsuccessful attempts, the engine spark plugs became wet and would not fire. To address the spark plug wetting problem, a device was fabricated and installed just upstream of the second drain consisting of a double thickness of fine stainless steel wire cloth mounted to an aluminum block. The wire cloth was used to knock down any unburned fuel droplets being carried by the product stream, and the aluminum block served as a dam to prevent the liquid from flowing along the floor of the combustor and direct it into the drain.

Testing as described above revealed that the double thickness of wire cloth restricted the flow through the combustor side too much, resulting in a lean mixture measured at the exhaust pipe. One thickness of the wire cloth was removed and the wire cloth/dam assembly reinstalled. With the shim restricting the flow through the fresh air side as much as possible, the composition of the combustor product stream was measured as $12.7 \% \mathrm{CO}, 8.0 \% \mathrm{CO}_{2}$, and $0.8 \% \mathrm{O}_{2}$. The composition of the sample taken from the exhaust pipe was $6.1 \% \mathrm{CO}, 4.1 \% \mathrm{CO}_{2}$, and $11.2 \% \mathrm{O}_{2}$. This composition indicates a lean mixture being fed to the engine, but no further adjustment to the shim is possible. The divider between the two sides of the combustor does not extend to the flange face. The shim, which is located at the flange face, had no surface to close against as it was moved further in. This means that the flow area could only be reduced to approximately $0.75 \mathrm{in}^{2}$. Because hydrogen has a wide flammability range, the mixture being fed to the engine may be combustible even though lean. 
Fresh dry spark plugs were installed in the engine, the ignition system of the engine was enabled, and a cold start attempt was made at $-25^{\circ} \mathrm{C}$. The engine started and idled on the first and fourth attempts as shown in Figures 28 and 29. The backfiring indicated is not fully understood, but is believed to be associated with the high flame speed of hydrogen combustion.

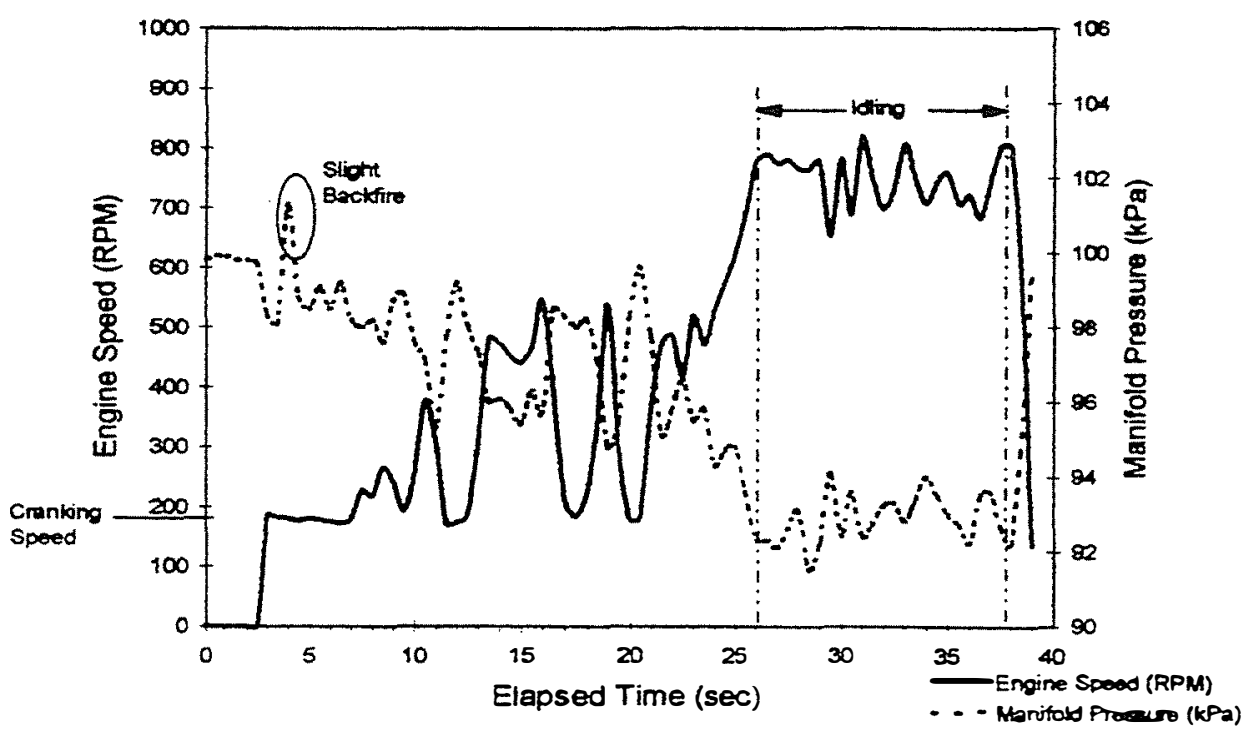

Figure 28. Successful cold start-first attempt at $-25^{\circ} \mathrm{C}$

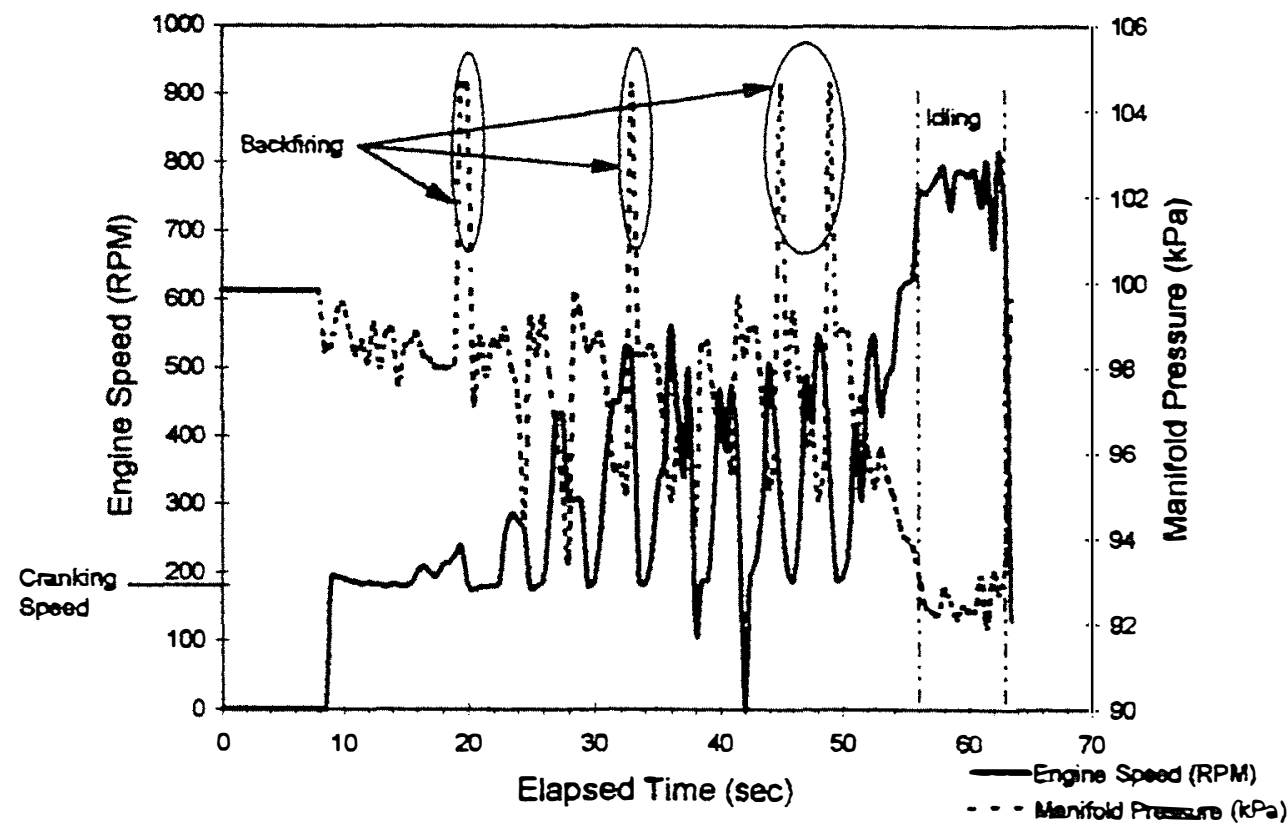

Figure 29. Successful cold start-second attempt at $-25^{\circ} \mathrm{C}$ 
As a result of this testing, the combustor was modified to add a throttle plate to replace the temporary shim. The added throttle plate would allow restricting the flow through fresh air side to the point of practically blocking it.

After the additional throttle plate was installed in the fresh air side of the combustor, calibration testing was performed using the dynamometer to drive the engine at the approximate cranking speed of $170 \mathrm{rpm}$. The results of that testing are shown in Table 7. The testing began with the throttle positioned such that the flow area was approximately equal to the $0.75 \mathrm{in}^{2}$ minimum achievable with the shim as described above. The first two samples taken indicate a lean mixture being supplied to the engine. To enrich the mixture being fed to the engine, the fresh air throttle plate was then positioned at its closed position for the remainder of the testing. The samples from the engine exhaust were taken with the engine spark plugs not firing. The sample mixture then represents the mixture being fed to the engine. As shown in Table 7, the $\mathrm{CO}$ content of the combustor product stream is fairly insensitive to the percent GPO, above $10 \%$ GPO.

Table 7. Calibration Testing with Fresh Air Throttle

\begin{tabular}{|c|c|c|c|c|}
\hline$\% \mathrm{GPO}$ & $\% \mathrm{CO}$ & $\% \mathrm{CO}_{2}$ & $\% \mathrm{O}_{2}$ & Sample location \\
\hline 10 & 12.7 & 7.9 & 0.7 & combustor \\
\hline 10 & 5.7 & 3.9 & 11.8 & exhaust \\
\hline 10 & 6.5 & 4.3 & 10.7 & exhaust \\
\hline 10 & 12.4 & 7.7 & 0.7 & combustor \\
\hline 12 & 12.7 & 8.1 & 0.7 & combustor \\
\hline 12 & 12.8 & 8.0 & 0.7 & combustor \\
\hline 14 & 12.5 & 7.7 & 0.6 & combustor \\
\hline 20 & 12.2 & 7.7 & 0.6 & combustor \\
\hline 30 & 12.3 & 8.0 & 0.7 & combustor \\
\hline 40 & 12.1 & 7.8 & 0.7 & combustor \\
\hline 10 & 12.4 & 8.0 & 0.7 & combustor \\
\hline 10 & 6.3 & 4.3 & 10.0 & exhaust \\
\hline & & & & \\
\hline & & & & \\
\hline
\end{tabular}

As shown in Table 6, the percent GPO value of 10 corresponds to the value programmed in the engine controller GPO lookup table for cranking speeds. Thus, the programmed GPO table should be the correct fueling schedule for the combustor for starting the engine with the fresh air throttle fully closed. The test cell was cooled to $-29^{\circ} \mathrm{C}$ and several start attempts were made at that temperature and then later at other temperatures. None of the tests resulted in a truly successful start. The engine would fire and run at approximately $300 \mathrm{rpm}$, with typical results shown in Figure 30. Examination of the engine spark plugs after the start attempts showed extreme wetting (the plugs dripped when removed from the engine), which was no doubt causing fouling. The plug wetting problem was compounded by the lowered battery voltage during cranking at low temperature. If the battery voltage is below 10 volts, the coils may not be 


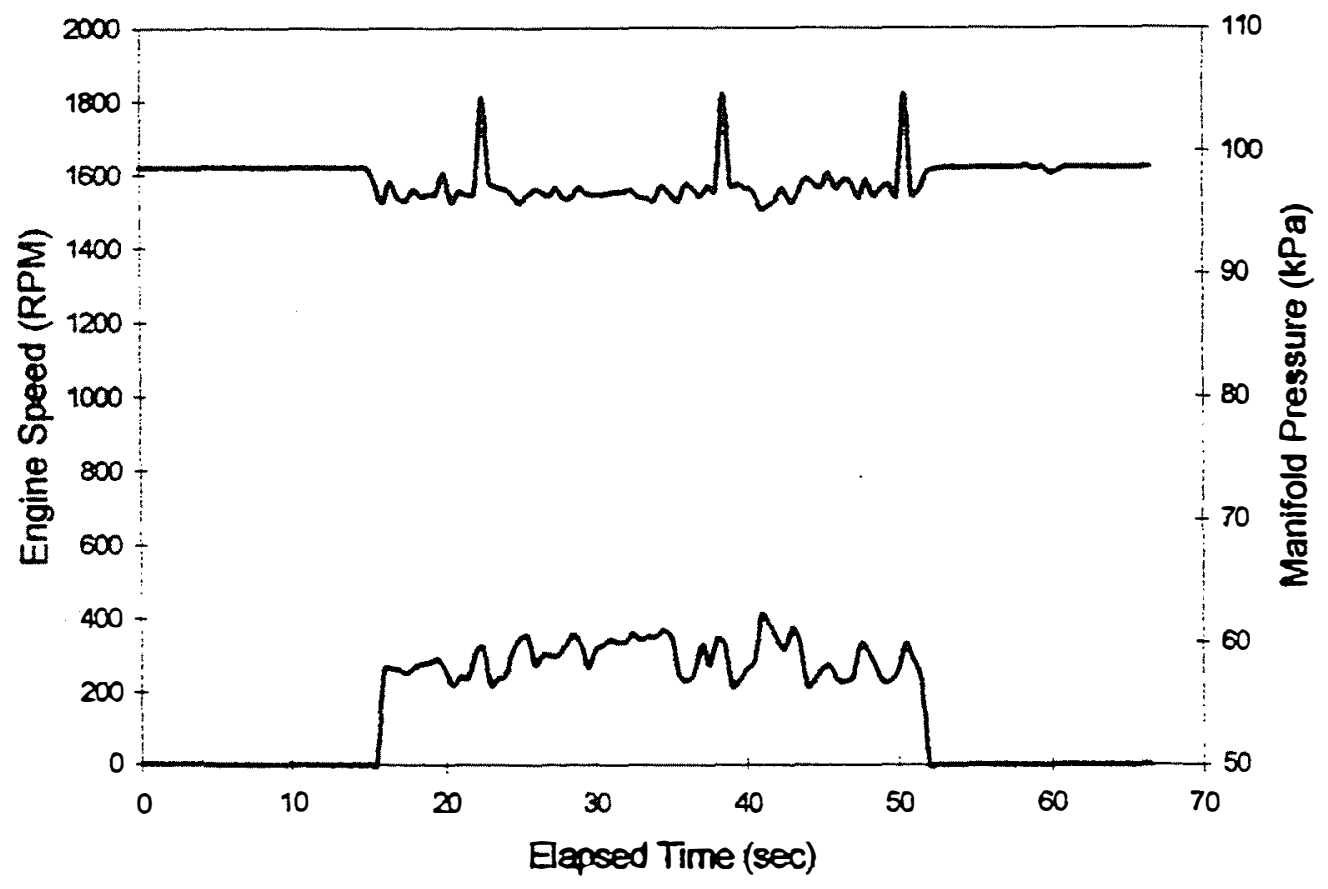

Figure 30. Start attempt at $-9^{\circ} \mathrm{C}$ after fresh air throttle installation

able to fire fouled plugs (Electromotive 1995). It was suspected that the screen device may not be performing properly. It was removed and found to have an area that had burned through. The screen was replaced with a new one, and the $1.59 \mathrm{~g} / \mathrm{s}$ quenching nozzle was re-activated. However, the spark plug wetting problem persisted.

The spark plug wetting problem was of course due to the condensation of water vapor, unburned fuel, and intermediate products present in the combustor product stream. The water vapor, laden with methanol and partial combustion products, condenses when exposed to the cold surfaces of the engine. This is particularly true in the cylinder, where additional condensation occurs because of the compression of the incoming charge on the compression stroke. The cavity between the spark insulator and the metal body is especially prone to collect the condensate. There is no practical method to prevent the $\mathrm{H}_{2} \mathrm{O}$ from forming in the combustor product stream (a catalyst would not be practical), so it was decided to attempt to condense the water vapor before it reaches the cylinder. Heat exchangers were designed and installed in the combustor as shown in Figure 31. A similar heat exchanger was installed in the plenum above the intake manifold. Using an external auxiliary pump, coolant from the radiator was circulated through the three heat exchangers in parallel and returned to the radiator.

The test cell was cooled to approximately $-10^{\circ} \mathrm{C}$ to test the effectiveness of the heat exchangers. To reduce the amount of vapor to be condensed by the heat exchangers, the quenching nozzle was disabled. The composition of the combustor product stream was measured as $12.4 \% \mathrm{CO}, 6.6 \% \mathrm{CO}_{2}$, and $2.2 \% \mathrm{O}_{2}$. The composition of the sample taken from the exhaust pipe was $6.5 \% \mathrm{CO}, 3.8 \% \mathrm{CO}_{2}$, and $10.8 \% \mathrm{O}_{2}$. This composition indicates a lean mixture being fed to the engine, but because hydrogen has a wide 


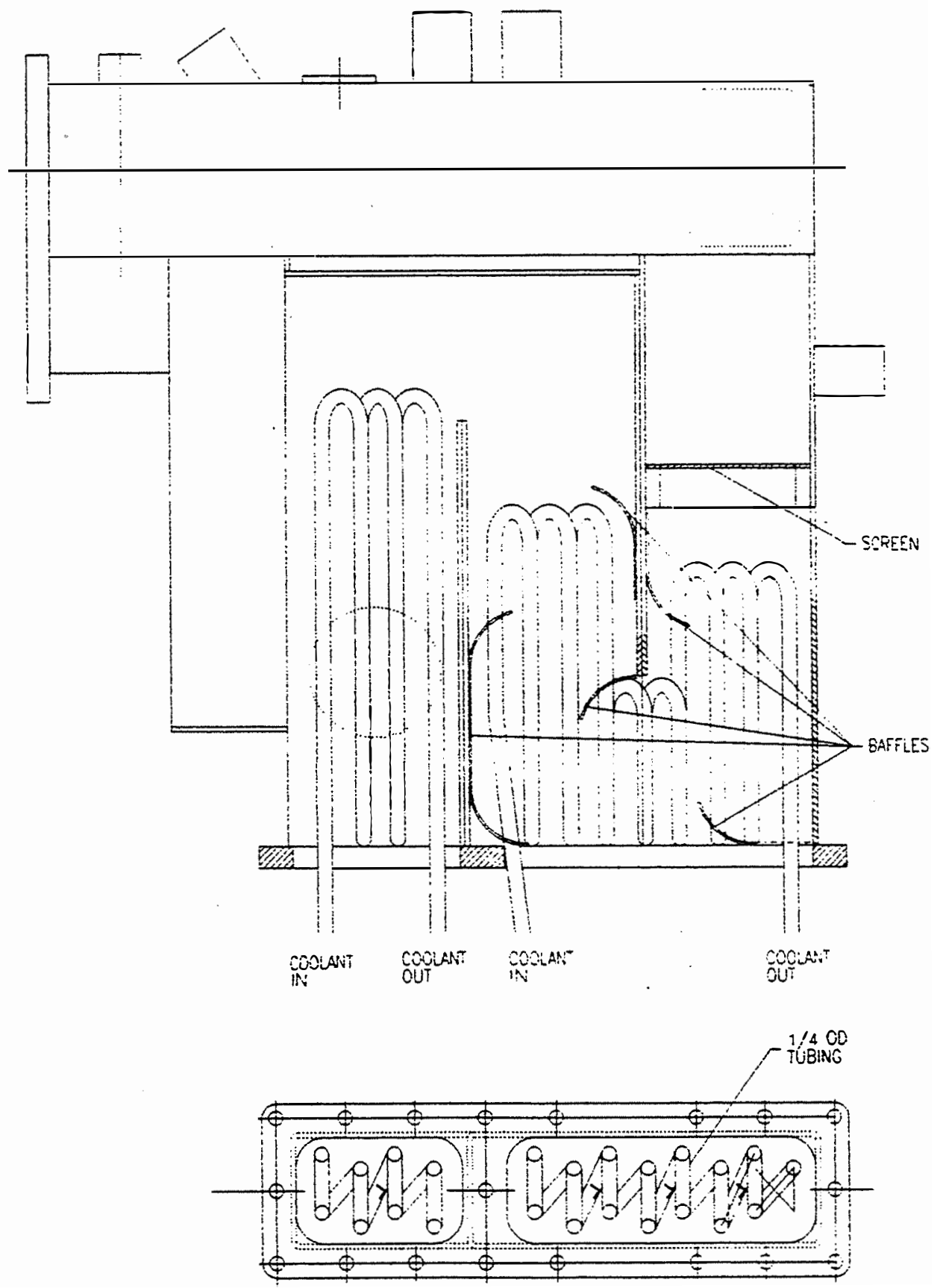

Figure 31. Heat exchanger installation 
flammability range, the mixture being fed to the engine should be combustible even though lean, as demonstrated earlier

The engine started and idled at approximately $800 \mathrm{rpm}$ for several repeated tests, for several days, at this temperature. We later suspected that these start attempts and subsequent (sometimes lengthy) periods of idling caused the block supporting the fine wire screen to melt. After these successful start attempts, the cold start performance of the engine was severely degraded. The engine would fire and run at approximately 300-400 rpm; sometimes help from the starter was required to maintain even this speed. Results were similar to those shown in Figure 30. Samples taken from the combustor, however, showed adequate combustibles to start the engine.

For the next several weeks, we found and addressed several problems. Although the performance improved slightly, the engine still would not reach idle speed. The battery voltage drop affected the fuel pressure because the fuel pump slowed at the lower voltage. The fuel pump was placed on an independent power supply to maintain the fuel pressure during cranking.

The solenoid valve in the fuel supply line to the combustor nozzles was wired such that the switch was energized at all times while the engine controller was on, so that if the combustor fuel switch was inadvertently left on after a test, the fuel continued to flow to the combustor. This was thought to be causing overfueling of the combustor, so the valve was rewired to be open only when the combustor fuel switch was closed and the engine was turning.

The transmission input shaft had become stuck in the pilot bearing in the rear of the crankshaft due to either corrosion or thermal expansion differences or both. At low temperatures, even with the transmission in neutral, the dynamometer would tum as a result of cranking the engine. Even though the transmission is a manual shift type, it is lubricated using automatic transmission fluid. The torque to turn and accelerate the dynamometer must be supplied by the engine in addition to what is required to accelerate the engine itself. This problem could be overcome, however, by simply motoring the dynamometer at a speed to match the engine speed during cranking and starting. A very important consequence of this problem was the generation of engine friction data at low temperature as shown in Figure 32.

Although these data are somewhat engine specific, they clearly illustrate the increase in engine friction as the temperature decreases. This information was incorporated into the engine model to more realistically determine the operating parameters required for starting at low temperatures.

The engine controller used has a feature that sets the spark advance to $0^{\circ} \mathrm{BTDC}$ for any engine speed below $400 \mathrm{rpm}$. The controller logic assumes that, at engine speeds below $400 \mathrm{rpm}$, the engine is being cranked and is not running. The spark advance may be adjusted via the PC interface once the engine reaches $400 \mathrm{rpm}$, but may not be changed below $400 \mathrm{rpm}$. We felt that the diluted mixture being fed to the engine might require some spark advance caused by the dilution effect on the flame propagation. The crank-mounted trigger wheel that is read by the magnetic sensor to determine crankshaft position was modified to allow rotating the wheel with respect to the crankshaft. This allowed several mounting positions to achieve a mechanical spark advance of $5^{\circ}, 10^{\circ}, 15^{\circ}, 20^{\circ}, 25^{\circ}$, or $35^{\circ}$ BTDC. The engine controller would still set the spark advance to $0^{\circ}$ BTDC; however, the actual spark advance below $400 \mathrm{rpm}$ would be the amount the trigger wheel had been rotated with respect to the crankshaft.

The actual spark advance at all operating points will be similarly offset. There is little potential for damage caused by excessive spark advance, however, at the engine operating speeds under consideration. 
After all these developments, the engine was still capable of running at only about $400 \mathrm{rpm}$ at all temperatures. We knew that the system was capable of much better performance, as previously demonstrated. However, the combination of parameters that produced a successful start previously could not be simply repeated because the combustor had been modified in the interim. After reviewing the test results to this point, a problem with the screen became the popular diagnosis of the problem. The installation of the heat exchangers and baffles had obscured the view from the sight glass of the screen, so the combustor was disassembled to inspect the screen. The screen was intact; however, the aluminum block to which the stainless steel screen was attached had melted into several pieces. The screen was found lying on the floor of the third leg of the combustor and thus was not performing its intended function. A new mounting block was fabricated from stainless steel and the screen assembly replaced. No other anomalies were found, and the combustor was reassembled.

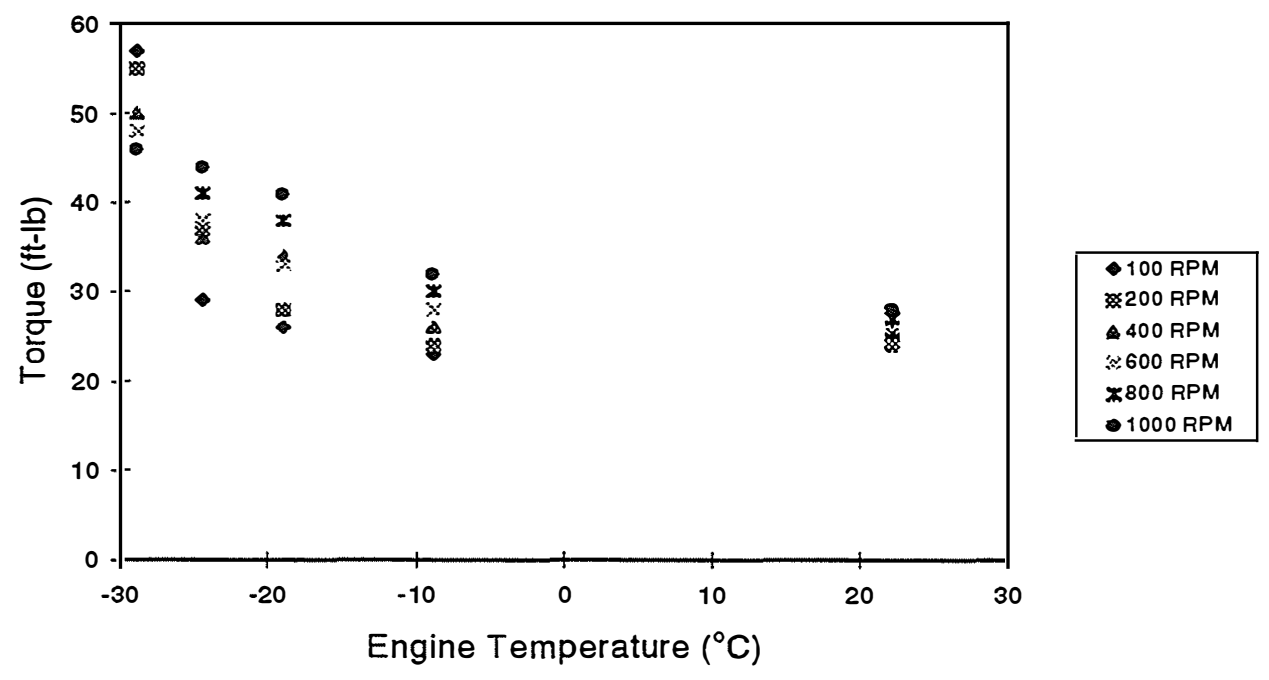

Figure 32. Engine friction at various temperatures using $0 \mathrm{~W}-30$ oil

The test cell was cooled to $-10^{\circ} \mathrm{C}$ and several starting attempts were made to determine the effect of mechanical advance on the cold start performance. We found that $10^{\circ}$ of mechanical spark advance gave the best results- the engine started in 8 seconds and idled at 600-700 rpm. Adjusting the number of steps that the idle air control (IAC) resets after opening all the way when turned on improved performance; a value of 50 steps to reset was optimum. The most improvement, however, was a result of opening the fresh air throttle slightly. The effect of opening the throttle was to increase the equivalence ratio in the combustor while maintaining approximately the same equivalence ratio in the engine, which is lean. This adjustment resulted in consistent starts at temperatures as low as $-20^{\circ} \mathrm{C}$, with less than consistent performance at $-30^{\circ} \mathrm{C}$. Encouraged by these results, methanol compatible fuel injectors were installed in the engine for operational testing of the transition to the main fuel injection system. Scrap injectors had been used not connected to the engine controller during the cold start testing to avoid damaging the ones planned for use in operational testing. The engine controller had previously been calibrated for normal operation on methanol fuel. 


\section{Transition Testing}

To develop the transition schedule from operation on the combustor alone to operation on the main fuel injection system alone, a switch was installed in the power lead to the main fuel injectors. This switch would allow tuming on and off the main fuel injection system; with the switch off, the output from the controller to the fuel injectors (they were pulled to ground) did nothing because there was no power to the injectors. When the switch was turned on to activate the main fuel injection system, the injectors were driven at whatever schedule the controller has determined for that operating point. The engine was operating lean during starting, so the engine controller was trying to enrich the mixture by adjusting the injector-on time. Fortunately, the engine controller acted quickly enough to adjust the mixture before it became too rich. The combustor fuel system was already controlled by a switch, allowing the combustor operation to be controlled.

For operation on methanol, we found that the main fuel injection system could be activated fairly soon after the engine reached idle speed operating on the rich combustor. The engine was operating on a lean mixture at that point and the engine controller adjusted the amount of liquid fuel injected based on the input from the EGO sensor. The EGO voltage reached a steady state value around the stoichiometric set point and the engine ran with both the combustor and the main fuel injection system operating. For this engine controller, the EGO signal was not used when the coolant temperature was below $0^{\circ} \mathrm{C}$. To implement this strategy, a $10 \mathrm{k} \Omega$ resistor was placed across the connector for the coolant temperature sensor to simulate a $10^{\circ} \mathrm{C}$ signal from the thermistor. When the engine surfaces warmed up sufficiently, the fuel supply to the combustor was turned off, and the engine continued to run on just the main fuel injection system.

Figure 33 shows a start to transition at $-9^{\circ} \mathrm{C}$. The temperature of the test was considered to be the temperature reported by a thermocouple installed through the block water jacket and in contact with the cylinder wall on the coolant side. The rapid increase in the EGO voltage indicates the point at which the main fuel injection system was activated. The voltage reaches a steady value when the engine equivalence ratio comes under control.

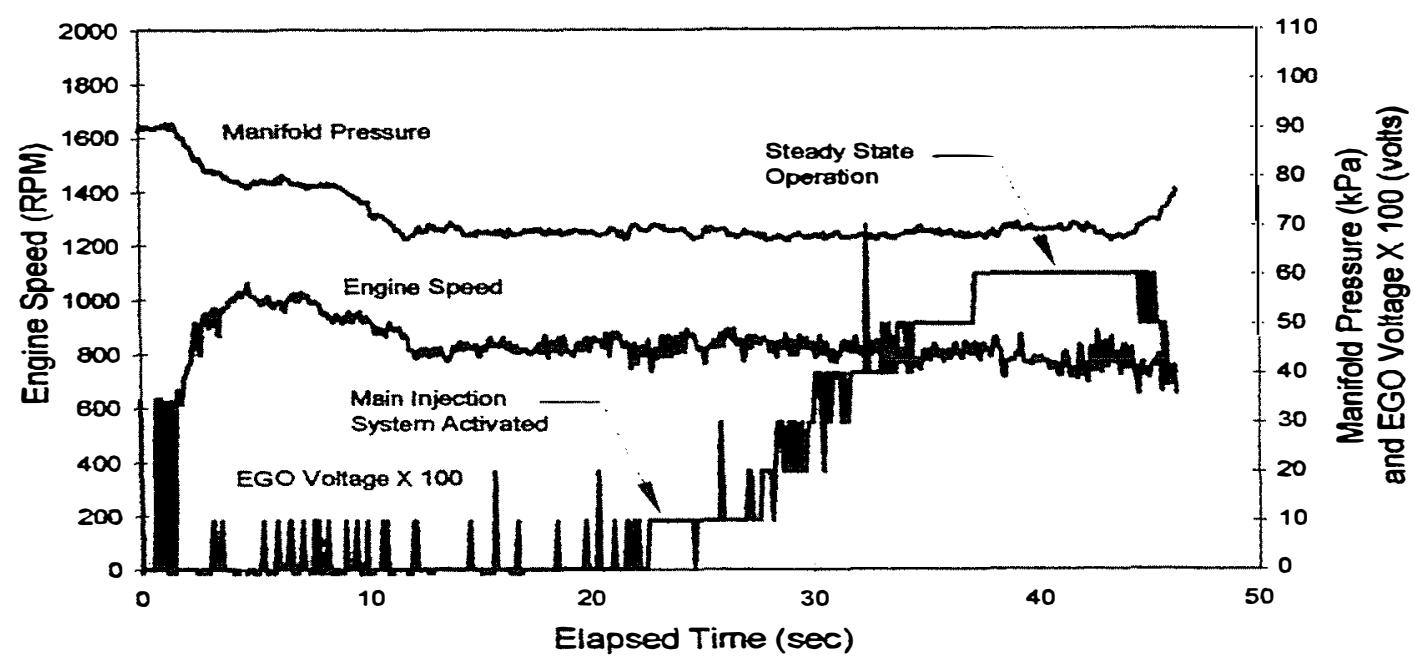

Figure 33. Start and transition to idle at $-9^{\circ} \mathrm{C}$, methanol fuel 
Figure 34 shows a start and transition to idle on the main fuel injection system at $-6^{\circ} \mathrm{C}$. The point at which the main system was turned on is indicated by the rapid increase in the EGO voltage, and Figure 35 shows the point at which the combustor was turned off. Also shown in Figure 35 is the engine running at approximately 3,500 rpm on the main fuel injection system alone after less than 3 minutes. Figures 36 and 37 illustrate a start and transition at $-18^{\circ} \mathrm{C}$. The point at which the main fuel injection system is activated is indicated by the rapid increase in the EGO voltage. The first attempt occurred after approximately 2 minutes and resulted in the engine stalling. The next three attempts were made immediately after the engine reached idle speed operating on the combustor, and all three caused the engine to stall. The fifth attempt at transition came after allowing the engine to idle on the combustor for approximately 90 seconds and resulted in the engine continuing to run on both systems and finally the main fuel injection system alone.

\section{Ethanol Testing}

The performance of the combustor using ethanol was evaluated. The ethanol used was fuel ethanol or E95 (95\% ethanol and 5\% denaturant). The only adjustments to the combustor system to switch from methanol to ethanol were made to the fueling parameters programmed in the engine controller. The method of determining the injector-on time employed by the controller allows adjusting a single parameter, essentially the maximum injector-on time, to recalibrate the fueling schedule for a different fuel. The controller does not display the correct desired or actual air/fuel ratio (it displays the equivalent values for gasoline), but the equivalence ratio is correct because the ratio is determined and controlled by the EGO signal. The GPO table was also adjusted for the different stoichiometry of ethanol. With no further modifications, the combustor was tested using ethanol.

Figures 38 and 39 show a start and transition at $-11^{\circ} \mathrm{C}$ using ethanol. The points at which the main fuel injection system is turned on and off are indicated. The engine continues to run with both systems operating until the combustor is turned off, causing the engine to stall. The engine was restarted and the transition attempted again, resulting in the engine running for a short period of time after the combustor was switched off. The third attempt resulted in the engine continuing to run after the combustor was switched off.

Figures 40 and 41 show a start and transition at $-20^{\circ} \mathrm{C}$. The point at which the main fuel injection system is activated is evident. Rather than turning the combustor off completely, the amount of fuel to the combustor was reduced by entering a negative GPO offset via the PC link to the engine controller. This method of phasing out the combustor operation via the fuel flow with constant air flow converts the rich combustor eventually to an air heater before being switched off completely. The points at which the GPO was offset by $10 \%$ each step are evident by a downward spike in the EGO voltage as well as a slope change in the plenum inlet temperature trace. This step-wise method was an improvement over the binary control previously used for the combustor, but the engine stalled as the method was learned. The engine was restarted and the transition was completed. Nothing unexpected occurs when the engine stalls and is restarted.

Figures 42 and 43 show a start and transition at $-30^{\circ} \mathrm{C}$. Note the extremely long time required for the engine to accelerate to idle speed. The point where the main fuel injector system was activated is indicated. Two steps of the step-wise schedule for combustor phase-out are evident in the EGO voltage trace. The engine stalled after the second step indicating that the schedule should be lengthened. The trace for the plenum inlet temperature shows that the combustor could be operated for a longer time with the temperature still in a reasonable range. 


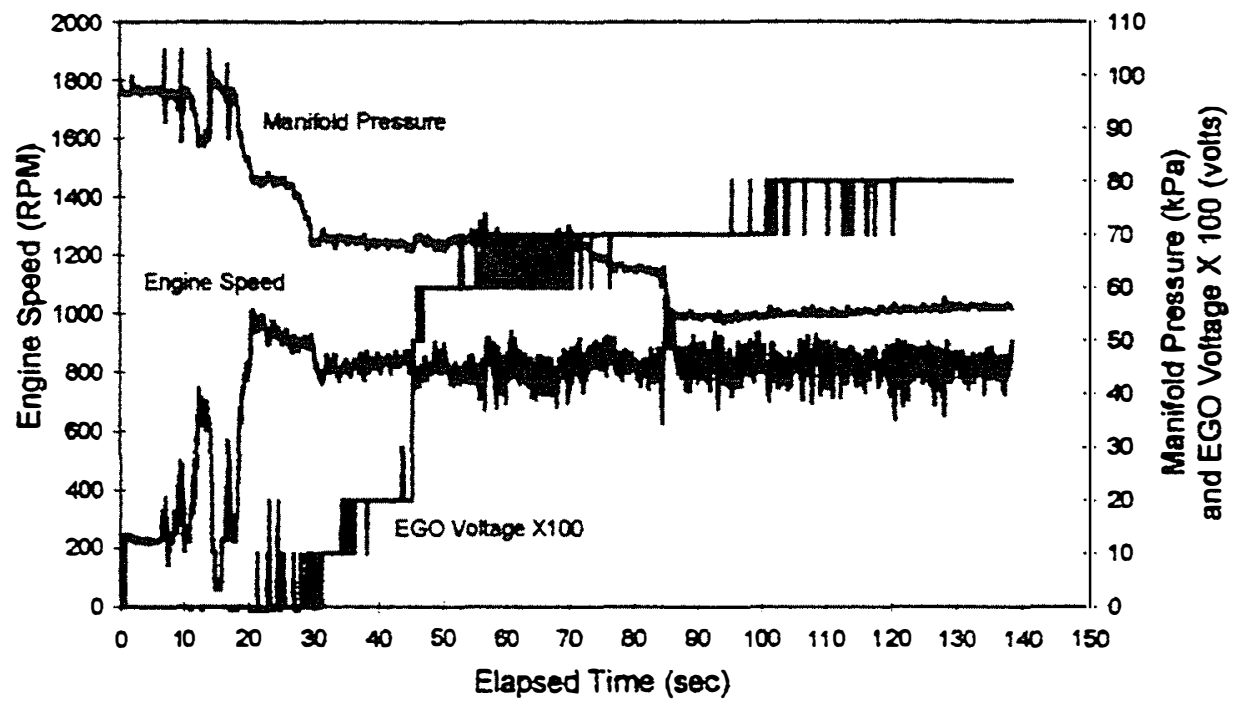

Figure 34. Start and transition at $-6^{\circ} \mathrm{C}$, methanol fuel

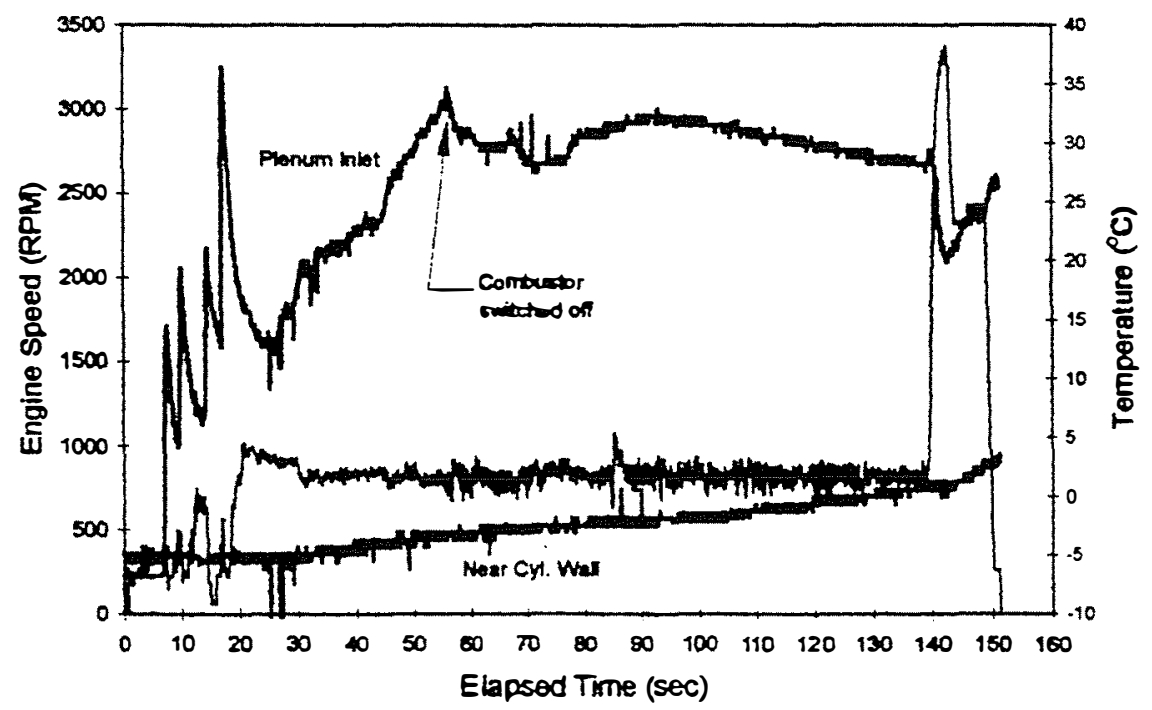

Figure 35. Start and transition at $-6^{\circ} \mathrm{C}$, methanol fuel 


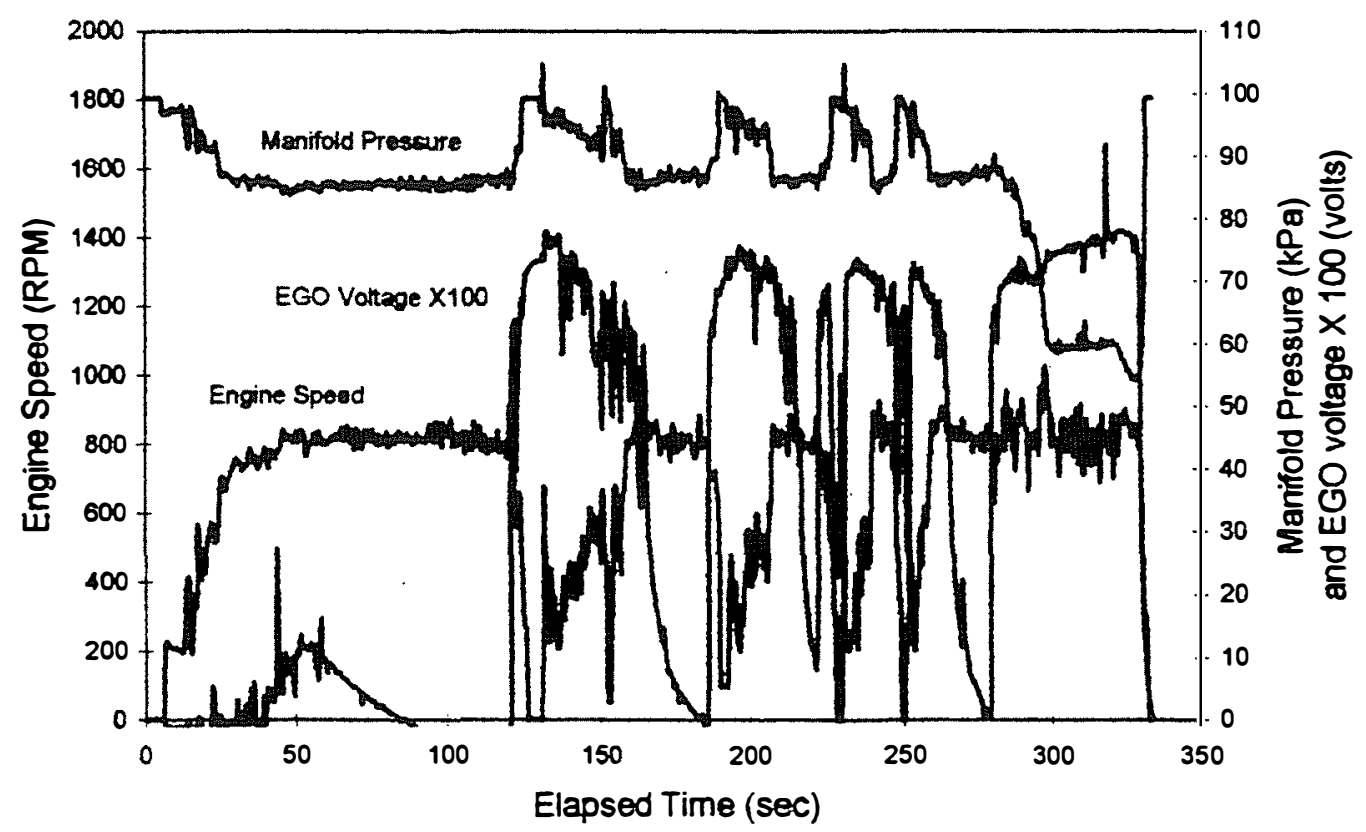

Figure 36. Start and transition at $-18^{\circ} \mathrm{C}$, methanol fuel

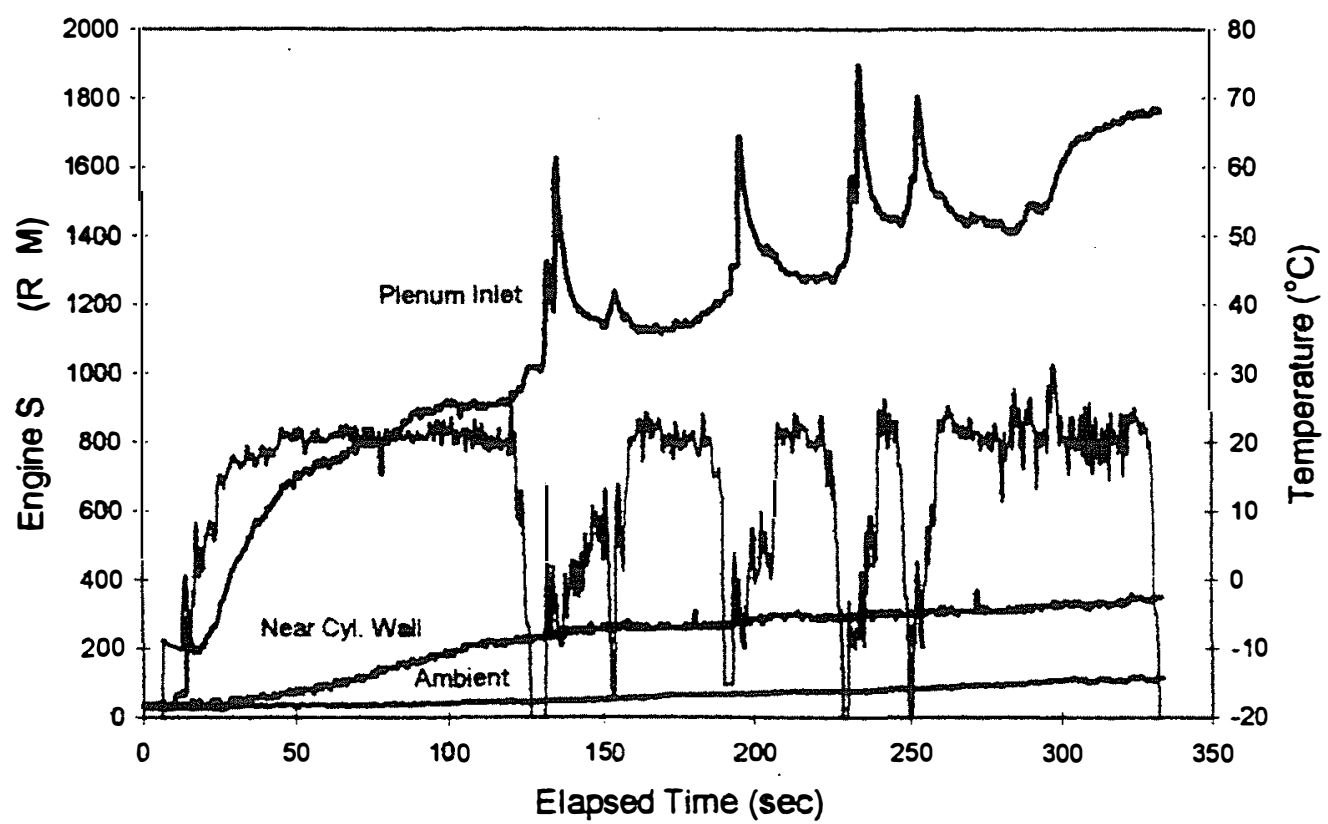

Figure 37. Start and transition at $-18^{\circ} \mathrm{C}$, methanol fuel 


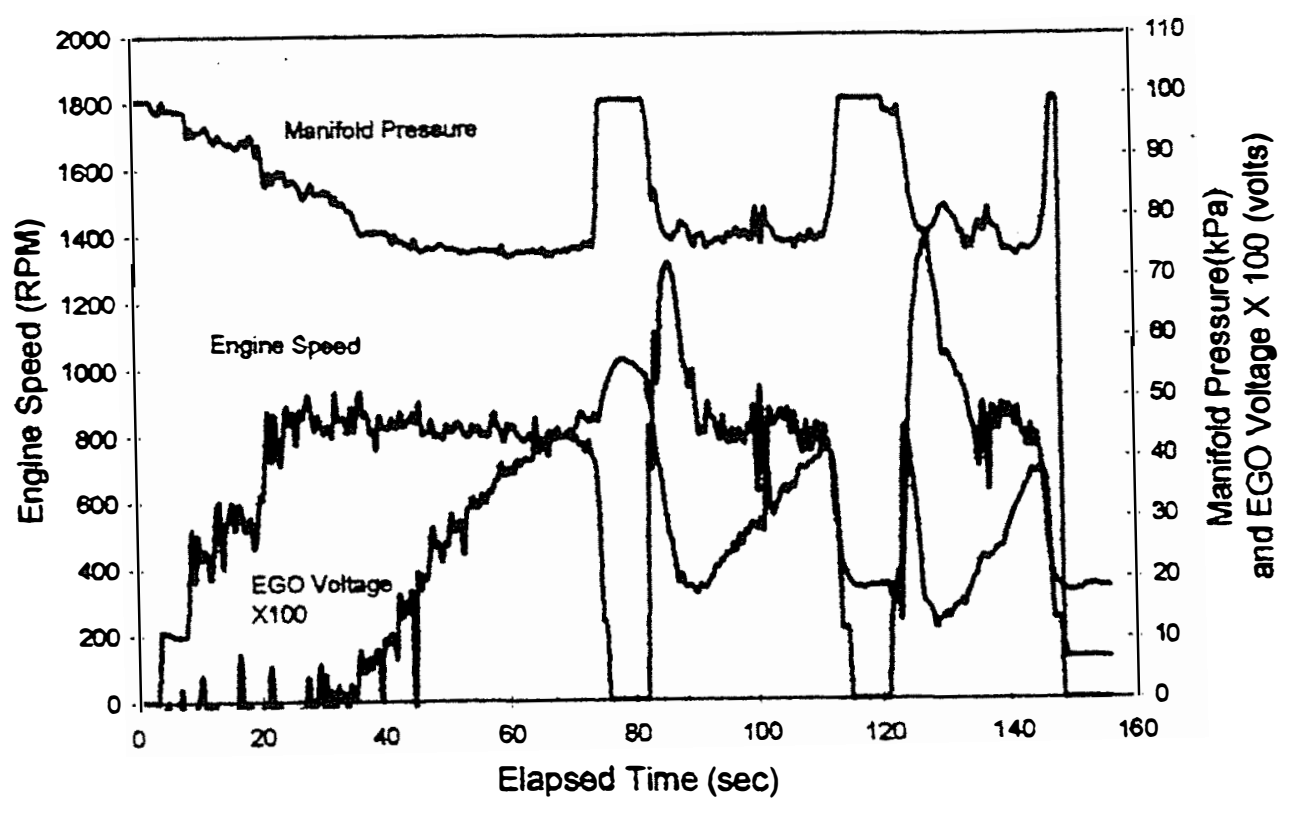

Figure 38. Start and transition at $-11^{\circ} \mathrm{C}$, ethanol fuel

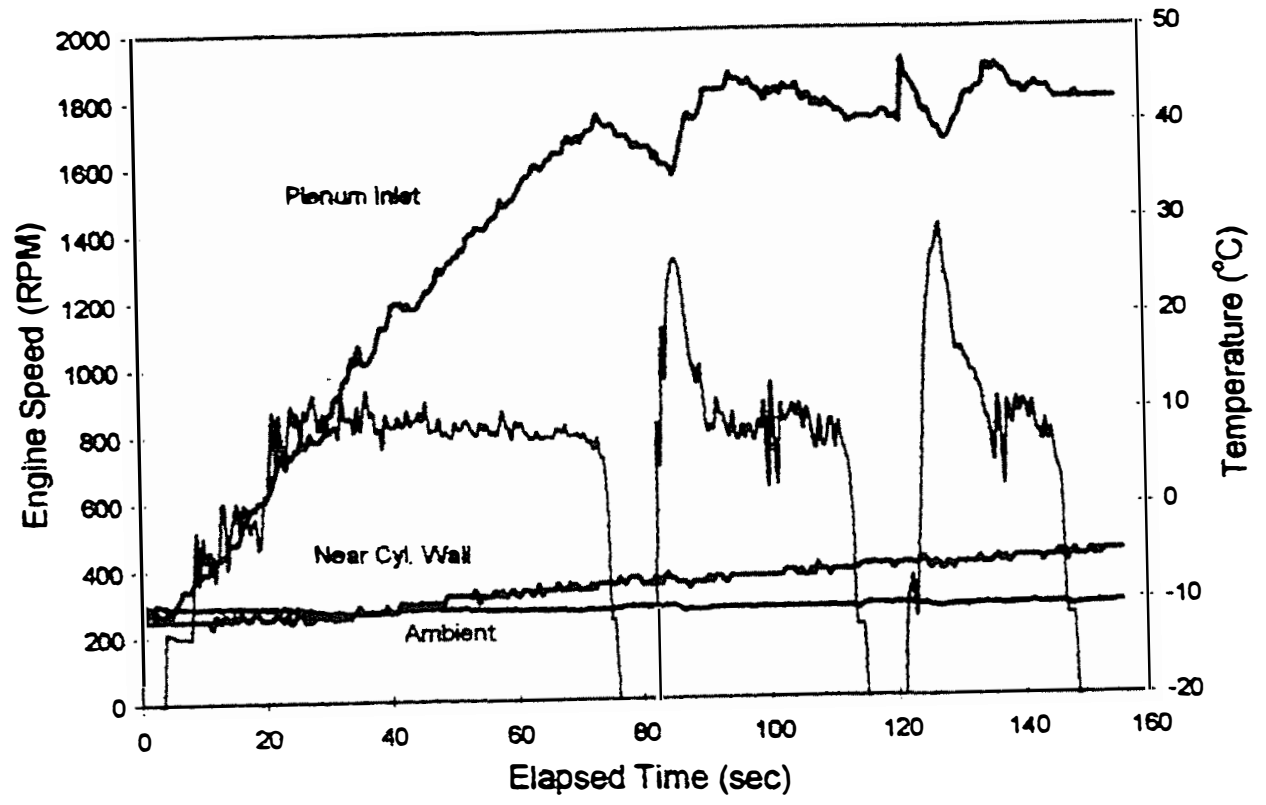

Figure 39. Temperatures for start and transition at $-11^{\circ} \mathrm{C}$, ethanol fuel 


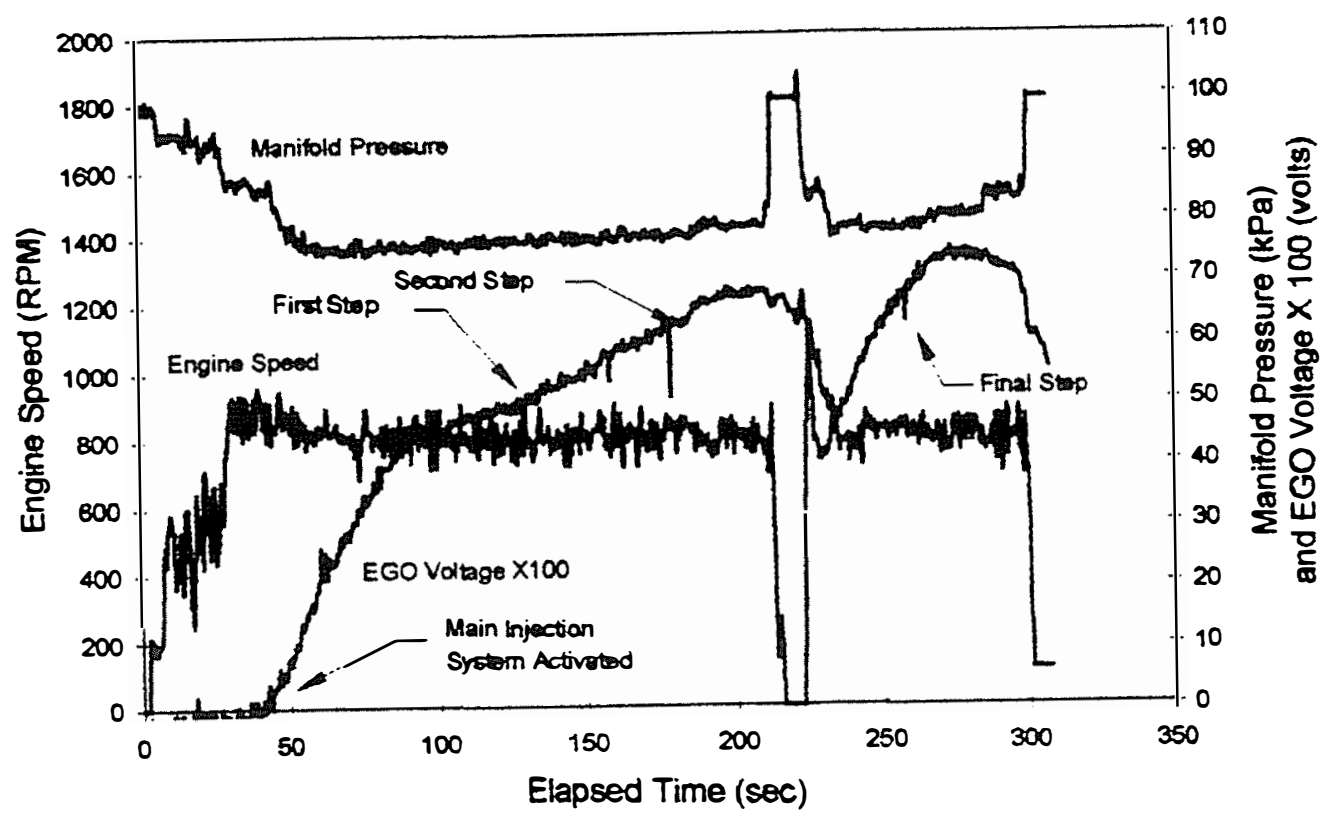

Figure 40. Start and transition at $-20^{\circ} \mathrm{C}$, ethanol fuel

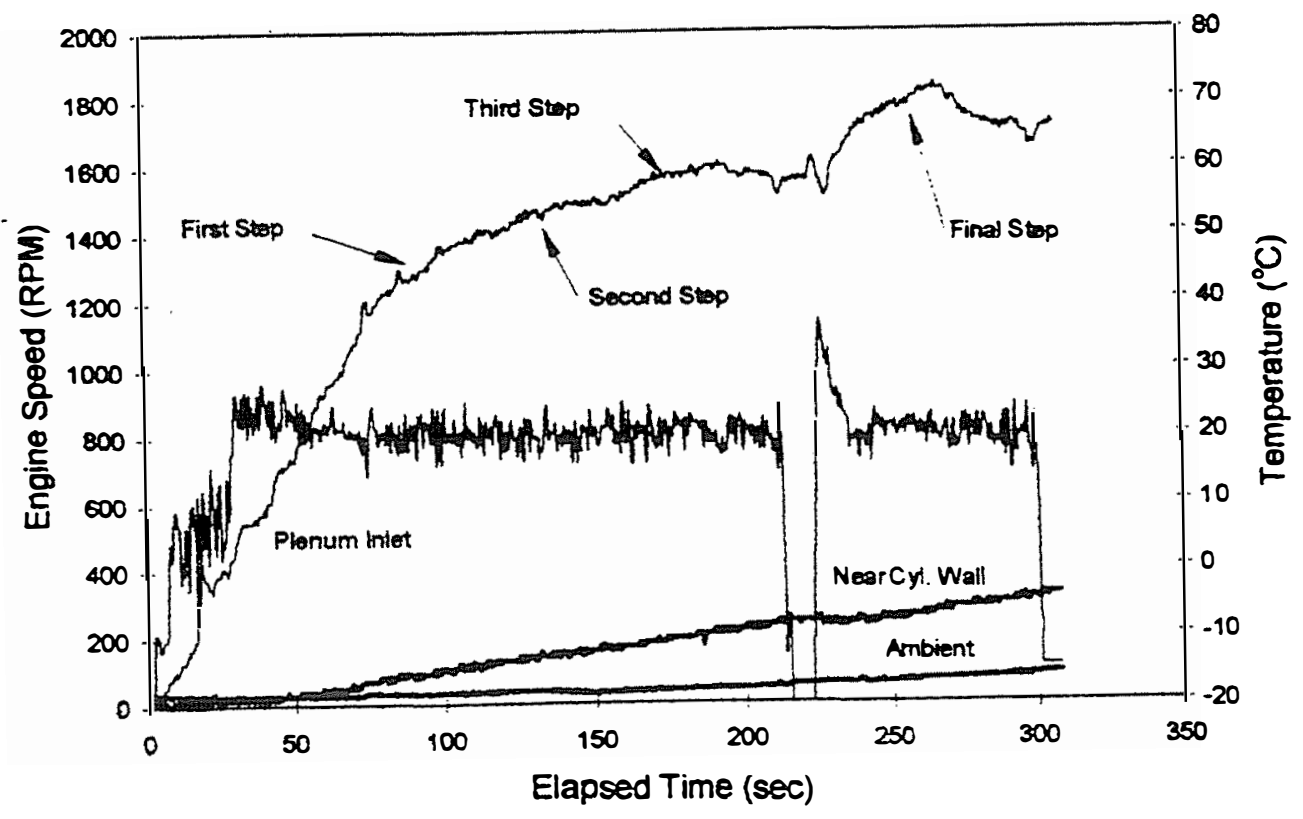

Figure 41. Start and transition at $-20^{\circ} \mathrm{C}$, ethanol fuel 


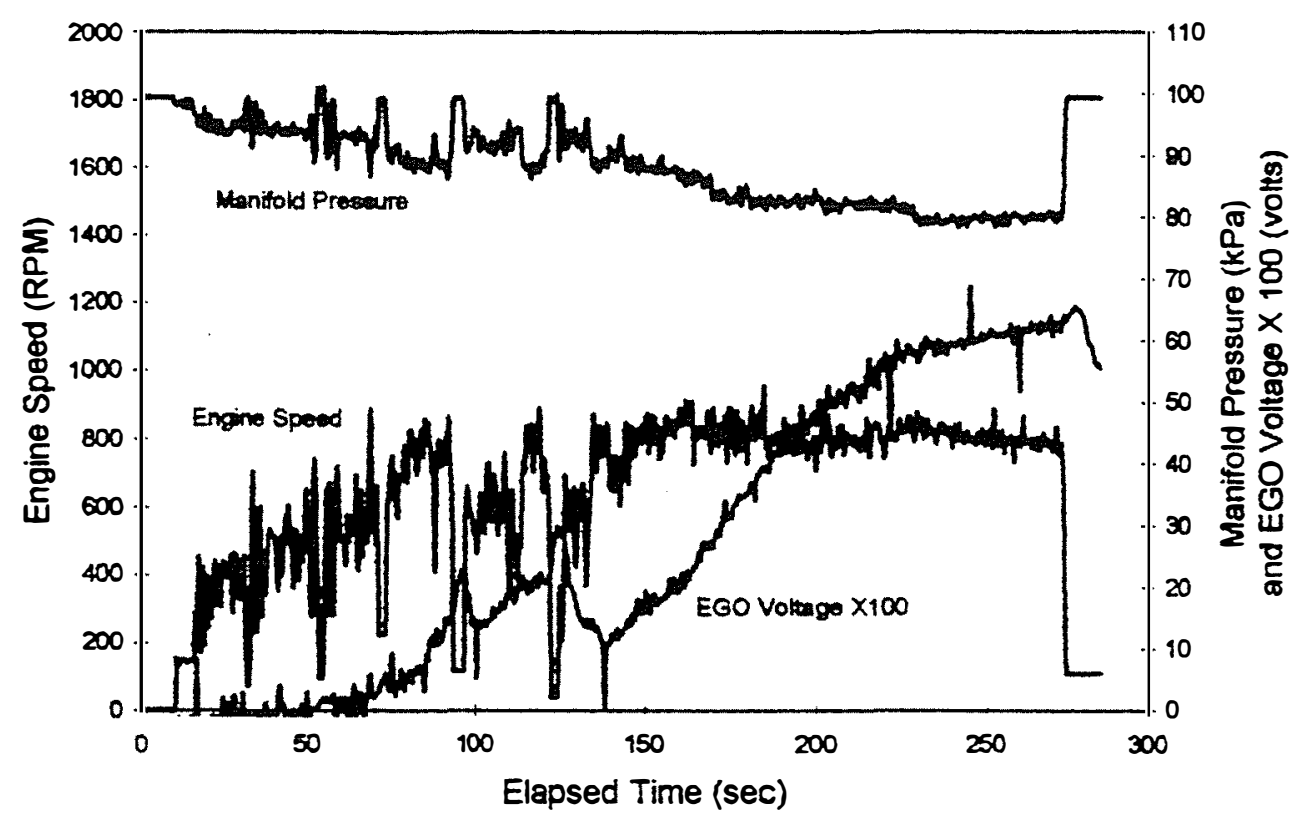

Figure 42. Start and transition at $-30^{\circ} \mathrm{C}$, ethanol fuel

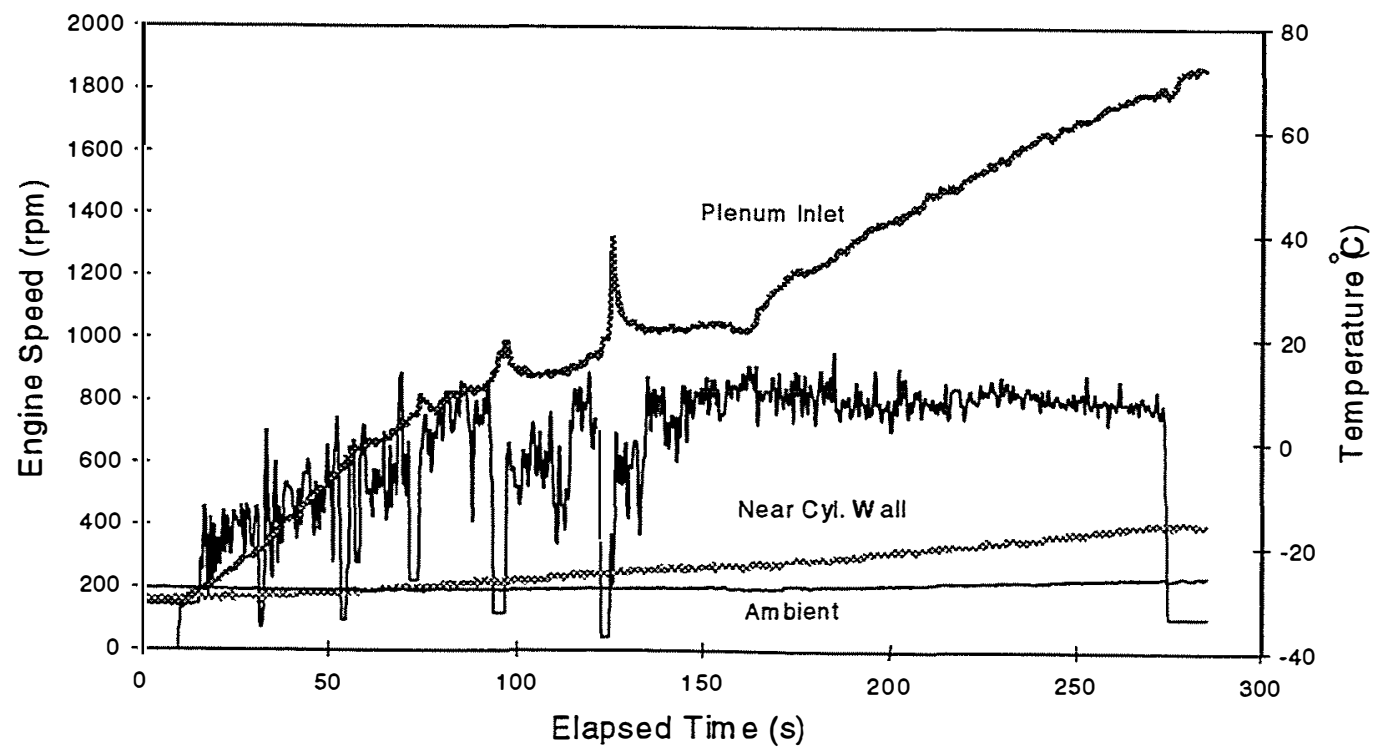

Figure 43. Start and transition at $-30^{\circ} \mathrm{C}$, ethanol fuel 
Figures 44 and 45 show a start and transition at $-11^{\circ} \mathrm{C}$. The step-wise method of combustor phase-out was employed. Note the plenum inlet temperature trace; the temperature reached a somewhat steady value as the fuel to the combustor was decreased in the step-wise fashion indicating that the schedule might have been extended to achieve a smooth transition to operation on the main fuel injection system.

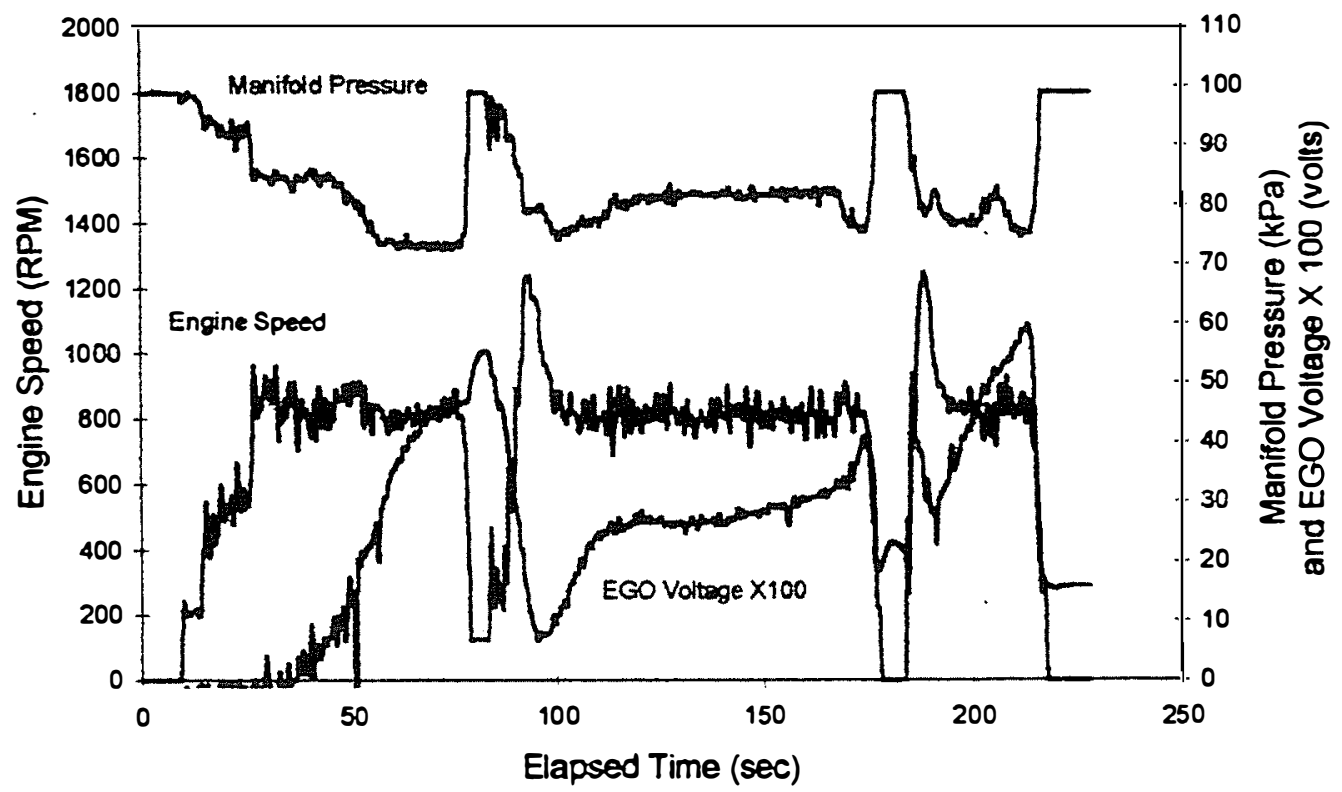

Figure 44. Start and step-wise transition at $-11^{\circ} \mathrm{C}$, ethanol fuel

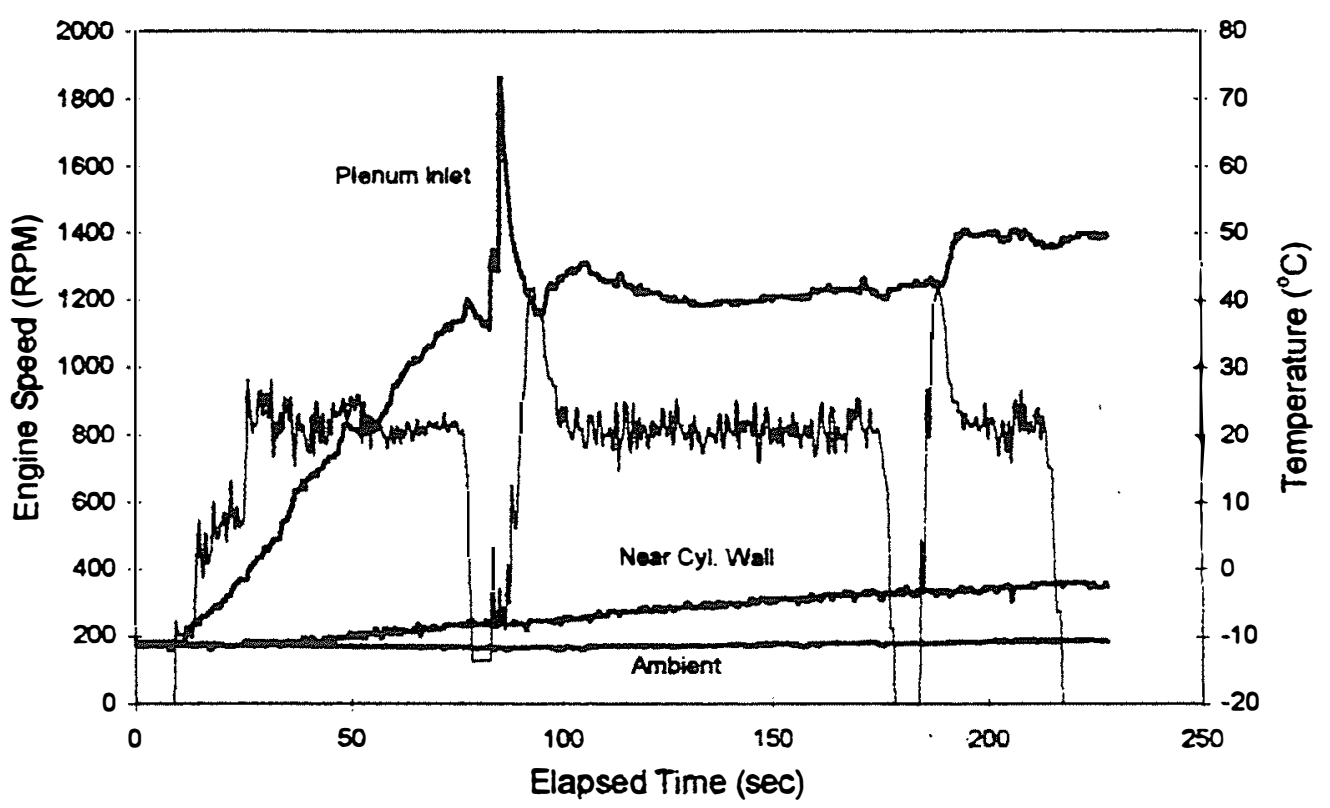

Figure 45. Start and step-wise transition at $-11^{\circ} \mathrm{C}$, ethanol fuel 


\section{Conclusions}

The rich combustor concept for improving the cold start performance of alcohol-fueled engines is practical. The ability to start an alcohol-fueled engine to temperatures as low as $-30^{\circ} \mathrm{C}$ has been demonstrated. Although $-30^{\circ} \mathrm{C}$ starts were not consistently successful, reliable cold starting has been demonstrated at $-20^{\circ} \mathrm{C}$ for both methanol and ethanol; a schedule for the transition to operation on the main fuel injection system has been developed but not demonstrated reliably. Reliable cold starting and transition to operation on the main fuel injection system has been demonstrated for approximately $-10^{\circ} \mathrm{C}$ for both methanol and ethanol.

Although the system was not installed on a vehicle, most of the vehicle integration issues were resolved during the development of the rich combustor system. A shift in interest between the alcohol fuels resulted in a change in the focus from methanol to ethanol. The ethanol testing was performed in lieu of emissions testing the system using methanol.

The development of the transition to main fuel injection system schedule should be refined to give a smooth transition at all temperatures. The test results presented indicate that it should be achievable. The ability to phase-in the main fuel injection system rather than switching it on would allow an earlier beginning of the transition process and would supply additional fuel to the lean-operating engine running on the combustor alone. Modifications to the engine controller software would be required to achieve this phase-in control of the main fuel injection system. Once this transition schedule is optimized, off-idle operation of the system should be developed with the goal of start up and drive away. 


\section{References}

Campbell, A.S. (1979), Thermodynamic Analysis of Internal Combustion Engines. John Wiley \& Sons, New York, 1979.

Dempsey, A.B. and Goetz, W.A. (1986), "Cold Start Testing of Methanol Powered Vehicles," Technical Report No. 5030-1, ES/CAFU/86-16, Transport Canada, Centre for Altemative Fuel Utilization, Ottawa, Ontario, 1986.

Electromotive (1995), “Total Engine Control Engine Management Systems- Installation and User's Manual,” Electromotive, Inc., Chantilly, VA, 1995.

Gardiner, D. P. (1993), "Sub-Zero Cold Starting of a Port-Injected M100 Engine Using Plasma Jet Ignition and Prompt EGR," SAE Paper No. 930331, 1993.

Höchsmann, G. (1989), “Cold Start Capability of Methanol-Fueled Engines,” Porsche AG R\&D Center, Weissach,Germany, 1989.

Hodgson, J.W. (1994), "The Development of a Device for Cold Starting Alcohol Fueled Vehicles and Reducing Cold Start Emissions from Gasoline Fueled Vehicles," Proposal to National Renewable Energy Laboratory, 1994.

Hodgson, J.W., Pike, M.S., Guglielmello, T,J. (1993), "Development of a Cold-Start Device for Methanol-Fueled Engines," SAE Paper No. 932772 (also published in SAE Special Publication SP-995), 1993.

Hodgson, J.W., and Lamas, J.A. (1990),. “A Simple Algorithm For Determining the Equilibrium Composition of Gaseous C/H/O/N Systems Involving Ten Species," 1990 ASEE-SE Section Proceedings, April 8-19, 1990, Charlotte, North Carolina.

Hydrogen Consultants, Inc., "Advanced Hydrogen/Methane Utilization Technology Demonstration, Phase II: Hydrogen Cold Start of a Methanol Vehicle”, Report XR-2-11175-1, National Renewable Energy Laboratory, 1995.

Iwai, N., Akai, M., Hosogai, D., Nishimura, J., and Saori, H. (1984), "Cold Startability Improvement of Neat Methanol S.I. Engine by Using Ultrasonic Partial Oxidation Combustor."

Karpuk, M:E. (1989), "Design and Testing of a Dissociated Methanol Vehicle,” DOE/CH/10093-H5, U.S. Department of Energy, Office of Vehicle and Engine R\&D, 1989.

Karpuk, M.E., and Cowley, S.W. (1988), "On Board Dimethyl Ether Generation to Assist Methanol Engine Cold Starting,” SAE Paper No. 881678, 1988.

Lalk, T.R., McCall, D.M., and McCanlies, . (1984), "Evaluation of Dissociated and Steam-Reformed Methanol as Automotive Engine Fuels," COE/NBB-0064, DOE/NASA/01420-1, NASA Cr168242, U.S. Department of Energy, Office of Vehicle and Engine R\&D, 1984.

Obert, E.F. (1973), Internal Combustion Engines and Air Pollution, Harper and Row, New York, 1973. 
Pefley, R.K., and Browning, L.H.(1986), "Research and Development of Alcohol Fuel Usage in SparkIgnited Engines," DOE/CE/50036-H1, U.S. Department of Energy, Office of Transportation Systems, 1986.

Pefley, R.K., Pullman, B., and Whitten, G. (1984), "The Impact of Alcohol Fuels on Urban Air Pollution: Methanol Photochemistry Study,” DOE/CE/50036-1, U.S. Department of Energy, Office of Vehicle and Engine R\&D, 1984.

Pettersson, L. and Sjöström, K. (1991), “Onboard Hydrogen Generation by Methanol Decomposition for the Cold Start of Neat Methanol Engines," International Journal of Hydrogen Energy, Vol. 16, No. 10, pp. 671-676, 1991.

Perry's Chemical Engineers Handbook (1993), McGraw-Hill, 1993.

Ross, M. and DeCicco, J. (1993), “An Updated Assessment of the Near-Term Potential for Improving Automotive Fuel Economy," American Council for an Energy-Efficient Economy, 1993. 


\section{Appendix A}

\section{Design Drawings-First Generation Rich Combustor}




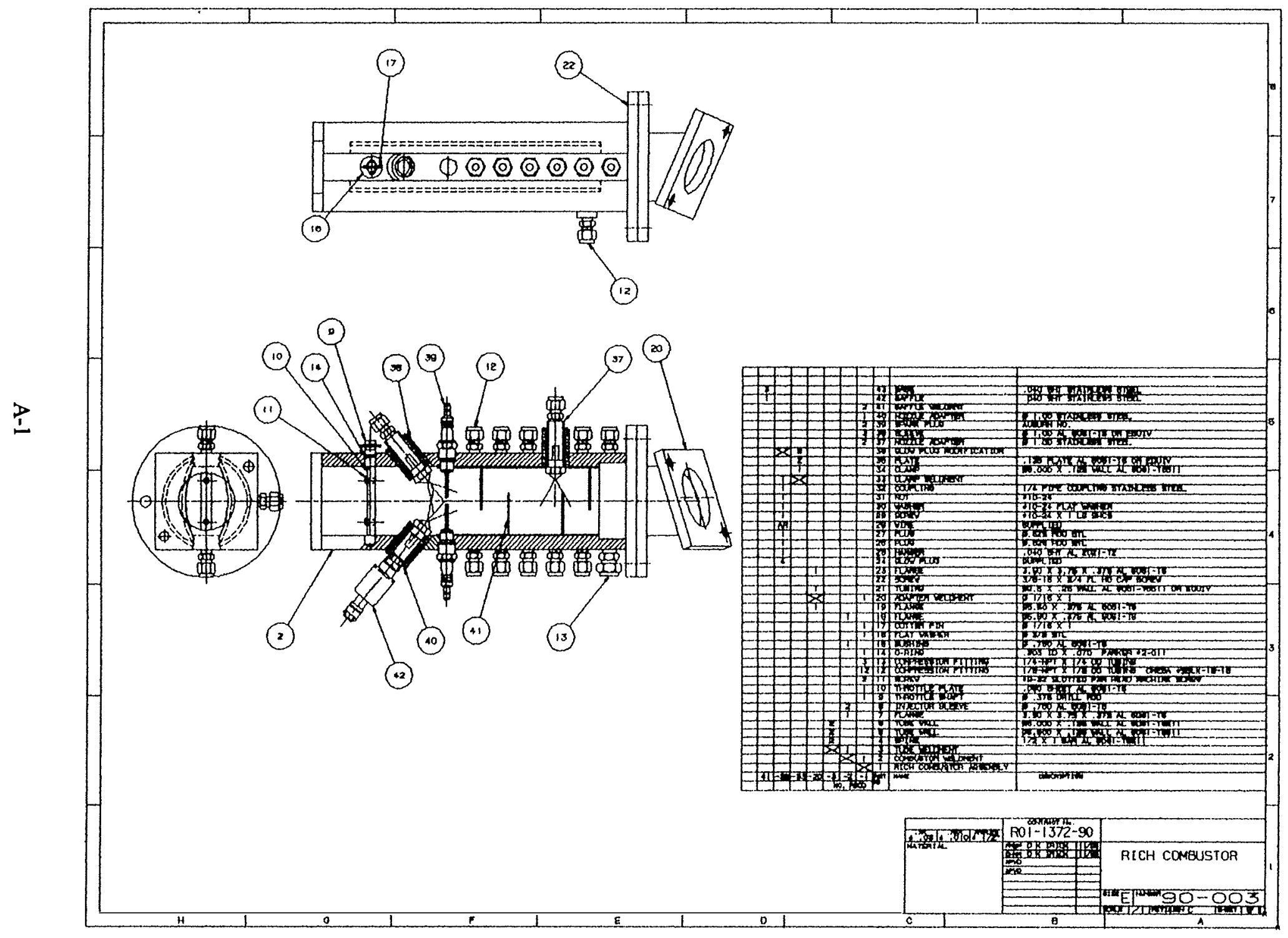




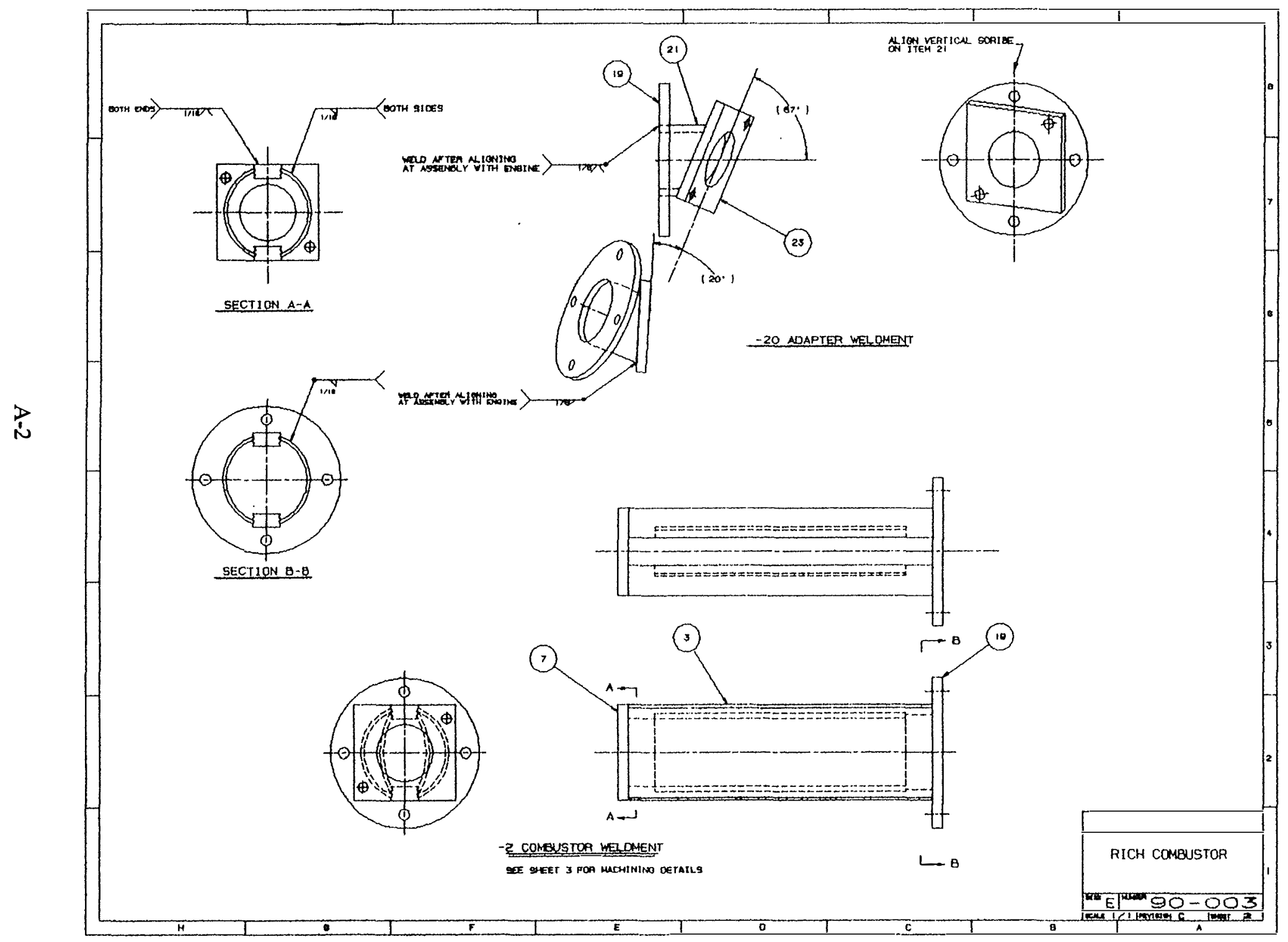




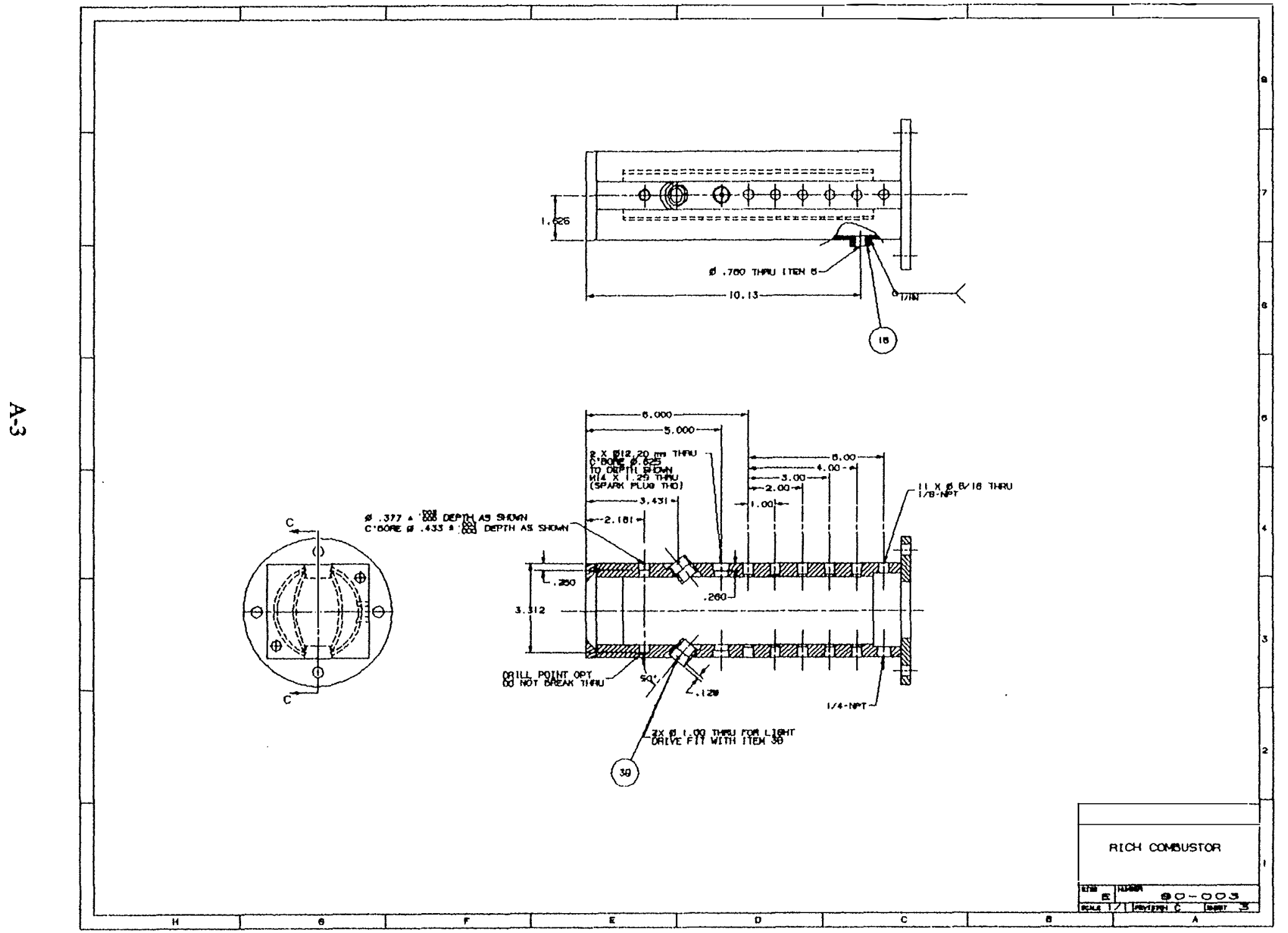




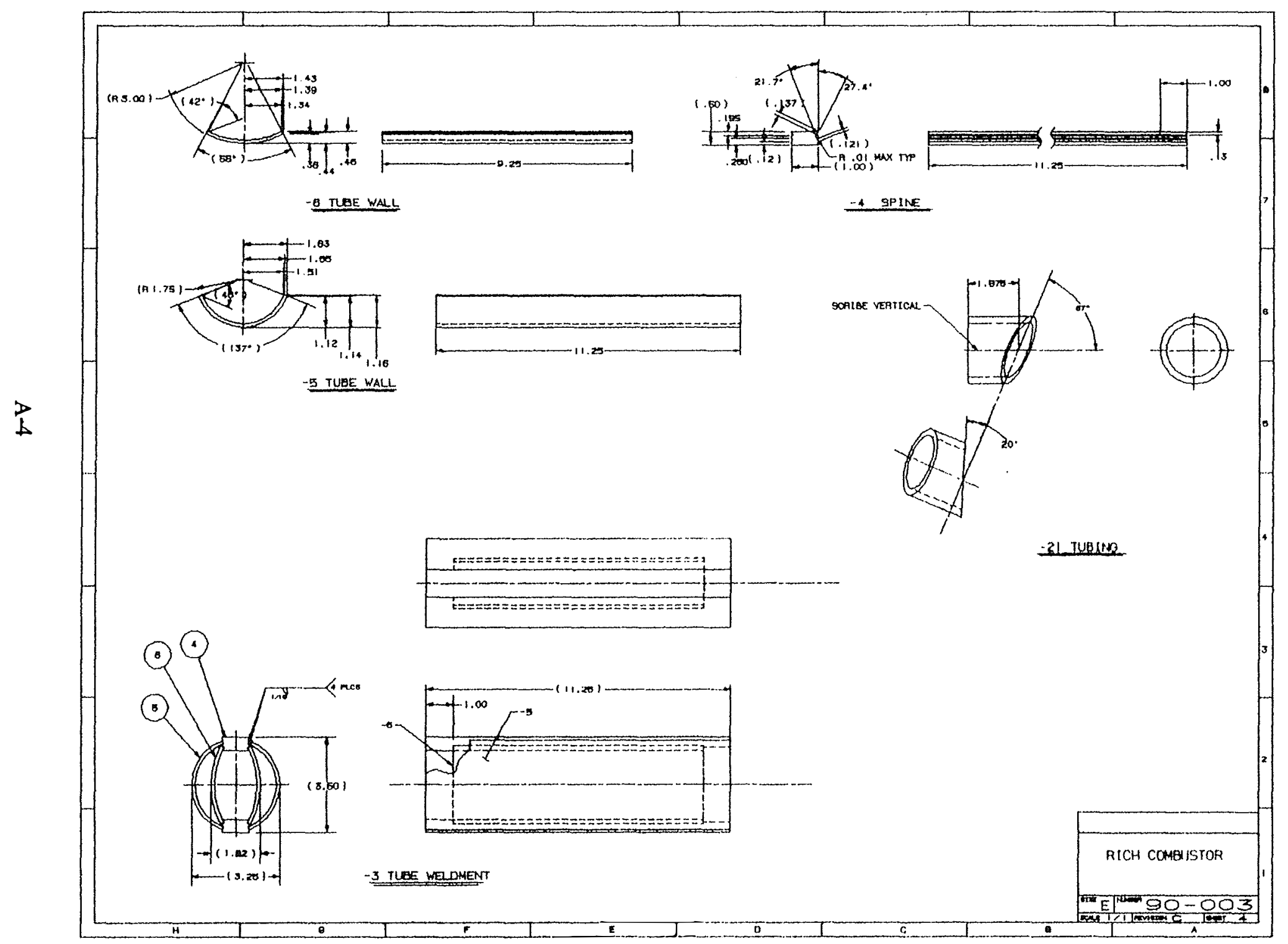




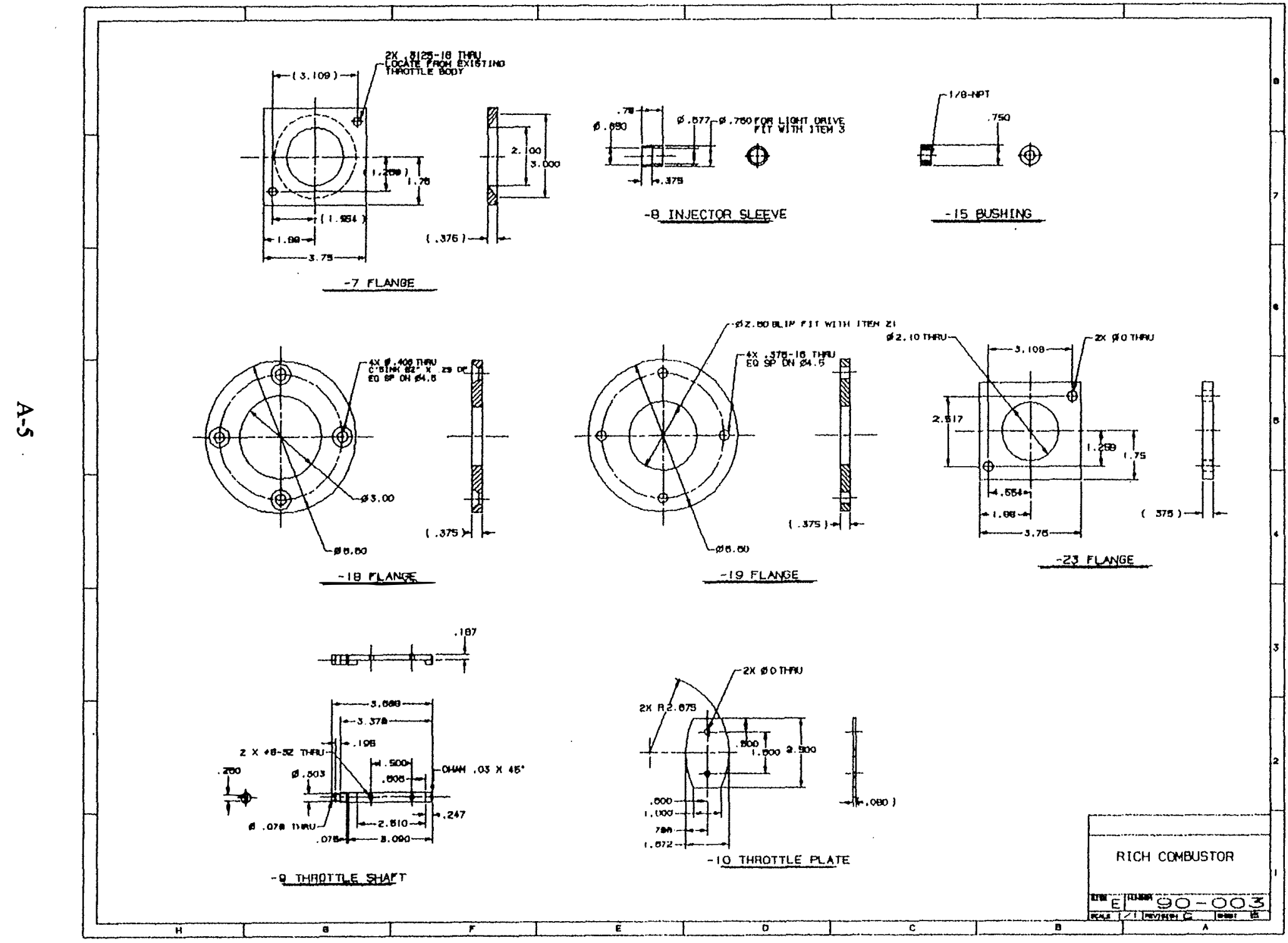




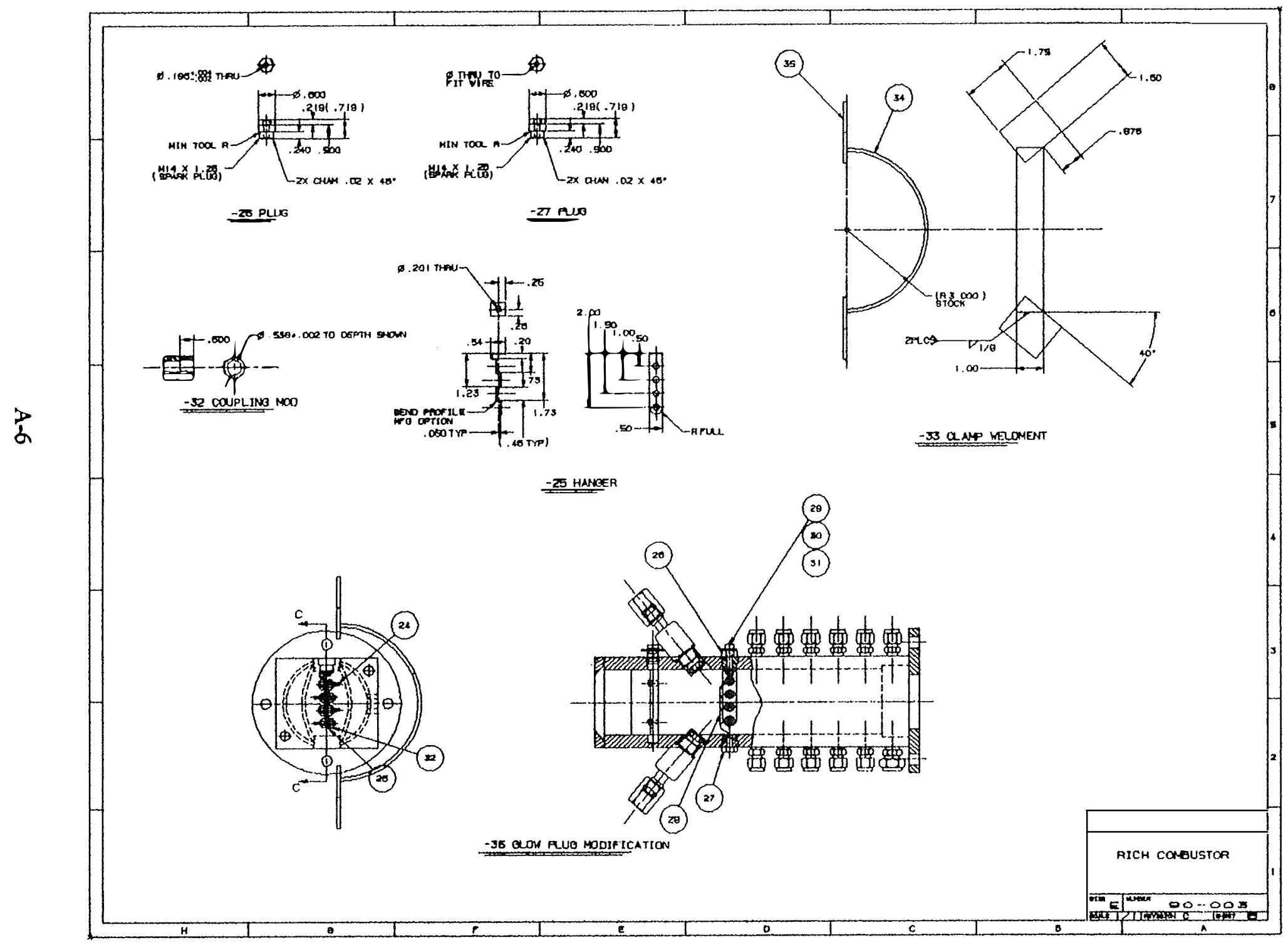




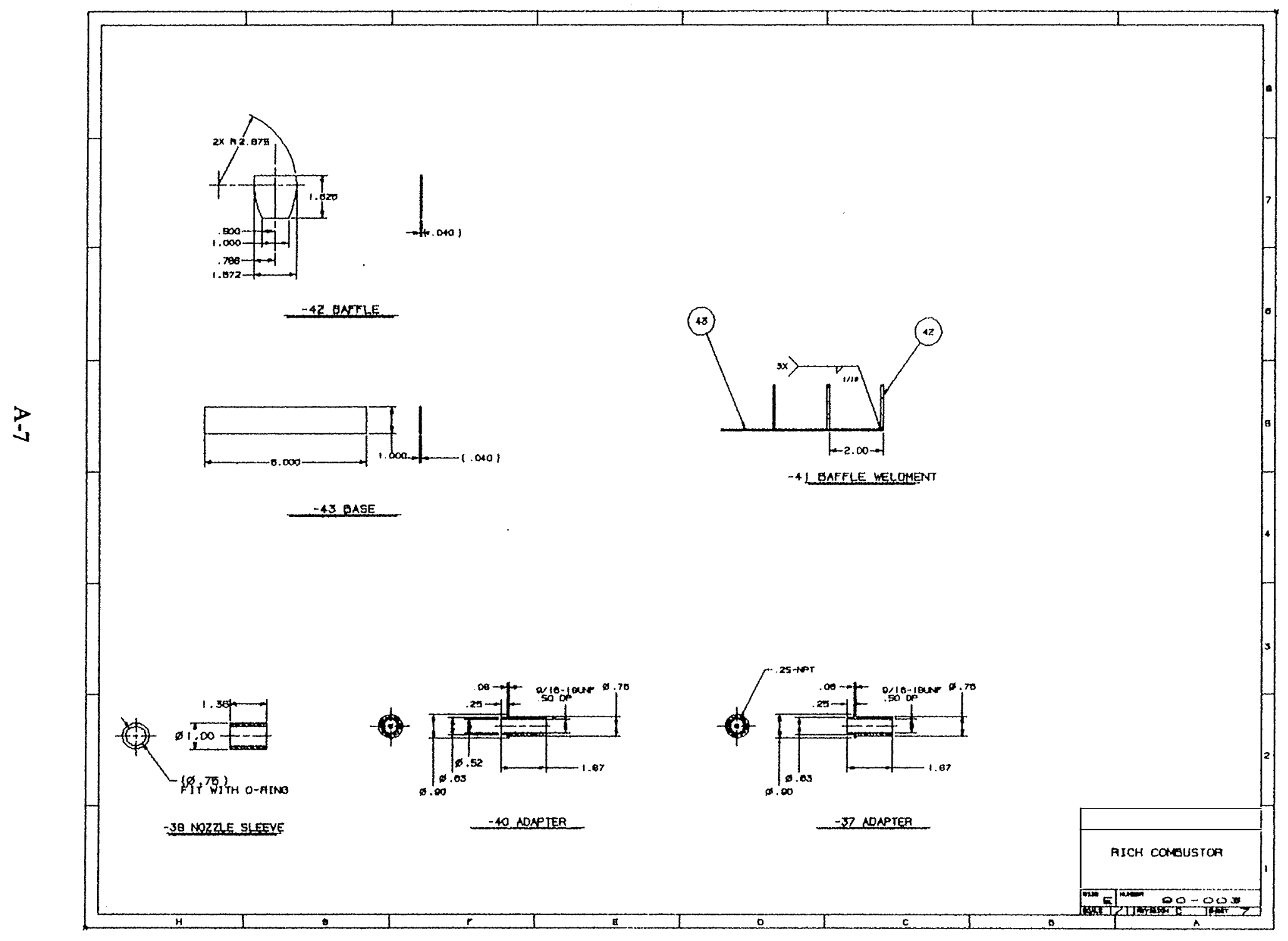


Appendix B

Design Drawings-Second Generation Rich Combustor 


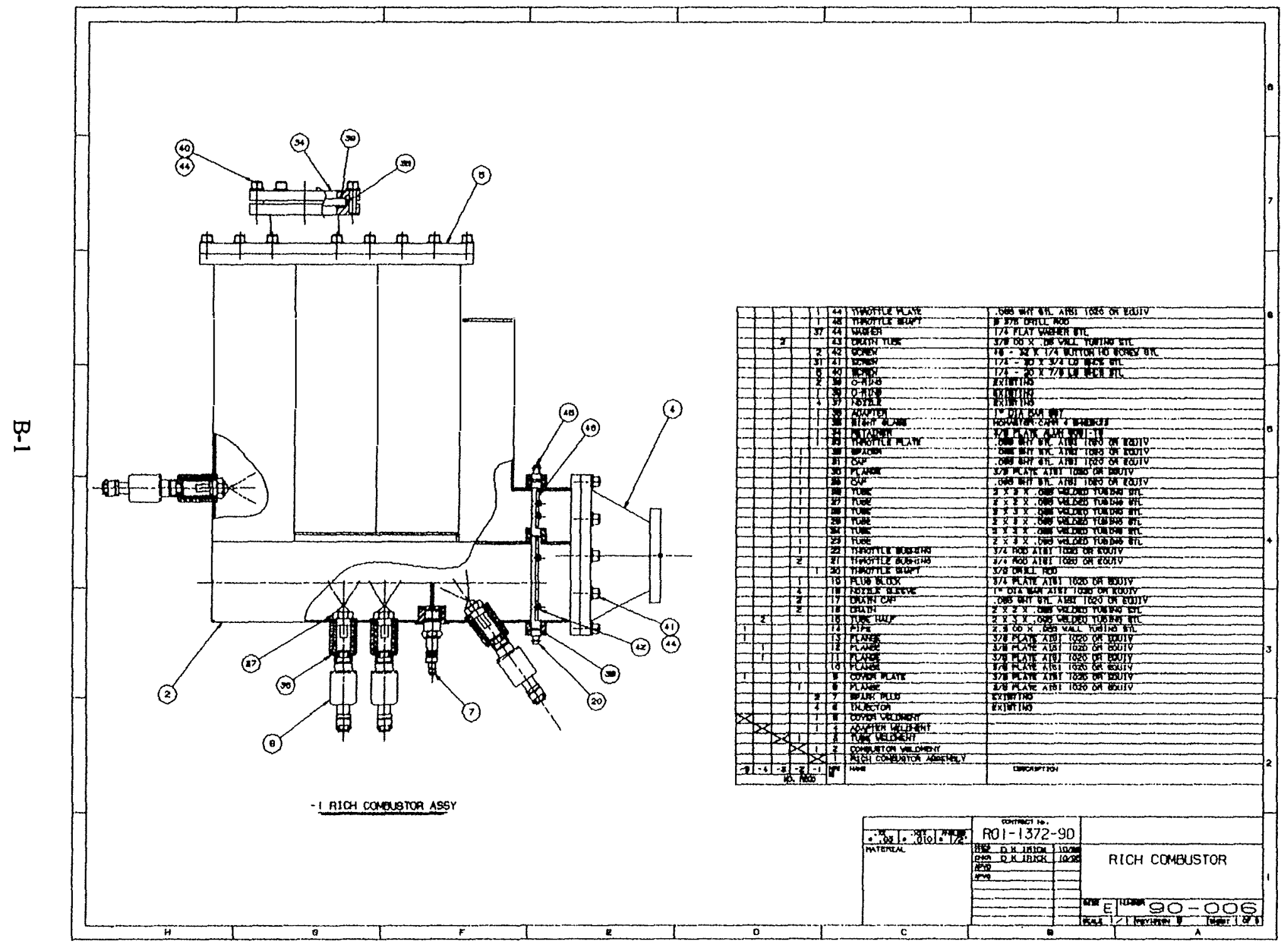




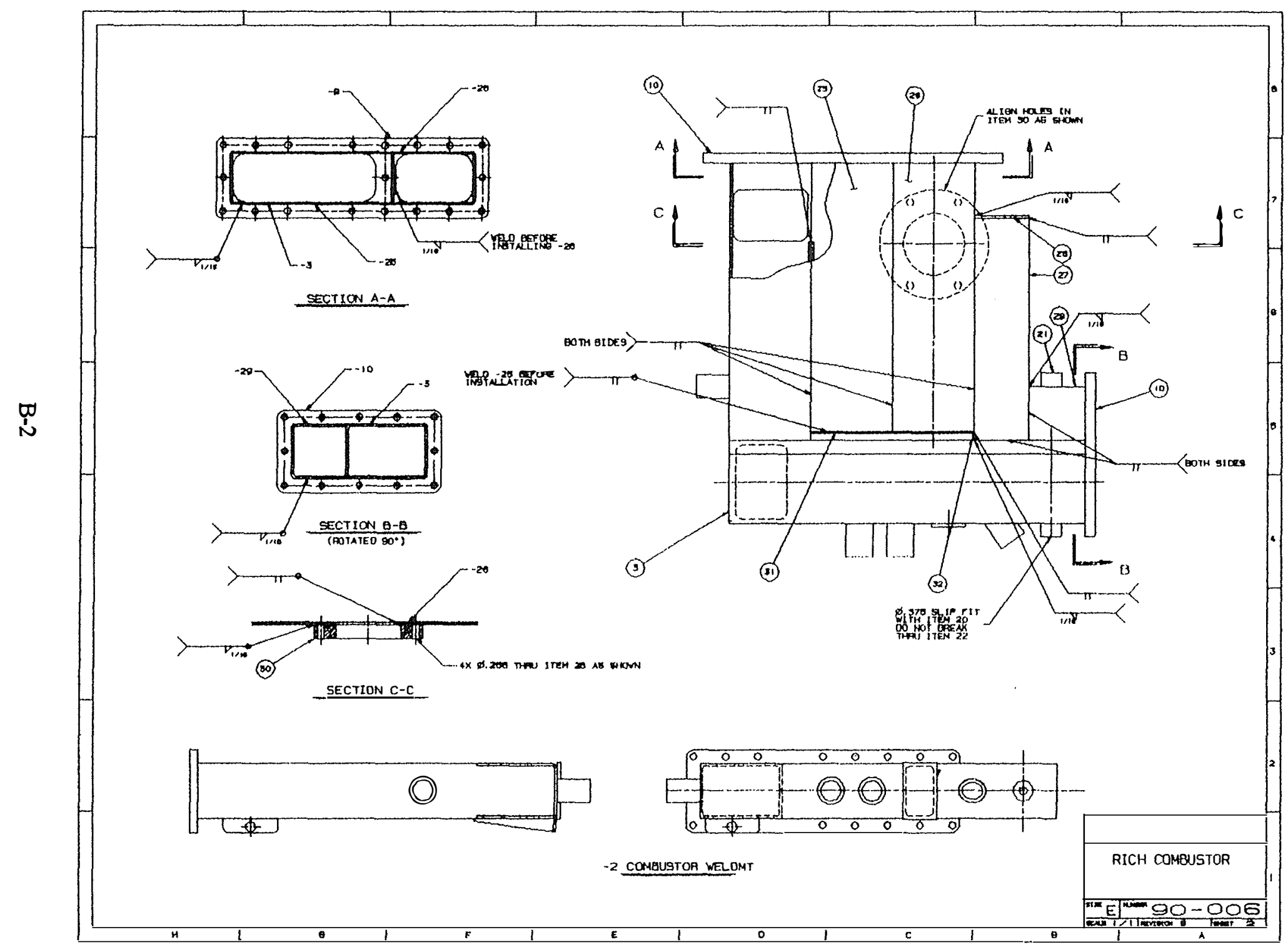




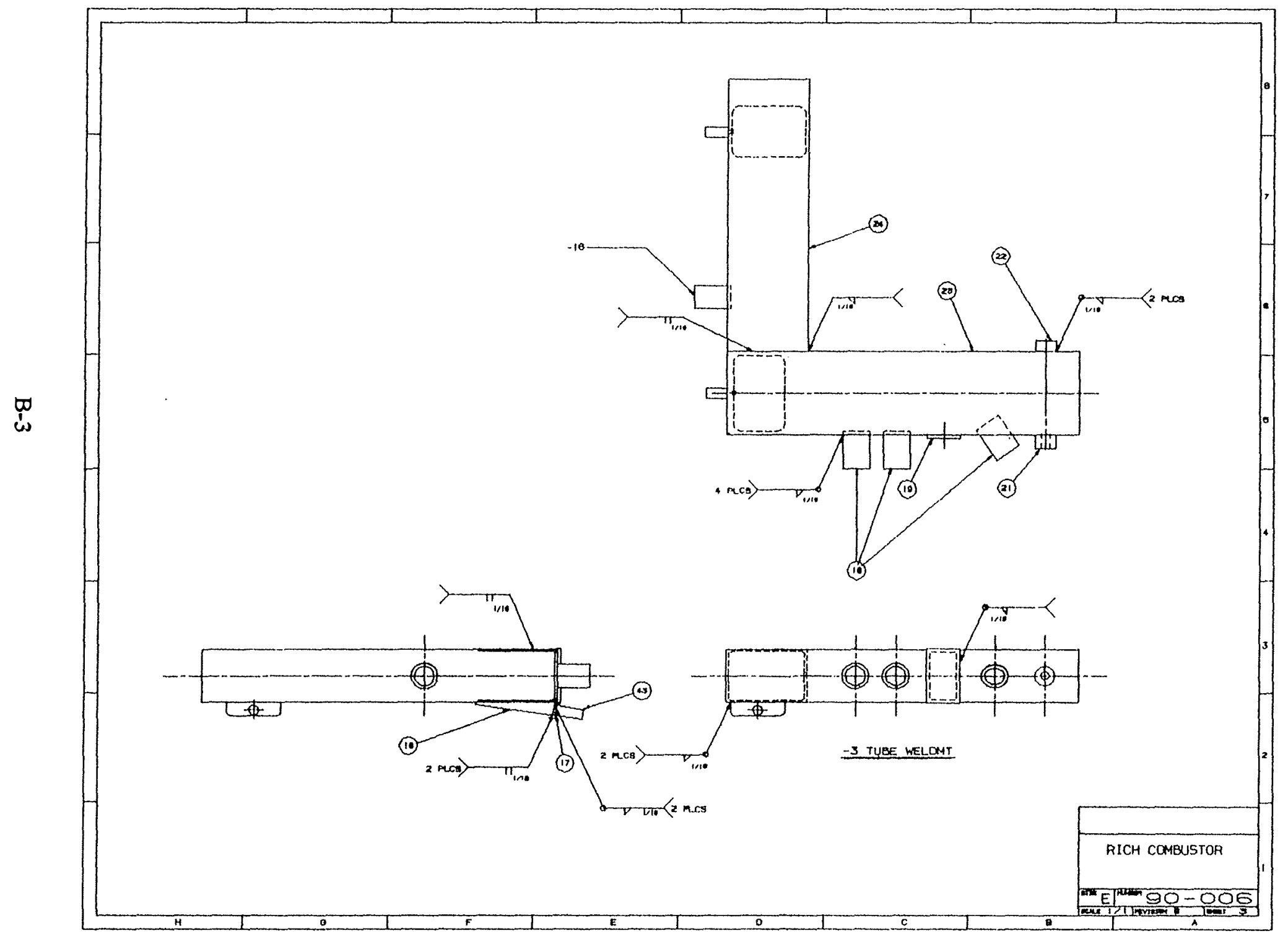




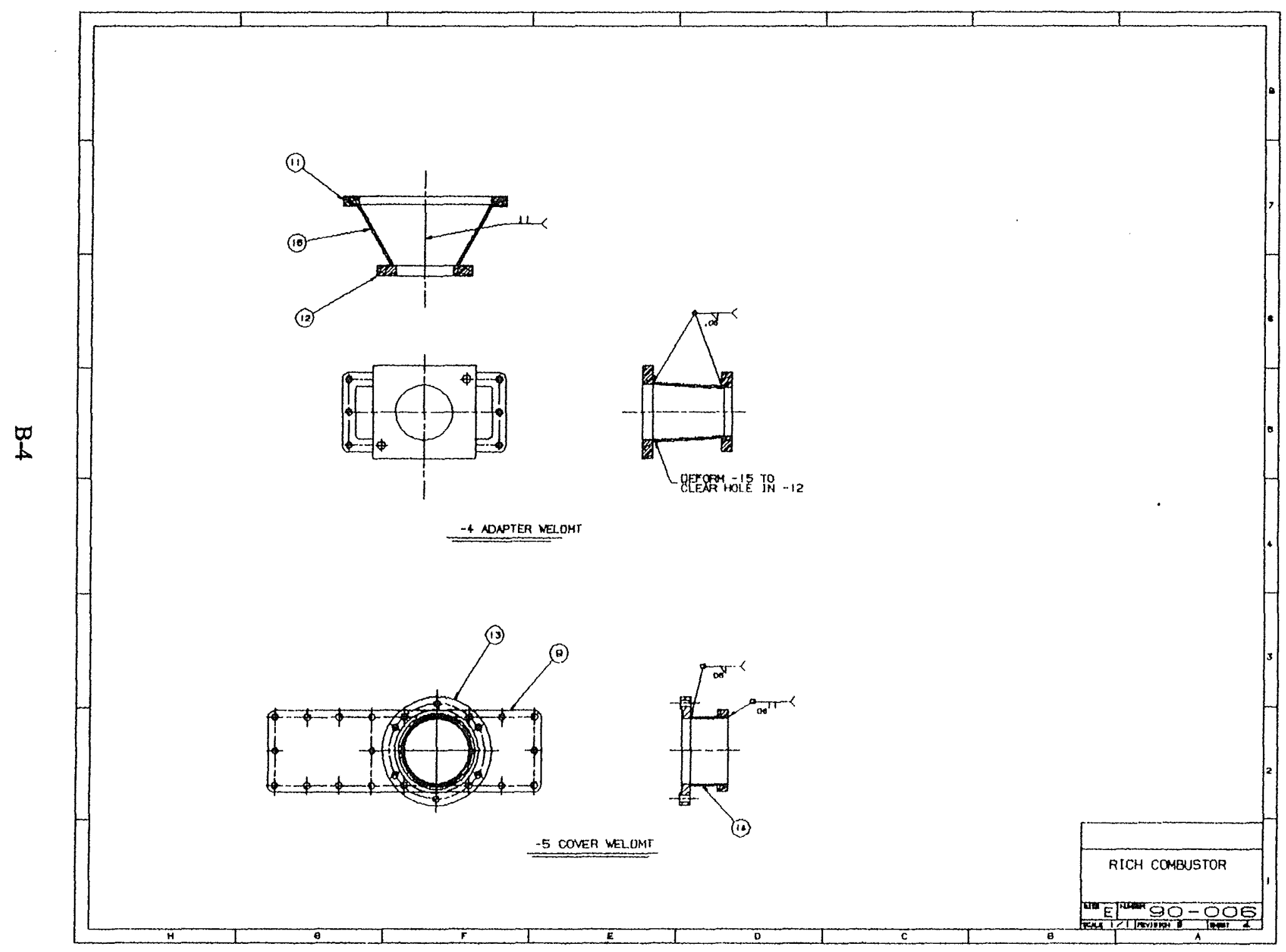




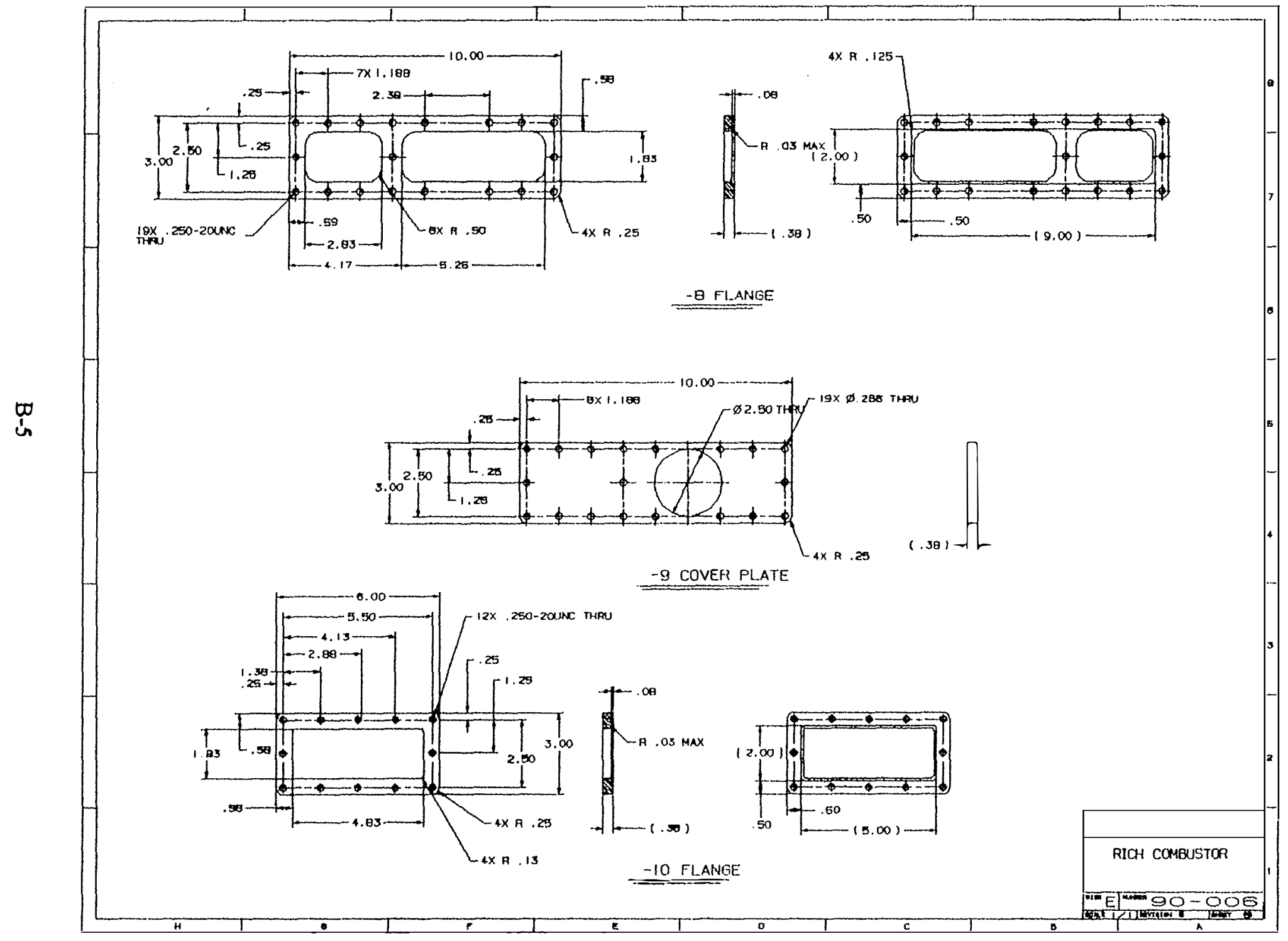




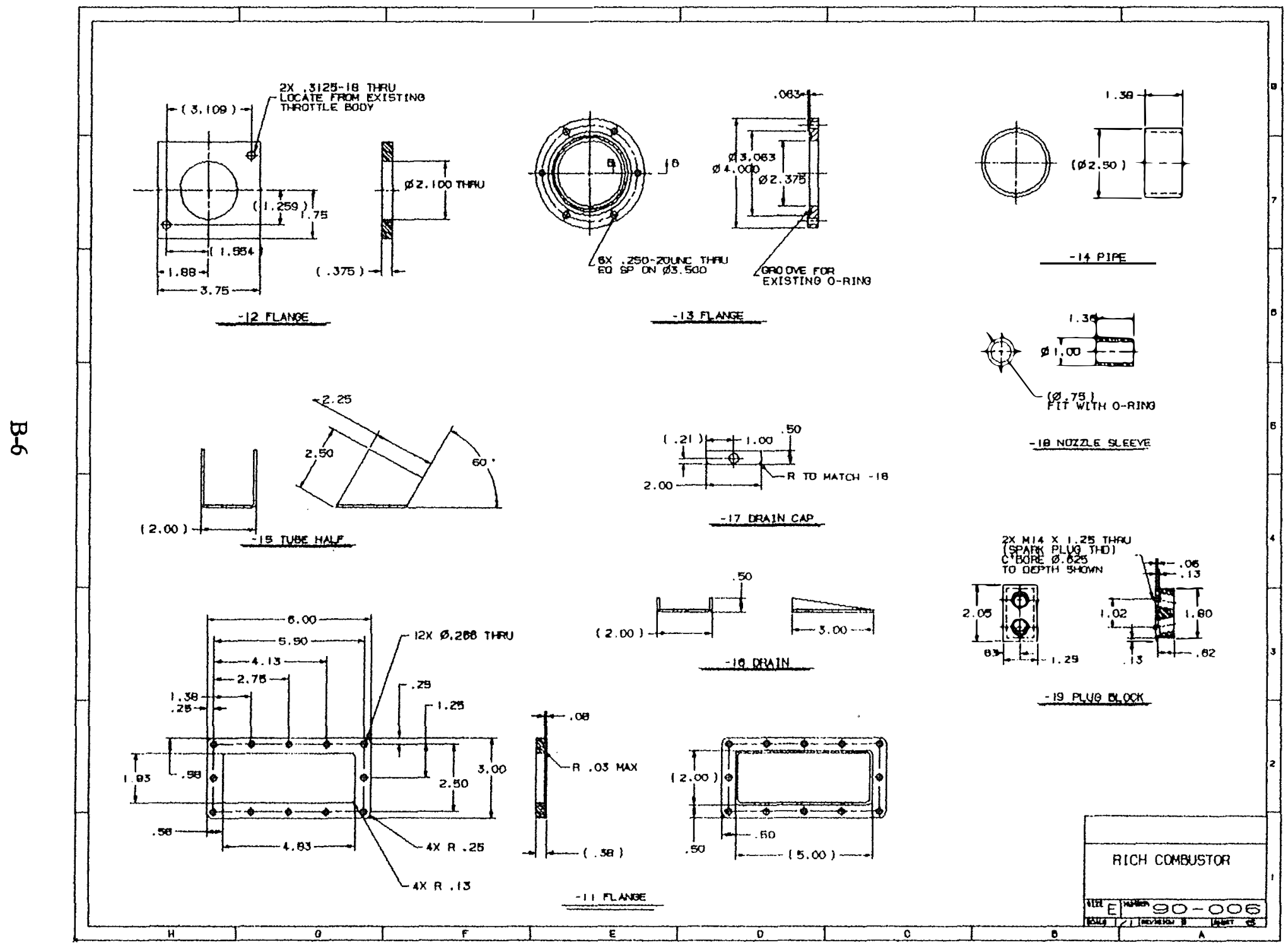




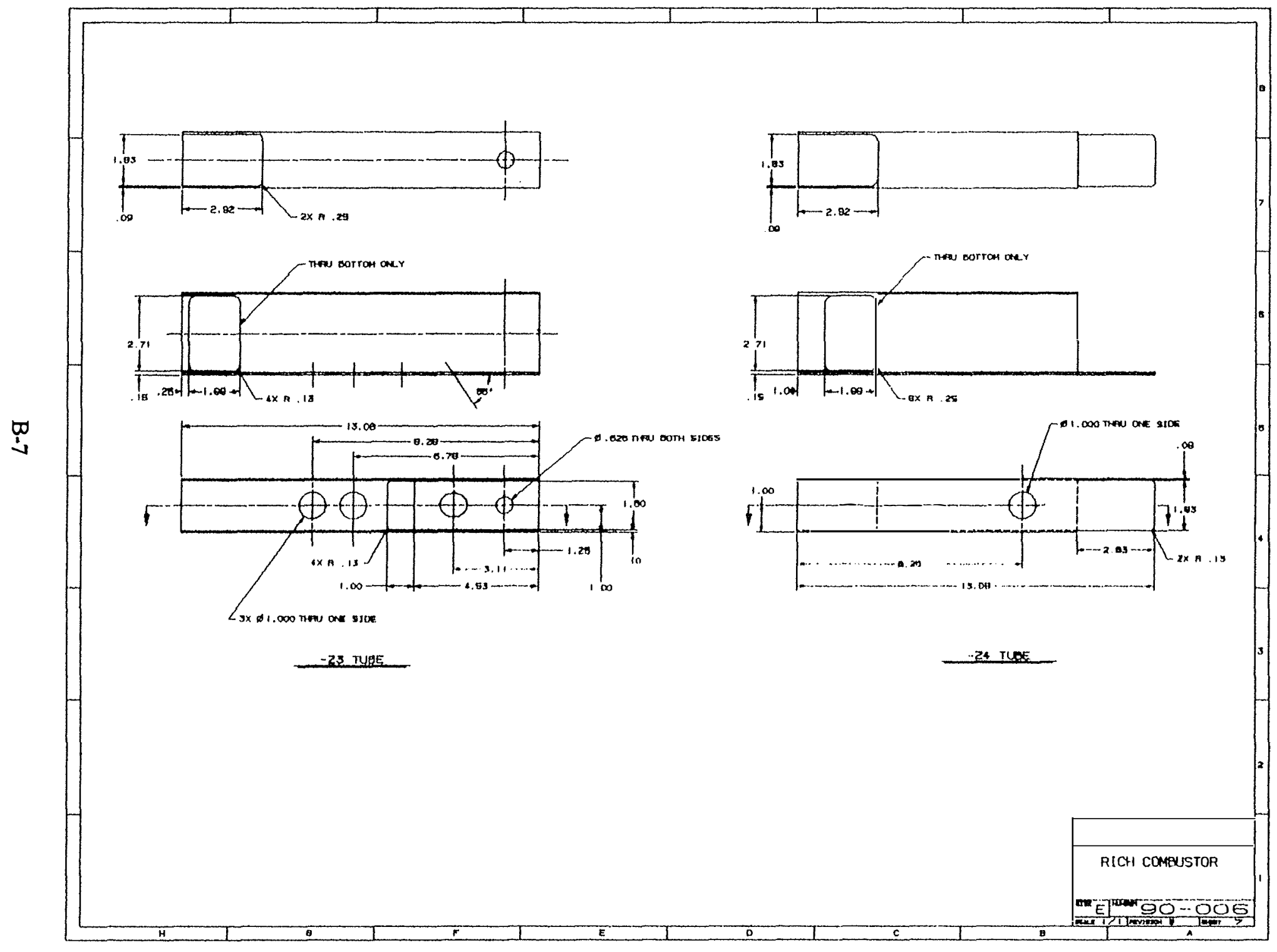




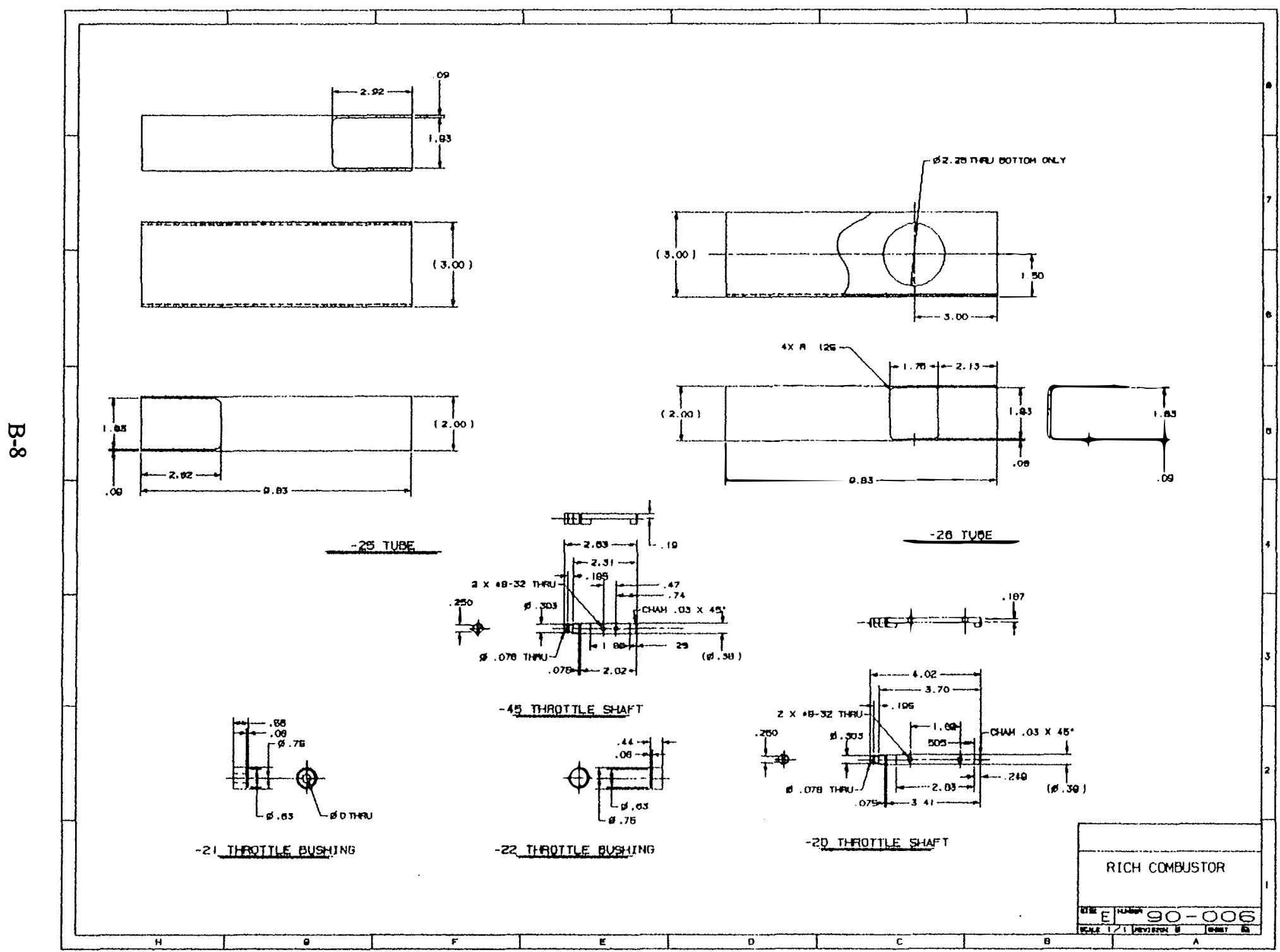




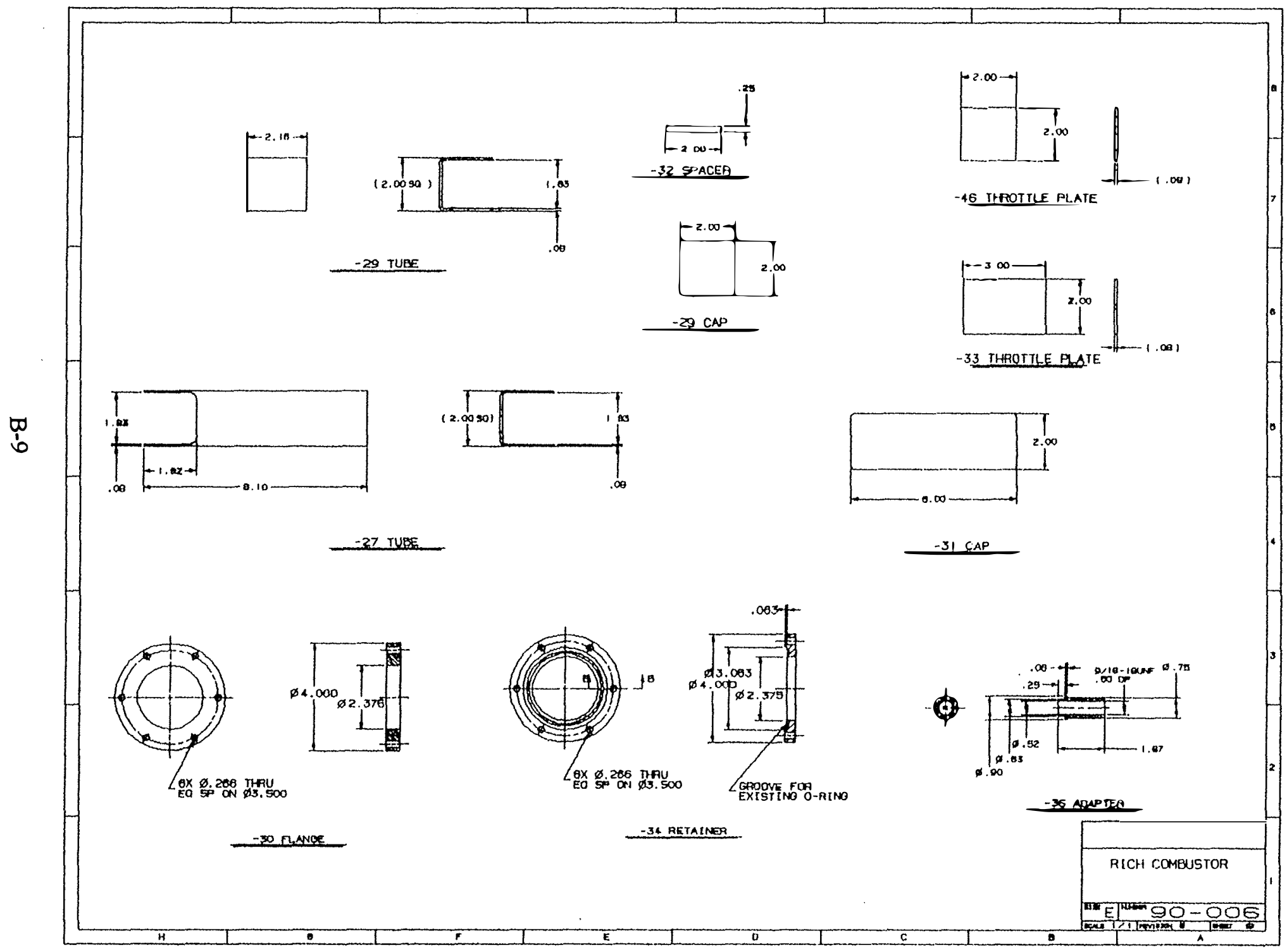




\section{Appendix C}

\section{Test Equipment Descriptions}




\section{Dynamometer}

General Electric Type TLC-3544 DC Dynamometer $300 \mathrm{hp}$ absorption

$250 \mathrm{hp} \mathrm{motoring}$ 2500-5000 RPM

Model \# 42G306aj

Serial \# AN-2-6

General Electric Company

Schenectady, NY 12345

\section{Gas Analyzer}

PGA-5 Five Gas Infrared Analyzer

Range and Accuracy:

$$
\begin{array}{lll}
\mathrm{HC} & 0-5000 \mathrm{ppm} & \begin{array}{l}
0-400 \pm 12 \mathrm{ppm} \\
\end{array} \\
\mathrm{CO} & 0-10 \% & 0-2 \pm .06 \\
& & >2 \pm .03 \\
\mathrm{CO}_{2} & 0-25 \% & 0-16 \pm .5 \\
& & >16 \pm .6 \% \text { of reading } \\
\mathrm{O}_{2} & 0-25 \% & 0-16 \pm .5 \\
& & >16 \pm .6 \% \text { of reading } \\
\mathrm{NO}_{x} & 0-4000 \mathrm{ppm} & 0-1000 \pm 32 \mathrm{ppm} \\
& & 1000-2000 \pm 60 \mathrm{ppm} \\
& & 2000-4000 \pm 120 \mathrm{ppm}
\end{array}
$$

MicroProcessor Systems Inc

Sterling Heights, MI

\section{Engine Controller}

\section{TEC-II PAF}

Serial \# 202776-34T2H-6CYL

Electromotive

Chantilly, VA 


\section{Refrigerated Enclosure}

\section{Refrigeration Unit}

Kold Pack Low Temprature Split Sytsem

Model \# 303FSSE

14000 Btw/hr

Kold Pack Refrigeration Systems

Hackson, MI 49201

\section{Enclosure}

10 ' X 8' X 12' with 12" thick walls, floor and roof Frame construction on site Insulation: 12" Styrofoam ( $\left.\mathrm{k}=0.03 \mathrm{Btu} / \mathrm{hr}-\mathrm{ft}-{ }^{\circ} \mathrm{F}\right)$

Heated window

$\mathrm{CO}_{2}$ fire supression system

\section{Solid State Relay}

Caydon Solid State Relay

Model D1D40

Line voltage: 0 - $100 \mathrm{Vdc}$

Load current range: 0 -40 Adc

Control voltage range: 3.5 - $32 \mathrm{Vdc}$

Control current @ 5Vdc: $1.6 \mathrm{~mA}$

Must release voltage: $1.0 \mathrm{Vdc}$

Surge current 10 ms: 106 A peak 


\section{In-house Developed Ignition Circuit}

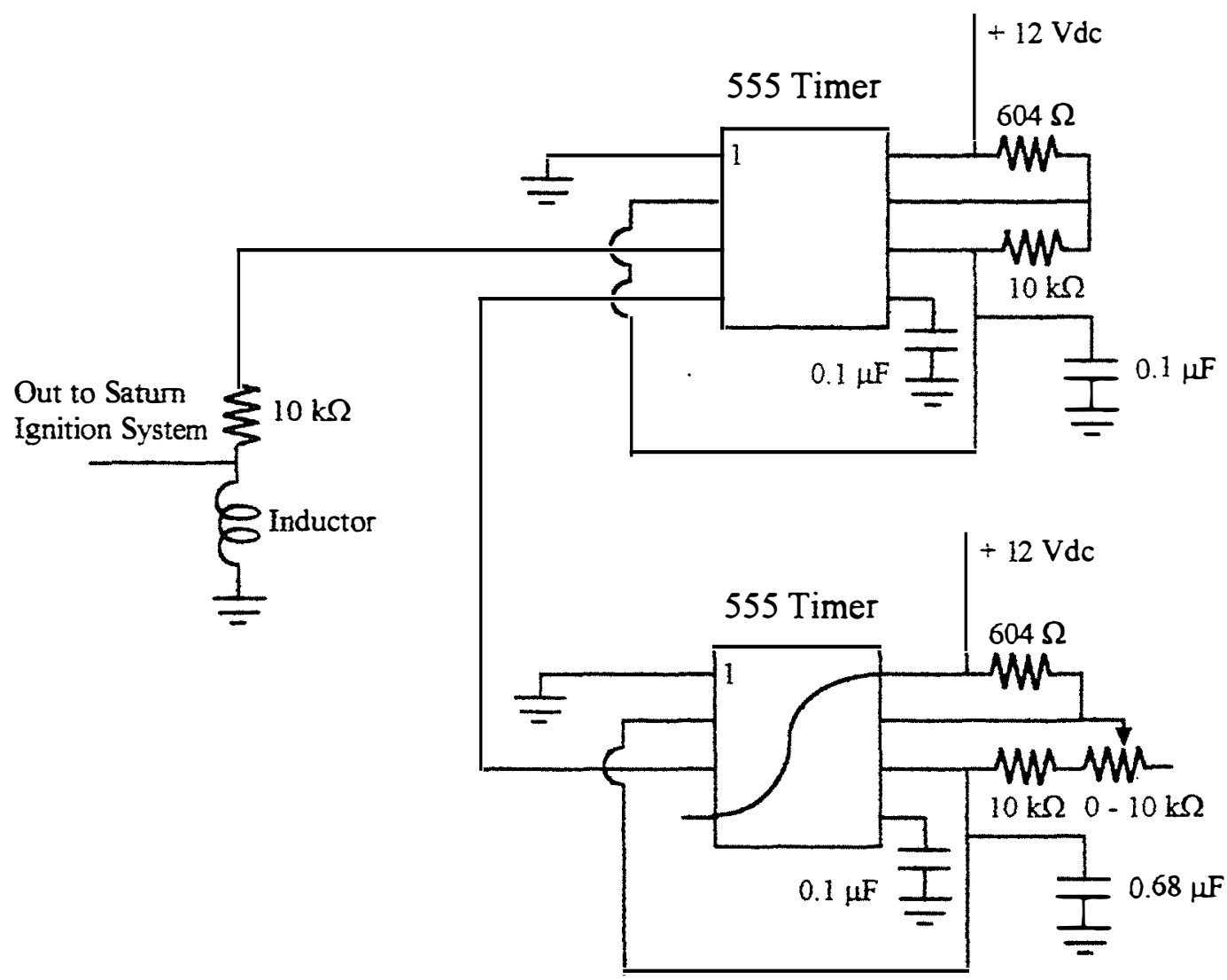




\section{Data Acquisition System}

Flight Recorder

In-Vehicle Data Acquisition System

Advance Electomic Diagnostics, Inc

10850 N. 24th Ave., Suite 101

Pheonix, AZ 85029

External Input Channels

Analog - 15 differential inputs. Cold junction compensation is handled internally. 12 bits resolution.

Serial Logging - 128 channels of RS-232 levels. Maximum baud rate of $131 \mathrm{kBaud}$.

Timer/Discrete Inputs - Frequency $0.2 \mathrm{~Hz}$ to $100 \mathrm{kHz}$. Pulsewidth - 10 microseconds to 5 seconds.

Sampling - 500 microseconds to 1 hour time between storage. 


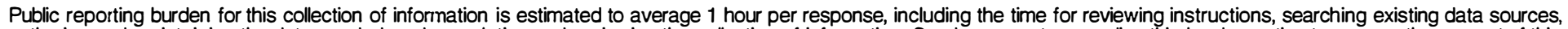

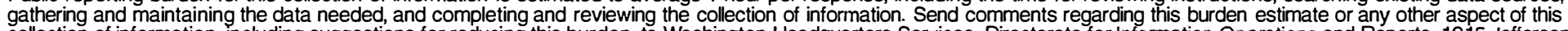

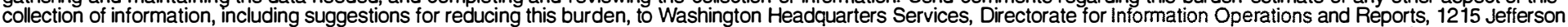

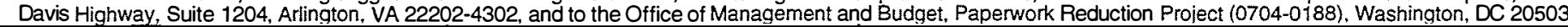

\begin{tabular}{l|l|l|l}
\hline 1. AGENCY USE ONLY (Leave blank) & 2. REPORT DATE & 3. REPORT TYPE AND DATES COVERED \\
& April 1998 & Subcontract report \\
\hline
\end{tabular}

\section{TITLE AND SUBTITLE}

Investigation and Demonstration of a Rich Combustor Cold-Start Device for Alcohol-Fueled Engines

6. AUTHOR(S)

J.W. Hodgson and D.K. Irick
5. FUNDING NUMBERS

(C) XCF-5-14050-03

(TA) FU702110

7. PERFORMING ORGANIZATION NAME(S) AND ADDRESS(ES)

The University of Tennessee

8. PERFORMING ORGANIZATION

Mechanical Engineering Dept. REPORT NUMBER

414 Dougherty Bldg.

Knoxville, TN 37996-2210

9. SPONSORING/MONITORING AGENCY NAME(S) AND ADDRESS(ES)

National Renewable Energy Laboratory

1617 Cole Boulevard

Golden, CO 80401-3393

10. SPONSORING/MONITORING AGENCY REPORT NUMBER

NREUSR-540-23864

\section{SUPPLEMENTARY NOTES}

\section{2a. DISTRIBUTION/AVAILABILITY STATEMENT}

National Technical Information Service

U.S. Department of Commerce

5285 Port Royal Road

Springfield, VA 22161 12b. DISTRIBUTION CODE

UC-1504

13. ABSTRACT (Maximum 200 words) Alcohol fuels such as methanol and ethanol show great promise for mitigating some of the problems associated with using petroleum-based fuels in vehicle engines. However, because the alcohol fuels have low vapor pressures, vehicles running on them sometimes have problems starting under cold conditions. Researchers at the University of Tennessee investigated the use of a rich combustor to aid in cold starting spark-ignition engines fueled with either neat ethanol or neat methanol. The rich combustor burns the alcohol fuel outside the engine under fuel-rich conditions to produce a combustible product stream that is then fed to the engine to aid cold starting. Testing under this project resulted in reliable cold starts on both neat methanol and neat ethanol at temperatures as low as $20^{\circ} \mathrm{C}$.

\section{SUBJECT TERMS}

Alternative fuels, alcohol fuels, cold startability, rich combustor technology

5. NUMBER OF PAGES

80

16. PRICE CODE

\section{SECURITY CLASSIFICATION OF REPORT}

\author{
18. SECURITY CLASSIFICATION \\ OF THIS PAGE
}

19. SECURITY CLASSIFICATION OF ABSTRACT

\section{LIMITATION OF ABSTRACT}

Standard Form 298 (Rev. 2-89) Prescribed by ANSI Std. 239-18 